\title{
Synthesis and Biological Evaluation of 8-Quinolinamines and Their Amino Acid Conjugates as Broad-Spectrum Anti-infectives
}

\author{
Meenakshi Jain, ${ }^{\dagger}$ C. V. Ravi P. Reddy, ${ }^{\dagger}$ Moumita Halder, ${ }^{\dagger}$ Savita Singh, ${ }^{\ddagger}$ Randheer Kumar, \\ Sagar Gajbe Wasudeo, ${ }^{\ddagger}$ Prati Pal Singh, ${ }^{\ddagger}$ Shabana I. Khan, ${ }^{\S}$ Melissa R. Jacob, ${ }^{\S}$ Babu L. Tekwani, ${ }^{\S}$ \\ and Rahul Jain*,† \\ ${ }^{\dagger}$ Department of Medicinal Chemistry and ${ }^{\ddagger}$ Department of Pharmacology and Toxicology, National Institute of Pharmaceutical \\ Education and Research, Sector 67, S. A. S. Nagar, Punjab 160 062, India \\ ${ }^{\S}$ National Center for Natural Products Research, School of Pharmacy, The University of Mississippi, University, Oxford, Mississippi \\ 38677, United States
}

Supporting Information

ABSTRACT: In the search of therapeutic agents for emerging drug-resistant parasites, the synthesis of newer classes of 8-quinolinamines has emerged as a successful chemotherapeutic approach. We report synthesis of 8-quinolinamines bearing 5-alkoxy, 4-methyl, and 2-tert-butyl groups in the quinoline framework and their amino acid conjugates as broad-spectrum anti-infectives. 8-Quinolinamines exhibited potent in vitro antimalarial activity $\left[\mathrm{IC}_{50}=20-\right.$ $4760 \mathrm{ng} / \mathrm{mL}$ (drug-sensitive Plasmodium falciparum D6 strain) and $\mathrm{IC}_{50}=22-$

$4760 \mathrm{ng} / \mathrm{mL}$ (drug-resistant P. falciparum W2 strain)]. The most promising analogues have cured all animals at $25 \mathrm{mg} / \mathrm{kg} / \mathrm{day}$ against drug-sensitive Plasmodium berghei and at $50 \mathrm{mg} / \mathrm{kg} /$ day against multidrug-resistant Plasmodium yoelii nigeriensis infections in Swiss mice. The in vitro antileishmanial activities ( $\mathrm{IC}_{50}=0.84-5.0 \mu \mathrm{g} / \mathrm{mL}$ and $\mathrm{IC}_{90}=1.95-7.0 \mu \mathrm{g} / \mathrm{mL}$ ) comparable to standard drug pentamidine were exhibited by several of the synthesized 8-quinolinamines. At the same time, very promising antifungal activities (Candida albicans- $\mathrm{IC}_{50}=4.93-19.38 \mu \mathrm{g} / \mathrm{mL} ;$ Candida glabrata- $\mathrm{IC}_{50}=3.96-19.22 \mu \mathrm{g} / \mathrm{mL}$; Candida krusei- $\mathrm{IC}_{50}=2.89-18.95 \mu \mathrm{g} / \mathrm{mL}$; Cryptococcus neoformans- $\mathrm{IC}_{50}=0.67-18.64 \mu \mathrm{g} / \mathrm{mL}$; and Aspergillus fumigatus- $\mathrm{IC}_{50}=6.0-$ $19.32 \mu \mathrm{g} / \mathrm{mL}$ ) and antibacterial activities (Staphylococcus aureus- $\mathrm{IC}_{50}=1.33-18.9 \mu \mathrm{g} / \mathrm{mL}$; methicillin-resistant $S$. aureus- $\mathrm{IC}_{50}$ $=1.38-15.34 \mu \mathrm{g} / \mathrm{mL}$; and Mycobacterium intracellulare- $\mathrm{IC}_{50}=3.12-20 \mu \mathrm{g} / \mathrm{mL}$ ) were also observed. None of the 8 quinolinamines exhibited cytotoxicity and therefore are a promising structural class of compounds as antiparasitic and antimicrobials.

\section{INTRODUCTION}

Infectious diseases are a leading cause of death worldwide. Malaria is one of the most prevalent protozoan parasitic diseases caused by Plasmodium species, particularly Plasmodium falciparum, Plasmodium vivax, Plasmodium malariae, and Plasmodium ovale. The disease spreads through vector female mosquitoes of the genus Anopheles. A fifth species causing malaria in humans, Plasmodium knowlesi, has recently emerged. P. knowlesi is distributed across South-East Asia and often misdiagnosed by microscopy as P. malariae. P. knowlesi causes a serious form of malaria, resulting in severe infection with a rate of $6-9 \%$ and a case fatality rate of $3 \%$. Malaria causes considerable morbidity and mortality and is associated with approximately 800000 deaths worldwide each year. ${ }^{1}$ Despite global effort to control malaria, the disease remains endemic in several parts of the world. According to the 2017 World Health Organization report, 212 million new cases of malaria worldwide in 91 countries have been reported and around 1.2 billion are at high risk. The disease is highly endemic in the African countries, where it causes significant mortality among the vulnerable children and pregnant women. ${ }^{2}$ At the same time, according to the WHO, leishmaniasis, a parasitic infectious disease, affects every year an estimated 1.3 million people from 98 nationalities, mainly in developing countries of the tropical and subtropical regions, but also around the Mediterranean area, including southern Europe., ${ }^{3,4}$ Leishmaniasis is the second most lethal parasitic infection with about 30000 annual deaths, considering that the number of cases is certainly underevaluated, as leishmaniasis is a reportable disease in only 33 countries. This infection is due to a protozoan parasite of the Leishmania genus, transmitted to its mammal hosts (humans, dogs, monkeys, and rodents) by the bite of an infected Phlebotominae sand fly. Similarly, increasing numbers of multidrug-resistant microbial pathogens have become a serious problem, particularly during the last decade and provide an impetus for the search and discovery of novel antibacterial and antifungal agents. ${ }^{5}$ Therefore, an urgent need for new treatments is necessary because of the spread of drug resistance to current medications.

Received: December 22, 2017

Accepted: March 2, 2018

Published: March 14, 2018 
Scheme 1. Synthesis of 2-tert-Butyl-4,5-disubstituted-6-methoxy-8-quinolinamines $(45-55)^{a}$<smiles>[R]c1c(OC)cc([N+](=O)[O-])c2nccc(Br)c12</smiles>

1-11

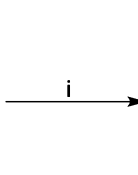

$\longrightarrow$

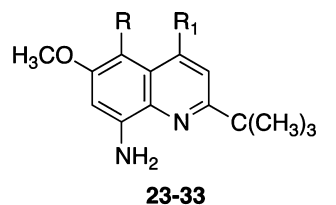

12-22
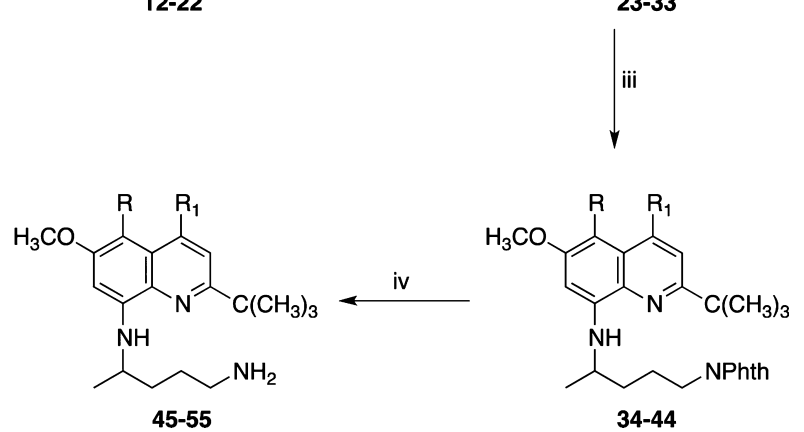

${ }^{a}$ Reactions and conditions: (i) $\left(\mathrm{CH}_{3}\right)_{3} \mathrm{CCO}_{2} \mathrm{H}, \mathrm{AgNO}_{3},\left(\mathrm{NH}_{4}\right)_{2} \mathrm{~S}_{2} \mathrm{O}_{8}, 10 \% \mathrm{H}_{2} \mathrm{SO}_{4}, \mathrm{CH}_{3} \mathrm{CN}, 80^{\circ} \mathrm{C}, 15 \mathrm{~min}$; (ii) Raney Ni, $\mathrm{H}_{2}, \mathrm{EtOH}, 45 \mathrm{psi}, 45 \mathrm{~min}$; (iii) 2-(4-bromopentyl)-1,3-isoindolinedione, $\mathrm{Et}_{3} \mathrm{~N}, 120^{\circ} \mathrm{C}, 16 \mathrm{~h}$; and (iv) $\mathrm{NH}_{2} \mathrm{NH}_{2} \cdot \mathrm{H}_{2} \mathrm{O}, \mathrm{EtOH}, 120{ }^{\circ} \mathrm{C}, 6 \mathrm{~h}$.

In an attempt to develop compounds that exhibit promising antimalarial, antileishmanial, and antimicrobial activities, we have previously observed that 8 -quinolinamine is a versatile class of compounds that exhibit a broad spectrum of biological and pharmacological activities such as antimalarial, antileishmanial, and antimicrobial. ${ }^{6-18}$ We have earlier reported several ring-substituted 8-quinolinamines possessing remarkable antimalarial activities. For instance, compounds containing alkoxy groups $\left(\mathrm{OC}_{5} \mathrm{H}_{11}\right.$ and $\left.\mathrm{OC}_{8} \mathrm{H}_{17}\right)$ at the $\mathrm{C}-5$ position and the alkyl group $\left(\mathrm{C}_{2} \mathrm{H}_{5}\right)$ at the $\mathrm{C}-4$ position of antimalarial drug primaquine $(\mathrm{PQ})$ exhibit in vitro and in vivo biological efficacy higher than chloroquine (CQ) against both CQ-sensitive $(\mathrm{CQS})$ and $\mathrm{CQ}$-resistant (CQR) strains $\left(\mathrm{IC}_{50}=9.4\right.$ and 9.7 $\mathrm{ng} / \mathrm{mL}$, respectively). ${ }^{10}$ We have also reported synthesis of a series containing metabolically stable bulky alkyl groups at the $\mathrm{C}-2$ position of the quinoline ring in $\mathrm{PQ}$. The most promising analogue, 2-tert-butylprimaquine, displayed potent in vitro antimalarial activity $\left(\mathrm{IC}_{50}=39 \mathrm{ng} / \mathrm{mL}\right)$, which was superior to that of $\mathrm{CQ}\left(\mathrm{IC}_{50}=113 \mathrm{ng} / \mathrm{mL}\right) .{ }^{11}$ Similarly, we have reported antimalarial activities of 4,5-disubsituted-8-quinolinamines and their amino acid conjugates. ${ }^{10,13,17,18}$ Trouet et al. have earlier proposed that linking PQ to small peptides reduces its toxicity and increases its activity. ${ }^{19}$ Later, Carroll et al. have reported peptide derivatives of $\mathrm{PQ}$ as potential antimalarials possessing blood schizontocidal activity against Plasmodium berghei in mice. ${ }^{20}$ Upon the basis of these observations, we synthesized and evaluated amino acid conjugates of PQ and other ring-substituted 8-quinolinamines. Several analogues display high in vitro and in vivo antimalarial activity and in vitro antileishmanial and antimicrobial activities. ${ }^{18}$ In continuation of our research on the structural diversification of 8quinolinamines, herein, we have synthesized hybrid derivatives in which the quinoline ring is substituted at the $\mathrm{C}-2$ position with a 2-tert-butyl group, while the $\mathrm{C}-4$ position of the ring is either unsubstituted or has a methyl group. The C-5 position of the ring in these cases is substituted with an alkoxy group or with a phenoxy group (45-55). The amino acid conjugates (90-123) of the 5-alkoxy-2-tert-butyl group containing 8quinolinamines (45-49) were subsequently synthesized wherein both hydrophobic and hydrophilic amino acids were placed at the side chain terminal amino group. Herein, we report synthesis, antimalarial, antileishmanial, and antimicrobial activities of the synthesized 8-quinolinamines and their amino acid conjugates.

\section{RESULTS AND DISCUSSION}

With a view to prepare the target quinoline derivatives, the key intermediates 6-methoxy-8-nitroquinolines $(1-11)$ were synthesized by adopting the literature methods. ${ }^{6-8}$ 5-Alkoxy/ aryloxy-6-methoxy-8-nitroquinolines (1-5 and 11) were synthesized by reaction of corresponding 4-alkoxy-6-methoxy2-nitroanilines with acrolein via Skraup synthesis in the presence of arsenic $(\mathrm{V})$ oxide and $o$-phosphoric acid at 100 ${ }^{\circ} \mathrm{C}$, whereas compounds 6-10 were prepared by the reaction of respective nitroanilines with methylvinylketone in the presence of $o$-phosphoric acid at $100{ }^{\circ} \mathrm{C}$. The 8-nitroquinolines $(\mathbf{1}-\mathbf{1 1})$ upon direct ring alkylation via silver-catalyzed radical oxidative decarboxylation of trimethylacetic acid in the presence of ammonium persulfate in $\mathrm{CH}_{3} \mathrm{CN}$ and $10 \% \mathrm{H}_{2} \mathrm{SO}_{4}$ at $80{ }^{\circ} \mathrm{C}$ produced 2-tert-butyl-5-alkoxy/aryloxy-6-methoxy-8-nitroquinolines $(\mathbf{1 2}-\mathbf{2 2})$. The nitroquinolines $(\mathbf{1 2}-\mathbf{2 2})$ were converted to the requisite 2-tert-butyl-4,5-disubstituted- $\mathrm{N}^{8}$-(4-amino-1methylbutyl)-6-methoxy-8-quinolinamines $(45-55)$ in three steps following the previously published procedure (Scheme 1). $9-11$

First, catalytic hydrogenation of 12-22 with Raney nickel in absolute ethanol gave 2-tert-butyl-6-methoxy-4/5-substituted-8aminoquinolines (23-33). Condensation reaction of (23-33) with 2-(4-bromopentyl)-1,3-isoindolinedione in the presence of triethylamine (TEA) at $120^{\circ} \mathrm{C}$ provides 2-[4-(2-tert-butyl-4/5substituted-8-quinolylamino)pentyl]-1,3-isoindolinediones (34-44), which upon hydrozinolysis with hydrazine hydrate in the presence of ethanol at $80{ }^{\circ} \mathrm{C}$ for $24 \mathrm{~h}$ afforded 4/5substituted-2-tert-butylprimaquine derivatives (45-55). 2-tertButyl-5-alkoxy-6-methoxy-8-quinolinamines (45-49) upon condensation reaction with $\mathrm{N}$ - $\alpha$-butoxycarbonyl (Boc)-protected amino acids in the presence of 1,3-dicyclohexylcarbodiimide (DCC) in dichloromethane $\left(\mathrm{CH}_{2} \mathrm{Cl}_{2}\right)$ for $4 \mathrm{~h}$ gave the protected amino acid derivatives (56-99) in excellent yields. ${ }^{12}$ The reactive amino group present at the side chain was protected by a Boc group in the cases of Lys and Orn. At the same time, Arg was protected by a dicarbobenzyloxy (di-Cbz) group on the guanido group, while amino acid His was protected by a $N \pi$-benzyloxymethyl group on the imidazole 
Scheme 2. Synthesis of Amino Acid Conjugates (90-123) of 2-tert-Butyl-5-alkoxy-6-methoxy-8-quinolinamines ${ }^{a}$
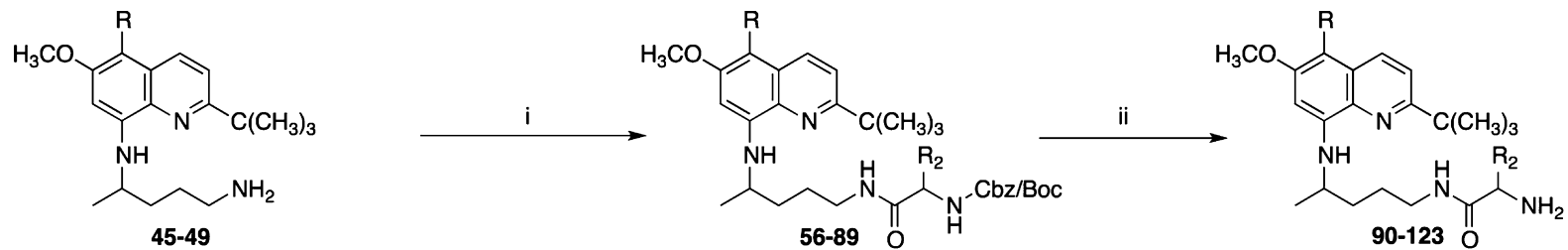

${ }^{a}$ Reactions and conditions: (i) Cbz/Boc-AA-OH, DCC, $\mathrm{CH}_{2} \mathrm{Cl}_{2}, 0{ }^{\circ} \mathrm{C}, 6 \mathrm{~h}$; and (ii) $10 \% \mathrm{Pd} / \mathrm{C}, \mathrm{H}_{2}, \mathrm{MeOH}, 1 \mathrm{~h}, \mathrm{rt}, 4 \mathrm{~N} \mathrm{HCl} / \mathrm{MeOH}, 1 \mathrm{~h}, \mathrm{rt}$.

ring. The remaining coupled amino acids required no protection on the side chain. A combination of hydrophobic amino acids (Leu, Ile, Phe, Ala, and Trp) and hydrophilic amino acids (Lys, Orn, Arg, D-Arg, Pro, and His) was conjugated with a view to examine the role of their side chains in bioactivity.

The removal of the side chain $\mathrm{N}-\mathrm{Cbz}$ group of the protected Arg amino acid derivatives was accomplished using 10\% Pd/C in $\mathrm{MeOH}$. The final Boc protection in the presence of $4 \mathrm{~N} \mathrm{HCl}$ in $\mathrm{MeOH}$ proceeded smoothly to afford the free amino group containing 8-quinolinamine amino acid conjugates (90-123) (Scheme 2). ${ }^{13}$

Antimalarial Activity. Determination of in vitro antimalarial activity was based on the assay of plasmodial lactate dehydrogenase $(\mathrm{LDH})$ activity. ${ }^{21}$ The antimalarial activities of all synthesized analogues are reported as $\mathrm{IC}_{50}$ values against CQS (D6) and CQR (W2) strains of P. falciparum in Table 1. Among the analogues, the most effective was $N^{4}$-(2-tert-butyl-6methoxy-5-(pentyloxy)quinolin-8-yl)-pentane-1,4-diamine $(\mathrm{R}=$ $\left.\mathrm{OC}_{5} \mathrm{H}_{11}, \mathrm{R}_{1}=\mathrm{H}, 46\right)$, which exhibited potent antimalarial activity with $\mathrm{IC}_{50}$ of $20 \mathrm{ng} / \mathrm{mL}$ for D6 strain and $22 \mathrm{ng} / \mathrm{mL}$ for W2 clone of $P$. falciparum. In the same test, standard drugs CQ produced $\mathrm{IC}_{50} \mathrm{~s}$ of $15.0 \mathrm{ng} / \mathrm{mL}$ (D6 clone) and $140 \mathrm{ng} / \mathrm{mL}$ (W2 clone) and artemisinin (ART) produced $\mathrm{IC}_{50} \mathrm{~s}$ of $11.0 \mathrm{ng} /$ $\mathrm{mL}$ (D6 clone) and $9.0 \mathrm{ng} / \mathrm{mL}$ (W2 clone).

Other notable analogues of the series, $47\left[\mathrm{R}=\mathrm{OC}_{6} \mathrm{H}_{13}, \mathrm{R}_{1}=\right.$ $\mathrm{H}, \mathrm{IC}_{50}=42 \mathrm{ng} / \mathrm{mL}$ (D6 strain), $\mathrm{IC}_{50}=42 \mathrm{ng} / \mathrm{mL}$ (W2 strain)], $48\left[\mathrm{R}=\mathrm{OC}_{7} \mathrm{H}_{15}, \mathrm{R}_{1}=\mathrm{H}, \mathrm{IC}_{50}=50 \mathrm{ng} / \mathrm{mL}\right.$ (D6 strain), $\mathrm{IC}_{50}=37 \mathrm{ng} / \mathrm{mL}$ (W2 strain) $], 49\left[\mathrm{R}=\mathrm{OC}_{8} \mathrm{H}_{17}, \mathrm{R}_{1}=\right.$ $\mathrm{H}, \mathrm{IC}_{50}=53 \mathrm{ng} / \mathrm{mL}$ (D6 strain), $\mathrm{IC}_{50}=40 \mathrm{ng} / \mathrm{mL}$ (W2 strain)], $55\left[\mathrm{R}=\mathrm{OPh}\left(3,4-\mathrm{Cl}_{2}\right), \mathrm{R}_{1}=\mathrm{H}, \mathrm{IC}_{50}=140 \mathrm{ng} / \mathrm{mL}\right.$ (D6 strain), $\mathrm{IC}_{50}=130 \mathrm{ng} / \mathrm{mL}$ (W2 strain) $], 92\left[\mathrm{R}=\mathrm{OC}_{5} \mathrm{H}_{11}, \mathrm{R}_{1}=\right.$ $\mathrm{H}, \mathrm{R}_{2}=\mathrm{Lys}, \mathrm{IC}_{50}=110 \mathrm{ng} / \mathrm{mL}$ (D6 strain), $\mathrm{IC}_{50}=52 \mathrm{ng} / \mathrm{mL}$ (W2 strain) ], $99\left[\mathrm{R}=\mathrm{OC}_{6} \mathrm{H}_{13}, \mathrm{R}_{1}=\mathrm{H}, \mathrm{R}_{2}=\mathrm{Lys}, \mathrm{IC}_{50}=90 \mathrm{ng} /\right.$ $\mathrm{mL}$ (D6 strain), $\mathrm{IC}_{50}=36 \mathrm{ng} / \mathrm{mL}$ (W2 strain)], $111[\mathrm{R}=$ $\mathrm{OC}_{7} \mathrm{H}_{15}, \mathrm{R}_{1}=\mathrm{H}, \mathrm{R}_{2}=\mathrm{Arg}, \mathrm{IC}_{50}=390 \mathrm{ng} / \mathrm{mL}$ (D6 strain), $\mathrm{IC}_{50}$ $=240 \mathrm{ng} / \mathrm{mL}(\mathrm{W} 2$ strain $)]$, and $120\left[\mathrm{R}=\mathrm{OC}_{8} \mathrm{H}_{17}, \mathrm{R}_{1}=\mathrm{H}, \mathrm{R}_{2}\right.$ $=$ Met, $\mathrm{IC}_{50}=160 \mathrm{ng} / \mathrm{mL}$ (D6 strain), $\mathrm{IC}_{50}=150 \mathrm{ng} / \mathrm{mL}$ (W2 strain)], also produced potent in vitro antimalarial activities (Table 1). The remaining analogues of the series were either moderately active or did not show any inhibition of $P$. falciparum. It is important to note that 8-quinolinamines produced higher inhibition of drug-resistant W2 strain compared to drug-sensitive D6 of $P$. falciparum, clearly amplifying the significance of this class in drug-resistant malaria. We observed potent antimalarial activity by 8quinolinamines (46-49) that contains an alkoxy group (ranged between $\mathrm{C5}$ and $\mathrm{C} 8$ ) and a 2-tert-butyl group. The addition of a methyl group at the $\mathrm{C}-4$ position compounds $46-49$ results in a dramatic loss of activity (compounds 50-54). The conjugation of compounds (45-49) with an amino acid generally results in the loss of antimalarial activity; however, basic amino acids (Lys and Arg)-conjugated compounds 92, 99, and 111 displayed promising antimalarial activity, though to a degree less than their nonconjugated counterparts.

All analogues were also evaluated for cytotoxicity up to the highest test concentration of $4760 \mathrm{ng} / \mathrm{mL}$ in a panel of four cancerous cell lines (SK-MEL, KB, BT-549, and SK-OV-3) and two noncancerous mammalian cells (VERO and LLC-PK1) using the neutral red assay procedure as described earlier, ${ }^{22,23}$ and none showed any cytotoxicity, thereby exhibiting a selectivity index ranged between $>216$ and $>1.2$ for the protozoan parasitic infection.

The most promising 8-quinoliamines were then evaluated for the blood-schizontocidal antimalarial activity against $P$. berghei (sensitive strain) in a rodent model (Table 2). ${ }^{10}$ Briefly, testing was conducted at various concentrations orally in Swiss mice (six mice per group). The concentrations tested were 100, 50, 25 , and $10 \mathrm{mg} / \mathrm{kg} /$ day $\times 4$ (oral). The compounds were administered on days $0-3$ after infection. The results were compared to a positive control group of mice treated with CQ at the suppressive dose of $10 \mathrm{mg} / \mathrm{kg} /$ day $\times 4$ (oral) and a negative control group of mice where no treatment for the infection was administered, and in this case, $100 \%$ mortality is observed within 6-8 days, with a mean survival time of 6.2 days. Except for 8-quinolinamine 51 that was inactive, all other analogues $(\mathbf{4 6}-\mathbf{5 0}, \mathbf{9 2}, \mathbf{9 9}, \mathbf{1 1 1}$, and 121$)$ produced $100 \%$ cure at the primary tested dose of $100 \mathrm{mg} / \mathrm{kg}$ against $P$. berghei infection in mice. Upon evaluation at the subsequent lower dose of $50 \mathrm{mg} / \mathrm{kg}$, compounds 46-49 and 111 produced 100\% cure with all treated animals surviving on day 60 (termination of experiment), while remaining compounds 50, 92, 99, and 121 produced suppressive activity. Analogues 46-49 also produced curative activity at the lower dose of $25 \mathrm{mg} / \mathrm{kg}$, while the remaining tested compounds were inactive with no animals surviving at the termination of the experiment on day 60 . None of the analogues (46-49) were curative at the lowest test concentration of $10 \mathrm{mg} / \mathrm{kg}$ but produced suppressive activity with few surviving animals (Table 2). Analogues 46-49 were then tested in vivo against multidrug-resistant Plasmodium yoelli nigeriensis. ${ }^{10}$ Compounds 46 and 47 cured $100 \%$ mice at a dose of 100 and $50 \mathrm{mg} / \mathrm{kg}$, respectively. The same compounds were suppressive at the lowest tested dose of $25 \mathrm{mg} / \mathrm{kg}$. At the same time, analogues 48 and 49 were suppressive at the tested dose of 100 and $50 \mathrm{mg} / \mathrm{kg}$, while they were inactive at the lowest tested dose of $25 \mathrm{mg} / \mathrm{kg}$ (Table 2). The in vitro results corroborated by the in vivo antimalarial results further confirmed the advantage of synthesized 8-quinolinamines in drug-resistant malaria chemotherapy. We noted that the presence of the pentaloxy group at the C-5 position of the quinoline ring along with a 2-tert-butyl group provide optimum activity, while the introduction of a methyl group at the C-4 position results in a dramatic loss of activity. In the cases of amino acid-conjugated 8-quinolinamines, the attachment of 
Table 1. In Vitro Antimalarial Activities and Cytoxicity of 8-Quinolinamines ${ }^{a}$

\begin{tabular}{|c|c|c|c|c|c|c|c|c|}
\hline \multirow[b]{2}{*}{ no. } & \multirow[b]{2}{*}{$\mathrm{R}$} & \multirow[b]{2}{*}{$\mathrm{R}_{1}$} & \multirow[b]{2}{*}{$\mathrm{R}_{2}$} & \multicolumn{2}{|c|}{ P. falciparum (D6) } & \multicolumn{2}{|c|}{ P. falciparum (W2) } & \multirow{2}{*}{$\frac{\text { cytotoxicity }(\mu \mathrm{g} / \mathrm{mL})}{\text { CTX }}$} \\
\hline & & & & $\mathrm{IC}_{50}(\mathrm{ng} / \mathrm{mL})$ & SI & $\mathrm{IC}_{50}(\mathrm{ng} / \mathrm{mL})$ & SI & \\
\hline 45 & $\mathrm{OC}_{4} \mathrm{H}_{9}$ & $\mathrm{H}$ & & NA & & 3300 & $>1.4$ & NC \\
\hline 46 & $\mathrm{OC}_{5} \mathrm{H}_{11}$ & $\mathrm{H}$ & & 20 & $>238$ & 22 & $>216$ & NC \\
\hline 47 & $\mathrm{OC}_{6} \mathrm{H}_{13}$ & $\mathrm{H}$ & & 42 & $>113$ & 40 & $>119$ & NC \\
\hline 48 & $\mathrm{OC}_{7} \mathrm{H}_{15}$ & $\mathrm{H}$ & & 50 & $>95$ & 37 & $>129$ & $\mathrm{NC}$ \\
\hline 49 & $\mathrm{OC}_{8} \mathrm{H}_{17}$ & $\mathrm{H}$ & & 53 & $>90$ & 40 & $>119$ & $\mathrm{NC}$ \\
\hline 50 & $\mathrm{OC}_{4} \mathrm{H}_{9}$ & $\mathrm{CH}_{3}$ & & 2200 & $>2.2$ & 980 & $>4.9$ & $\mathrm{NC}$ \\
\hline 51 & $\mathrm{OC}_{5} \mathrm{H}_{11}$ & $\mathrm{CH}_{3}$ & & 4500 & $>1.1$ & 3800 & $>1.3$ & $\mathrm{NC}$ \\
\hline 52 & $\mathrm{OC}_{6} \mathrm{H}_{13}$ & $\mathrm{CH}_{3}$ & & NA & & NA & & $\mathrm{NC}$ \\
\hline 53 & $\mathrm{OC}_{7} \mathrm{H}_{15}$ & $\mathrm{CH}_{3}$ & & 2000 & $>2.4$ & 1300 & $>3.7$ & $\mathrm{NC}$ \\
\hline 54 & $\mathrm{OC}_{8} \mathrm{H}_{17}$ & $\mathrm{CH}_{3}$ & & NA & & NA & & $\mathrm{NC}$ \\
\hline 55 & $\mathrm{O}-\mathrm{Ph}\left(3,4-\mathrm{Cl}_{2}\right)$ & $\mathrm{H}$ & & 140 & $>34$ & 130 & $>37$ & $\mathrm{NC}$ \\
\hline 90 & $\mathrm{OC}_{4} \mathrm{H}_{9}$ & $\mathrm{H}$ & Lys & 4700 & $>1$ & 2900 & $>1.6$ & $\mathrm{NC}$ \\
\hline 91 & $\mathrm{OC}_{4} \mathrm{H}_{9}$ & $\mathrm{H}$ & Orn & 2800 & $>1.7$ & 1300 & $>3.7$ & $\mathrm{NC}$ \\
\hline 92 & $\mathrm{OC}_{5} \mathrm{H}_{11}$ & $\mathrm{H}$ & Lys & 110 & $>43$ & 52 & $>92$ & NC \\
\hline 93 & $\mathrm{OC}_{5} \mathrm{H}_{11}$ & $\mathrm{H}$ & Orn & 1000 & $>5$ & 870 & $>5.5$ & $\mathrm{NC}$ \\
\hline 94 & $\mathrm{OC}_{5} \mathrm{H}_{11}$ & $\mathrm{H}$ & Arg & 4760 & $>1$ & 4000 & $>1.2$ & $\mathrm{NC}$ \\
\hline 95 & $\mathrm{OC}_{5} \mathrm{H}_{11}$ & $\mathrm{H}$ & Leu & 3500 & $>1.4$ & 2300 & $>2.1$ & $\mathrm{NC}$ \\
\hline 96 & $\mathrm{OC}_{5} \mathrm{H}_{11}$ & $\mathrm{H}$ & Ile & NA & & NA & & $\mathrm{NC}$ \\
\hline 97 & $\mathrm{OC}_{5} \mathrm{H}_{11}$ & $\mathrm{H}$ & Phe & 2500 & $>1.9$ & 1300 & $>3.7$ & NC \\
\hline 98 & $\mathrm{OC}_{5} \mathrm{H}_{11}$ & $\mathrm{H}$ & $\operatorname{Trp}$ & NA & & NA & & $\mathrm{NC}$ \\
\hline 99 & $\mathrm{OC}_{6} \mathrm{H}_{13}$ & $\mathrm{H}$ & Lys & 90 & $>53$ & 36 & $>132$ & $\mathrm{NC}$ \\
\hline 100 & $\mathrm{OC}_{6} \mathrm{H}_{13}$ & $\mathrm{H}$ & Orn & 860 & $>5.5$ & 730 & $>6.5$ & $\mathrm{NC}$ \\
\hline 101 & $\mathrm{OC}_{6} \mathrm{H}_{13}$ & $\mathrm{H}$ & D-Arg & 800 & $>6$ & 330 & $>14.4$ & $\mathrm{NC}$ \\
\hline 102 & $\mathrm{OC}_{6} \mathrm{H}_{13}$ & $\mathrm{H}$ & Met & 2800 & $>1.7$ & 2800 & $>1.7$ & NC \\
\hline 103 & $\mathrm{OC}_{6} \mathrm{H}_{13}$ & $\mathrm{H}$ & Pro & 4000 & $>1.2$ & 2700 & $>1.8$ & $\mathrm{NC}$ \\
\hline 104 & $\mathrm{OC}_{6} \mathrm{H}_{13}$ & $\mathrm{H}$ & Ile & 4760 & $>1$ & 4000 & $>1.2$ & $\mathrm{NC}$ \\
\hline 105 & $\mathrm{OC}_{6} \mathrm{H}_{13}$ & $\mathrm{H}$ & His & 2400 & $>2$ & 1700 & $>2.8$ & $\mathrm{NC}$ \\
\hline 106 & $\mathrm{OC}_{6} \mathrm{H}_{13}$ & $\mathrm{H}$ & Phe & $\mathrm{NA}$ & & NA & & $\mathrm{NC}$ \\
\hline 107 & $\mathrm{OC}_{6} \mathrm{H}_{13}$ & $\mathrm{H}$ & Ala & NA & & NA & & $\mathrm{NC}$ \\
\hline 108 & $\mathrm{OC}_{6} \mathrm{H}_{13}$ & $\mathrm{H}$ & $\operatorname{Trp}$ & NA & & NA & & $\mathrm{NC}$ \\
\hline 109 & $\mathrm{OC}_{7} \mathrm{H}_{15}$ & $\mathrm{H}$ & Lys & 800 & $>6$ & 680 & $>7$ & $\mathrm{NC}$ \\
\hline 110 & $\mathrm{OC}_{7} \mathrm{H}_{15}$ & $\mathrm{H}$ & Orn & 3200 & $>1.5$ & 1600 & $>3$ & $\mathrm{NC}$ \\
\hline 111 & $\mathrm{OC}_{7} \mathrm{H}_{15}$ & $\mathrm{H}$ & Arg & 390 & $>12$ & 240 & $>20$ & $\mathrm{NC}$ \\
\hline 112 & $\mathrm{OC}_{7} \mathrm{H}_{15}$ & $\mathrm{H}$ & Phe & 3200 & $>1.5$ & 2200 & $>2.2$ & $\mathrm{NC}$ \\
\hline 113 & $\mathrm{OC}_{7} \mathrm{H}_{15}$ & $\mathrm{H}$ & Pro & 2400 & $>2$ & 1500 & $>3.2$ & $\mathrm{NC}$ \\
\hline 114 & $\mathrm{OC}_{7} \mathrm{H}_{15}$ & $\mathrm{H}$ & Ile & 4500 & $>1.1$ & 2900 & $>1.6$ & $\mathrm{NC}$ \\
\hline 115 & $\mathrm{OC}_{7} \mathrm{H}_{15}$ & $\mathrm{H}$ & $\operatorname{Trp}$ & 3300 & $>1.4$ & 2800 & $>1.7$ & NC \\
\hline 116 & $\mathrm{OC}_{7} \mathrm{H}_{15}$ & $\mathrm{H}$ & Met & 4760 & $>1$ & 3200 & $>1.5$ & $\mathrm{NC}$ \\
\hline 117 & $\mathrm{OC}_{8} \mathrm{H}_{17}$ & $\mathrm{H}$ & Lys & NA & & NA & & $\mathrm{NC}$ \\
\hline 118 & $\mathrm{OC}_{8} \mathrm{H}_{17}$ & $\mathrm{H}$ & Orn & NA & & NA & & $\mathrm{NC}$ \\
\hline 119 & $\mathrm{OC}_{8} \mathrm{H}_{17}$ & $\mathrm{H}$ & Ile & NA & & NA & & $\mathrm{NC}$ \\
\hline 120 & $\mathrm{OC}_{8} \mathrm{H}_{17}$ & $\mathrm{H}$ & Met & 160 & $>30$ & 150 & $>32$ & $\mathrm{NC}$ \\
\hline 121 & $\mathrm{OC}_{8} \mathrm{H}_{17}$ & $\mathrm{H}$ & Phe & NA & & NA & & $\mathrm{NC}$ \\
\hline 122 & $\mathrm{OC}_{8} \mathrm{H}_{17}$ & $\mathrm{H}$ & $\operatorname{Trp}$ & NA & & NA & & $\mathrm{NC}$ \\
\hline 123 & $\mathrm{OC}_{8} \mathrm{H}_{17}$ & $\mathrm{H}$ & Pro & NA & & NA & & $\mathrm{NC}$ \\
\hline CQ & & & & 15.0 & $>317$ & 140 & $>34$ & \\
\hline ART & & & & 11.0 & $>433$ & 9.0 & $>529$ & \\
\hline
\end{tabular}

${ }^{a} \mathrm{IC}_{50}$ is the concentration $(\mu \mathrm{g} / \mathrm{mL})$ that affords $50 \%$ inhibition of growth; NC, not cytotoxic up to $4760 \mathrm{ng} / \mathrm{mL}(4.76 \mu \mathrm{g} / \mathrm{mL})$. NA, not active. Selectivity index is the ratio of $\mathrm{IC}_{50}$ in Vero cells to $\mathrm{IC}_{50}$ in P. falciparum (D6 or W2).

basic amino acids, especially Lys, results in enhanced antimalarial activity.

Antileishmanial Activity. Antileishmanial activity of the 8quinolinamines was tested in vitro against a culture of Leishmania donovani promastigotes by alamarBlue assay. ${ }^{24,25}$ It was interesting to note that 8-quinolinamine analogues, 47$49,50,52-53,95,97-98,102-103,105,113-114$, and 116 exhibited strong antileishmanial activities, with $\mathrm{IC}_{50}$ values ranging between 0.84 and $5.9 \mu \mathrm{g} / \mathrm{mL}$ (Table 3). The activity was comparable to the standard drug pentamidine $\left(\mathrm{IC}_{50}=1.4\right.$ $\mu \mathrm{g} / \mathrm{mL}$ ) used as the positive control. Their $\mathrm{IC}_{90}$ values ranged from 1.95 to $22 \mu \mathrm{g} / \mathrm{mL}$ as compared to $\mathrm{IC}_{90}$ of $6.0 \mu \mathrm{g} / \mathrm{mL}$ for pentamidine. However, analogues were less potent than amphotericin $\mathrm{B}\left(\mathrm{IC}_{50}=0.1 \mu \mathrm{g} / \mathrm{mL}\right.$ and $\left.\mathrm{IC}_{90}=0.3 \mu \mathrm{g} / \mathrm{mL}\right)$. The notable examples that produced potent activities are $\mathbf{5 2}$ $\left(\mathrm{IC}_{50}=1.77 \mu \mathrm{g} / \mathrm{mL}, \mathrm{IC}_{90}=2.55 \mu \mathrm{g} / \mathrm{mL}\right), 53\left(\mathrm{IC}_{50}=0.84 \mu \mathrm{g} /\right.$ $\left.\mathrm{mL}, \mathrm{IC}_{90}=1.95 \mu \mathrm{g} / \mathrm{mL}\right), 95\left(\mathrm{IC}_{50}=3.5 \mu \mathrm{g} / \mathrm{mL}, \mathrm{IC}_{90}=6.5 \mu \mathrm{g} /\right.$ $\mathrm{mL}), 97\left(\mathrm{IC}_{50}=4.0 \mu \mathrm{g} / \mathrm{mL}, \mathrm{IC}_{90}=6.5 \mu \mathrm{g} / \mathrm{mL}\right), 105\left(\mathrm{IC}_{50}=\right.$ 
Table 2. In Vivo Antimalarial Activities of 8-Quinolinamines ${ }^{a}$

\begin{tabular}{|c|c|c|c|c|c|c|c|}
\hline \multirow[b]{2}{*}{$\begin{array}{l}\text { no. } \\
46\end{array}$} & \multicolumn{4}{|c|}{ P. berghei $(\mathrm{mg} / \mathrm{kg} /$ day $\times 4$, oral $)$} & \multicolumn{3}{|c|}{ P. yoelii nigeriensis $(\mathrm{mg} / \mathrm{kg} / \mathrm{day} \times 4$, oral $)$} \\
\hline & $\begin{array}{l}100 \mathrm{mg} / \mathrm{kg} \\
\text { curative }(6 / 6)\end{array}$ & $\begin{array}{l}50 \mathrm{mg} / \mathrm{kg} \\
\text { curative }(6 / 6)\end{array}$ & $\begin{array}{l}25 \mathrm{mg} / \mathrm{kg} \\
\text { curative }(6 / 6)\end{array}$ & $\begin{array}{l}10 \mathrm{mg} / \mathrm{kg} \\
\text { active }(4 / 6)\end{array}$ & $\begin{array}{l}100 \mathrm{mg} / \mathrm{kg} \\
\text { curative }(6 / 6)\end{array}$ & $\begin{array}{l}50 \mathrm{mg} / \mathrm{kg} \\
\text { curative }(6 / 6)\end{array}$ & $\begin{array}{l}25 \mathrm{mg} / \mathrm{kg} \\
\text { active }(4 / 6)\end{array}$ \\
\hline 47 & curative $(6 / 6)$ & curative $(6 / 6)$ & curative $(6 / 6)$ & active $(5 / 6)$ & curative $(6 / 6)$ & curative $(6 / 6)$ & inactive $(0 / 6)$ \\
\hline 48 & curative $(6 / 6)$ & curative $(6 / 6)$ & curative $(6 / 6)$ & active $(4 / 6)$ & active $(4 / 6)$ & active $(3 / 6)$ & inactive $(0 / 6)$ \\
\hline 49 & curative $(6 / 6)$ & curative $(6 / 6)$ & curative $(6 / 6)$ & active $(4 / 6)$ & active $(4 / 6)$ & active $(3 / 6)$ & inactive $(0 / 6)$ \\
\hline 50 & curative $(6 / 6)$ & active $(4 / 6)$ & & & & & \\
\hline 51 & inactive $(0 / 6)$ & & & & & & \\
\hline 92 & curative $(6 / 6)$ & active $(4 / 6)$ & inactive $(0 / 6)$ & & & & \\
\hline 99 & curative $(6 / 6)$ & active $(3 / 6)$ & inactive $(0 / 6)$ & & & & \\
\hline 111 & curative $(6 / 6)$ & curative $(6 / 6)$ & inactive $(0 / 6)$ & & & & \\
\hline 121 & curative $(6 / 6)$ & active $(3 / 6)$ & inactive $(0 / 6)$ & & & & \\
\hline CQ & curative $(6 / 6)$ & curative $(6 / 6)$ & curative $(6 / 6)$ & active $(2 / 6)$ & inactive $(0 / 6)$ & inactive $(0 / 6)$ & inactive $(0 / 6)$ \\
\hline
\end{tabular}

$\left.3.5 \mu \mathrm{g} / \mathrm{mL}, \mathrm{IC}_{90}=7.0 \mu \mathrm{g} / \mathrm{mL}\right), 113\left(\mathrm{IC}_{50}=3.8 \mu \mathrm{g} / \mathrm{mL}, \mathrm{IC}_{90}=\right.$ $7 \mu \mathrm{g} / \mathrm{mL})$, and $114\left(\mathrm{IC}_{50}=3.8 \mu \mathrm{g} / \mathrm{mL}, \mathrm{IC}_{90}=7 \mu \mathrm{g} / \mathrm{mL}\right)$.

It is interesting to note that most active antileishmanial compound $53\left(\mathrm{R}=\mathrm{OC}_{7} \mathrm{H}_{15}, \mathrm{R}_{1}=\mathrm{CH}_{3}\right)$ produced very weak antimalarial activity, hence providing a high degree of selectivity for leishmania infection. Interestingly, an exact opposite trend for activity was noted for leishmania when compared to malaria. In these cases, higher activity was observed for compounds that possess a methyl group at the C-4 position. The same trend was also observed for conjugated 8-quinolinamines, wherein almost all basic amino acid conjugates were inactive as antileishmanials while those with hydrophobic amino acids displayed high activity (Table 3).

Antifungal Activity. The antifungal activities of the 8quinolinamines against the opportunistic yeast Candida albicans, Candida glabrata, Candida krusei, Cryptococcus neoformans, and Aspergillus fumigatus along with the positive control amphotericin $\mathrm{B}$ are summarized in Table $4 . \mathrm{IC}_{50} \mathrm{~s}$, MICs, and MFCs were determined according to the National Committee for Clinical Laboratory Standards (NCCLS) methods. ${ }^{26-28}$

Analogue 48 exhibited a broad spectrum of antifungal activities among all 8-quinolinamines tested and produced fungicidal action against $C$. albicans $\left(\mathrm{IC}_{50}=4.93 \mu \mathrm{g} / \mathrm{mL}, \mathrm{MIC}=\right.$ MFC $=10 \mu \mathrm{g} / \mathrm{mL})$, C. glabrata $\left(\mathrm{IC}_{50}=3.96 \mu \mathrm{g} / \mathrm{mL}\right.$, MIC $=$ MFC $=5.0 \mu \mathrm{g} / \mathrm{mL})$, C. krusei $\left(\mathrm{IC}_{50}=4.44 \mu \mathrm{g} / \mathrm{mL}\right.$, MIC $=$ $\mathrm{MFC}=5.0 \mu \mathrm{g} / \mathrm{mL})$, C. neoformans $\left(\mathrm{IC}_{50}=2.07 \mu \mathrm{g} / \mathrm{mL}, \mathrm{MIC}=\right.$ MFC $=2.50 \mu \mathrm{g} / \mathrm{mL})$, and A. fumigatus $\left(\mathrm{IC}_{50}=6.0 \mu \mathrm{g} / \mathrm{mL}\right)$. Analogues 49, 52, and 53 also exhibited promising activity against all the fungal strains with MICs as low as $5.0 \mu \mathrm{g} / \mathrm{mL}$. Several other compounds produced promising antifungal effects with $\mathrm{IC}_{50}$ values in the range of $0.58-6.8 \mu \mathrm{g} / \mathrm{mL}$ against $C$. neoformans. These compounds also exhibited MICs in the range of $1.25-5.0 \mu \mathrm{g} / \mathrm{mL}$ against $C$. neoformans with MFC values in the range of $2.5-5.0 \mu \mathrm{g} / \mathrm{mL}$ (Table 4). Compounds $\mathbf{5 0}$ and $\mathbf{5 3}$ turned out to be highly effective against $C$. neoformans with $\mathrm{IC}_{50}$ of 0.58 and $0.67 \mu \mathrm{g} / \mathrm{mL}$, respectively. These values are comparable to standard drug amphotericin used in the experiments. In a nutshell, the presence of the C-5-heptyloxy group with or without a C-4 methyl group at the 8quinolinamine structure exhibited potent antifungal activity while the attachment of amino acids to the quinoline side chain produced inactive analogues.
Antibacterial Activity. The antibacterial activities of the 8quinolinamines against Staphylococcus aureus (SA), methicillinresistant Staphylococcus aureus (MRSA), and Mycobacterium intracellulare are reported in Table 5, including the positive control ciprofloxacin. Susceptibility of SA and MRSA to test compounds was determined according to the procedure as described by the NCCLS. ${ }^{27,28}$

Susceptibility of $M$. intracellulare was done using the modified alamarBlue procedure of Franzblau et al. ${ }^{29}$ Most of the analogues (46-50, 52-53, 55, 94-98, 101-103, 105, 108, 112-116, 119, and 121) exhibited potent antibacterial activity against SA $\left(\mathrm{IC}_{50}=1.33-9.04 \mu \mathrm{g} / \mathrm{mL}, \mathrm{MIC}=2.5-10.0 \mu \mathrm{g} / \mathrm{mL}\right.$, $\mathrm{MBC}=5.0-20.0 \mu \mathrm{g} / \mathrm{mL}$ ). Compounds $49,50,52-53,55,95$, $98,103,105$, and 112-116 were bactericidal at 5.0 and 10.0 $\mu \mathrm{g} / \mathrm{mL}$ against SA (Table 5). Several analogues (46-50, 52$53,55,94-98,101-106,108,112-116,120$, and 122-123) exhibited high antibacterial activity against MRSA ( $\mathrm{IC}_{50}=$ $1.38-10.48 \mu \mathrm{g} / \mathrm{mL}$ and $\mathrm{MIC}=5.0-10.0 \mu \mathrm{g} / \mathrm{mL}$ ). Compounds $47-48,50,52-53,55,98$, and 114-115 were bactericidal at 5 and $10 \mu \mathrm{g} / \mathrm{mL}$ against MRSA (MBC). Analogues 47-53, 55, 93-98, 100, 102-103, 108, 114-115, and 118 showed activity against $M$. intracellulare $\left(\mathrm{IC}_{50}=3.12-14.95 \mu \mathrm{g} / \mathrm{mL}\right.$ and $\mathrm{MIC}=5.0-20.0 \mu \mathrm{g} / \mathrm{mL}$ ). Compounds 47-48 and 52-53 were bactericidal against $M$. intracellulare at 5.0 and $10.0 \mu \mathrm{g} / \mathrm{mL}$ (Table 5). It can be seen that analogues (47-48, 52-53, 98, 103, and 114) displayed a broad spectrum of antibacterial activities by exhibiting promising inhibition of all strains at a low micromolar concentration. In these cases, both 8quinolinamines and their amino acid analogues displayed activity. The choice of amino acid did not impact much with reference to activity as both hydrophobic and hydrophilic amino acid conjugates showed antibacterial activity.

\section{CONCLUSIONS}

We have synthesized new 8-quinolinamines and examined their biological activity. Analogues 46-49 produced potent antimalarial activity in vitro against drug-sensitive and drugresistant strains of $P$. falciparum. The same compounds were $100 \%$ curative against drug-sensitive $P$. berghei and multidrugresistant $P$. yoelli nigeriensis infection in mice. The reported quinolinamines also produced potent in vitro activity against $L$. donovani with $\mathrm{IC}_{50}$ as low as $0.84 \mu \mathrm{g} / \mathrm{mL}$. At the same time, very promising and potent activities were observed against 
Table 3. In Vitro Antileishmanial Activities of 8-Quinolinamines ${ }^{a}$

\begin{tabular}{|c|c|c|c|c|c|}
\hline \multirow[b]{2}{*}{ no. } & \multirow[b]{2}{*}{$\mathrm{R}$} & \multirow[b]{2}{*}{$\mathrm{R}_{1}$} & \multirow[b]{2}{*}{$\mathrm{R}_{2}$} & \multicolumn{2}{|c|}{ L. donovani } \\
\hline & & & & $\mathrm{IC}_{50}(\mu \mathrm{g} / \mathrm{mL})$ & $\mathrm{IC}_{90}(\mu \mathrm{g} / \mathrm{mL})$ \\
\hline 45 & $\mathrm{OC}_{4} \mathrm{H}_{9}$ & $\mathrm{H}$ & & NA & NA \\
\hline 46 & $\mathrm{OC}_{5} \mathrm{H}_{11}$ & $\mathrm{H}$ & & 32 & $>40$ \\
\hline 47 & $\mathrm{OC}_{6} \mathrm{H}_{13}$ & $\mathrm{H}$ & & 4.6 & $>40$ \\
\hline 48 & $\mathrm{OC}_{7} \mathrm{H}_{15}$ & $\mathrm{H}$ & & 5.0 & $>40$ \\
\hline 49 & $\mathrm{OC}_{8} \mathrm{H}_{17}$ & $\mathrm{H}$ & & 5.2 & $>40$ \\
\hline 50 & $\mathrm{OC}_{4} \mathrm{H}_{9}$ & $\mathrm{CH}_{3}$ & & 1.5 & 3.65 \\
\hline 51 & $\mathrm{OC}_{5} \mathrm{H}_{11}$ & $\mathrm{CH}_{3}$ & & 16.17 & 23.87 \\
\hline 52 & $\mathrm{OC}_{6} \mathrm{H}_{13}$ & $\mathrm{CH}_{3}$ & & 1.77 & 2.55 \\
\hline 53 & $\mathrm{OC}_{7} \mathrm{H}_{15}$ & $\mathrm{CH}_{3}$ & & 0.84 & 1.95 \\
\hline 54 & $\mathrm{OC}_{8} \mathrm{H}_{17}$ & $\mathrm{CH}_{3}$ & & 9.74 & 15.56 \\
\hline 55 & $\mathrm{O}-\mathrm{Ph}\left(3,4-\mathrm{Cl}_{2}\right)$ & $\mathrm{H}$ & & 11 & $>40$ \\
\hline 90 & $\mathrm{OC}_{4} \mathrm{H}_{9}$ & $\mathrm{H}$ & Lys & NA & NA \\
\hline 91 & $\mathrm{OC}_{4} \mathrm{H}_{9}$ & $\mathrm{H}$ & Orn & NA & NA \\
\hline 92 & $\mathrm{OC}_{5} \mathrm{H}_{11}$ & $\mathrm{H}$ & Lys & NA & NA \\
\hline 93 & $\mathrm{OC}_{5} \mathrm{H}_{11}$ & $\mathrm{H}$ & Orn & NA & NA \\
\hline 94 & $\mathrm{OC}_{5} \mathrm{H}_{11}$ & $\mathrm{H}$ & Arg & 18 & 32 \\
\hline 95 & $\mathrm{OC}_{5} \mathrm{H}_{11}$ & $\mathrm{H}$ & Leu & 3.5 & 6.5 \\
\hline 96 & $\mathrm{OC}_{5} \mathrm{H}_{11}$ & $\mathrm{H}$ & Ile & 8.65 & 32.65 \\
\hline 97 & $\mathrm{OC}_{5} \mathrm{H}_{11}$ & $\mathrm{H}$ & Phe & 4.0 & 6.5 \\
\hline 98 & $\mathrm{OC}_{5} \mathrm{H}_{11}$ & $\mathrm{H}$ & $\operatorname{Trp}$ & 1.81 & 2.93 \\
\hline 99 & $\mathrm{OC}_{6} \mathrm{H}_{13}$ & $\mathrm{H}$ & Lys & NA & NA \\
\hline 100 & $\mathrm{OC}_{6} \mathrm{H}_{13}$ & $\mathrm{H}$ & Orn & NA & NA \\
\hline 101 & $\mathrm{OC}_{6} \mathrm{H}_{13}$ & $\mathrm{H}$ & D-Arg & NA & NA \\
\hline 102 & $\mathrm{OC}_{6} \mathrm{H}_{13}$ & $\mathrm{H}$ & Met & 5.9 & 22 \\
\hline 103 & $\mathrm{OC}_{6} \mathrm{H}_{13}$ & $\mathrm{H}$ & Pro & 4.0 & 6.8 \\
\hline 104 & $\mathrm{OC}_{6} \mathrm{H}_{13}$ & $\mathrm{H}$ & Ile & 16 & 30 \\
\hline 105 & $\mathrm{OC}_{6} \mathrm{H}_{13}$ & $\mathrm{H}$ & His & 3.5 & 7 \\
\hline 106 & $\mathrm{OC}_{6} \mathrm{H}_{13}$ & $\mathrm{H}$ & Phe & 9.89 & $>40$ \\
\hline 107 & $\mathrm{OC}_{6} \mathrm{H}_{13}$ & $\mathrm{H}$ & Ala & 17.13 & 37.31 \\
\hline 108 & $\mathrm{OC}_{6} \mathrm{H}_{13}$ & $\mathrm{H}$ & $\operatorname{Trp}$ & 19.1 & $>40$ \\
\hline 109 & $\mathrm{OC}_{7} \mathrm{H}_{15}$ & $\mathrm{H}$ & Lys & NA & NA \\
\hline 110 & $\mathrm{OC}_{7} \mathrm{H}_{15}$ & $\mathrm{H}$ & Orn & NA & NA \\
\hline 111 & $\mathrm{OC}_{7} \mathrm{H}_{15}$ & $\mathrm{H}$ & Arg & NA & NA \\
\hline 112 & $\mathrm{OC}_{7} \mathrm{H}_{15}$ & $\mathrm{H}$ & Phe & 20 & 36 \\
\hline 113 & $\mathrm{OC}_{7} \mathrm{H}_{15}$ & $\mathrm{H}$ & Pro & 3.8 & 7 \\
\hline 114 & $\mathrm{OC}_{7} \mathrm{H}_{15}$ & $\mathrm{H}$ & Ile & 3.8 & 7 \\
\hline 115 & $\mathrm{OC}_{7} \mathrm{H}_{15}$ & $\mathrm{H}$ & $\operatorname{Trp}$ & 19 & 32 \\
\hline 116 & $\mathrm{OC}_{7} \mathrm{H}_{15}$ & $\mathrm{H}$ & Met & 4.1 & 12 \\
\hline 117 & $\mathrm{OC}_{8} \mathrm{H}_{17}$ & $\mathrm{H}$ & Lys & NA & NA \\
\hline 118 & $\mathrm{OC}_{8} \mathrm{H}_{17}$ & $\mathrm{H}$ & Orn & 26.61 & 37.9 \\
\hline 119 & $\mathrm{OC}_{8} \mathrm{H}_{17}$ & $\mathrm{H}$ & Ile & 6.04 & 26.93 \\
\hline 120 & $\mathrm{OC}_{8} \mathrm{H}_{17}$ & $\mathrm{H}$ & Met & 6.99 & 26.44 \\
\hline 121 & $\mathrm{OC}_{8} \mathrm{H}_{17}$ & $\mathrm{H}$ & Phe & 11.82 & 28.66 \\
\hline 122 & $\mathrm{OC}_{8} \mathrm{H}_{17}$ & $\mathrm{H}$ & $\operatorname{Trp}$ & 9.32 & 25.69 \\
\hline 123 & $\mathrm{OC}_{8} \mathrm{H}_{17}$ & $\mathrm{H}$ & Pro & 12.38 & 38.39 \\
\hline pentamidine & & & & 1.1 & 2.5 \\
\hline amphotericin B (AMP) & & & & 0.1 & 0.3 \\
\hline
\end{tabular}

opportunistic pathogenic infections such as C. neoformans, SA, and MRSA $\left(\mathrm{IC}_{50} \mathrm{~s} \geq 0.58, \geq 1.33\right.$ and $\geq 1.38 \mu \mathrm{g} / \mathrm{mL}$, respectively). None of the analogues exhibit any cytotoxicity at the highest test concentration, confirming their selectivity for the pathogenic infections. As evident from the abovementioned discussion, many 8-quinolinamines besides exhibiting potent antimalarial activity also exhibit potent antileishmanial and antimicrobial activities and therefore provide impetus to develop this class of quinolines as a broad-spectrum antiinfective. The results of this study confirm the importance of the 8-qunolinamines class of compounds in the treatment of parasitic infections and microbial infections. The most promising analogues reported herein forms a panel for further optimization and preclinical studies.

\section{EXPERIMENTAL SECTION}

General Chemistry. Reagents and starting material were available from commercial suppliers and used without any purification unless otherwise stated. Various heterocycles, solvent, and other reagents were purchased from commercial 
Table 4. In Vitro Antifungal Activities of 8-Quinolinamines ${ }^{a}$

\begin{tabular}{|c|c|c|c|c|c|c|c|c|c|c|c|c|c|c|c|}
\hline \multirow[b]{2}{*}{ no. } & \multicolumn{3}{|c|}{ C. albicans } & \multicolumn{3}{|c|}{ C. glabrata } & \multicolumn{3}{|c|}{ C. krusei } & \multicolumn{3}{|c|}{ C. neoformans } & \multicolumn{3}{|c|}{ A. fumigatus } \\
\hline & $\mathrm{IC}_{50}$ & MIC & MFC & $\mathrm{IC}_{50}$ & MIC & MFC & $\mathrm{IC}_{50}$ & MIC & MFC & $\mathrm{IC}_{50}$ & MIC & MFC & $\mathrm{IC}_{50}$ & MIC & MFC \\
\hline 45 & NA & NA & NA & NA & NA & NA & NA & NA & NA & NA & NA & NA & NA & NA & NA \\
\hline 46 & NA & NA & NA & NA & NA & NA & NA & NA & NA & NA & NA & NA & NA & NA & NA \\
\hline 47 & 15.45 & 20.00 & 20.00 & 11.49 & 20.00 & 20.00 & 7.16 & 10.00 & 10.00 & 2.97 & 5.00 & 5.00 & NA & NA & NA \\
\hline 48 & 4.93 & 10.00 & 10.00 & 3.96 & 5.00 & 5.00 & 4.44 & 5.00 & 5.00 & 2.07 & 2.50 & 2.50 & 6.00 & $>20$ & $>20$ \\
\hline 49 & 7.44 & 10.00 & 10.00 & 6.19 & 10.00 & 10.00 & 5.82 & 10.00 & 10.00 & 2.15 & 5.00 & 5.00 & NA & NA & NA \\
\hline 50 & 15.00 & $>20$ & $>20$ & 16.27 & $>20$ & $>20$ & 5.75 & 10.00 & 10.00 & 0.58 & 1.25 & 2.50 & 14.70 & $>20$ & $>20$ \\
\hline 51 & NA & NA & NA & NA & NA & NA & NA & NA & NA & 4.45 & 20.00 & 20.00 & NA & NA & NA \\
\hline 52 & 5.91 & 10.00 & 10.00 & 5.16 & 10.00 & 20.00 & 3.73 & 5.00 & 5.00 & 0.84 & 1.25 & 2.50 & 19.00 & $>20$ & $>20$ \\
\hline 53 & 5.06 & 10.00 & 10.00 & 4.3 & 5.00 & 5.00 & 2.89 & 5.00 & 5.00 & 0.67 & 1.25 & 1.25 & 19.32 & $>20$ & $>20$ \\
\hline 54 & NA & NA & NA & NA & NA & NA & NA & NA & NA & 9.96 & $>20$ & $>20$ & NA & NA & NA \\
\hline 55 & NA & NA & NA & 19.41 & 20.00 & 20.00 & 8.65 & 20.00 & 20.00 & 3.18 & 5.00 & 5.00 & NA & NA & NA \\
\hline 90 & NA & NA & NA & NA & NA & NA & NA & NA & NA & NA & NA & NA & NA & NA & NA \\
\hline 91 & NA & NA & NA & NA & NA & NA & NA & NA & NA & NA & NA & NA & NA & NA & NA \\
\hline 92 & NA & NA & NA & NA & NA & NA & NA & NA & NA & 10.86 & $>20$ & $>20$ & NA & NA & NA \\
\hline 93 & NA & NA & NA & NA & NA & NA & NA & NA & NA & 10.13 & $>20$ & $>20$ & NA & NA & NA \\
\hline 94 & 18.64 & 20.00 & 20.00 & 19.05 & 20.00 & 20.00 & NA & NA & NA & 1.41 & 2.50 & 2.50 & NA & NA & NA \\
\hline 95 & 18.45 & $>20$ & $>20$ & 11.31 & 20.00 & 20.00 & 8.73 & 10.00 & 10.00 & 1.68 & 2.50 & 2.50 & NA & NA & NA \\
\hline 96 & NA & NA & NA & 15.24 & $>20$ & $>20$ & NA & NA & NA & 4.95 & 10.00 & 10.00 & NA & NA & NA \\
\hline 97 & NA & NA & NA & 10.95 & 20.00 & 20.00 & 7.37 & 10.00 & 10.00 & 2.29 & 2.50 & 2.50 & NA & NA & NA \\
\hline 98 & 18.75 & $>20$ & $>20$ & 9.72 & 20.00 & 20.00 & 4.28 & 10.00 & 10.00 & 1.21 & 2.50 & 2.50 & NA & NA & NA \\
\hline 99 & NA & NA & NA & NA & NA & NA & NA & NA & NA & 18.64 & $>20$ & $>20$ & NA & NA & NA \\
\hline 100 & NA & NA & NA & NA & NA & NA & NA & NA & NA & NA & NA & NA & NA & NA & NA \\
\hline 101 & NA & NA & NA & NA & NA & NA & NA & NA & NA & 14.30 & $>20$ & $>20$ & NA & NA & NA \\
\hline 102 & NA & NA & NA & NA & NA & NA & NA & NA & NA & NA & NA & NA & NA & NA & NA \\
\hline 103 & 11.54 & 20.00 & 20.00 & 8.91 & 10.00 & 10.00 & 8.76 & 10.00 & 10.00 & 1.49 & 2.50 & 2.50 & NA & NA & NA \\
\hline 104 & NA & NA & NA & NA & NA & NA & NA & NA & NA & NA & NA & NA & NA & NA & NA \\
\hline 105 & 19.38 & $>20$ & $>20$ & 19.22 & 20.00 & 20.00 & 18.95 & $>20$ & $>20$ & NA & NA & NA & NA & NA & NA \\
\hline 106 & NA & NA & NA & NA & NA & NA & NA & NA & NA & 9.83 & 20.00 & 20.00 & NA & NA & NA \\
\hline 107 & NA & NA & NA & NA & NA & NA & NA & NA & NA & NA & NA & NA & NA & NA & NA \\
\hline 108 & NA & NA & NA & NA & NA & NA & NA & NA & NA & 5.09 & 10.00 & 10.00 & NA & NA & NA \\
\hline 109 & NA & NA & NA & NA & NA & NA & NA & NA & NA & NA & NA & NA & NA & NA & NA \\
\hline 110 & NA & NA & NA & NA & NA & NA & NA & NA & NA & NA & NA & NA & NA & NA & NA \\
\hline 111 & NA & NA & NA & NA & NA & NA & NA & NA & NA & 13.24 & $>20$ & $>20$ & NA & NA & NA \\
\hline 112 & NA & NA & NA & NA & NA & NA & NA & NA & NA & 4.56 & 5.00 & 5.00 & NA & NA & NA \\
\hline 113 & NA & NA & NA & NA & NA & NA & NA & NA & NA & 2.93 & 5.00 & 5.00 & NA & NA & NA \\
\hline 114 & 14.22 & $>20$ & $>20$ & 5.01 & 10.00 & 10.00 & 4.38 & 10.00 & 10.00 & 1.07 & 2.50 & 2.50 & NA & NA & NA \\
\hline 115 & NA & NA & NA & NA & NA & NA & NA & NA & NA & 1.36 & 2.50 & 2.50 & NA & NA & NA \\
\hline 116 & NA & NA & NA & NA & NA & NA & NA & NA & NA & 1.29 & 10.00 & 10.00 & NA & NA & NA \\
\hline 117 & NA & NA & NA & NA & NA & NA & NA & NA & NA & 11.92 & $>20$ & $>20$ & NA & NA & NA \\
\hline 118 & 19.95 & $>20$ & $>20$ & 8.05 & $>20$ & $>20$ & 15.36 & $>20$ & $>20$ & 4.93 & $>20$ & $>20$ & NA & NA & NA \\
\hline 119 & NA & NA & NA & NA & NA & NA & NA & NA & NA & 2.87 & 10.00 & 10.00 & NA & NA & NA \\
\hline 120 & NA & NA & NA & NA & NA & NA & NA & NA & NA & 2.74 & 5.00 & 5.00 & NA & NA & NA \\
\hline 121 & NA & NA & NA & NA & NA & NA & NA & NA & NA & 17.32 & $>20$ & $>20$ & NA & NA & NA \\
\hline 122 & NA & NA & NA & NA & NA & NA & NA & NA & NA & 6.80 & 20.00 & $>20$ & NA & NA & NA \\
\hline 123 & NA & NA & NA & 10.96 & 20.00 & 20.00 & NA & NA & NA & 2.89 & 5.00 & 5.00 & NA & NA & NA \\
\hline AMP & 0.17 & 0.63 & 1.25 & 0.31 & 0.63 & 1.25 & 0.49 & 1.25 & 1.25 & 0.30 & 0.63 & 0.63 & 0.68 & 1.25 & 2.50 \\
\hline
\end{tabular}

${ }^{a} \mathrm{IC}_{50}=$ the concentration $(\mu \mathrm{g} / \mathrm{mL})$ that affords $50 \%$ growth inhibition. MIC, minimum inhibitory concentration (the lowest concentration in $\mu \mathrm{g} /$ $\mathrm{mL}$ that allows no detectable growth). MFC, minimum fungicidal concentration (the lowest concentration in $\mu \mathrm{g} / \mathrm{mL}$ that kills the organism). NA, no activity at the highest test concentration of $20 \mu \mathrm{g} / \mathrm{mL}$.

sources such as Sigma-Aldrich, Alfa Aesar, Merck, TCI, Avra, and Chem-Impex. Nuclear magnetic resonance (NMR) spectra were recorded on a Bruker AVANCE III 400 spectrometer. Chemical shifts of the given data for ${ }^{1} \mathrm{H}$ NMR were reported as $\delta$ values, and coupling constants were in hertz $(\mathrm{Hz})$. The following abbreviations were used for spin multiplicity: $s=$ singlet, $\mathrm{d}=$ doublet, $\mathrm{t}=$ triplet, $\mathrm{dd}=$ double doublet, $\mathrm{m}=$ multiplet, $\mathrm{q}=$ quadruplet, $\mathrm{td}=$ triplet of doublet, $\mathrm{dt}=$ doublet of triplet, br s = broad singlet, and if splitting patterns could not be interpreted easily, they are reported as multiplet $(\mathrm{m})$. Thin layer chromatography (TLC) was performed on Merck precoated silica gel plates $(0.25 \mathrm{~mm}, 60 \AA$ pore size $)$ impregnated with a fluorescent indicator $(254 \mathrm{~nm})$. Visualization on TLC was observed under UV light $(254 \mathrm{~nm})$ or staining with iodine or Dragendorff's reagent solution. Synthesized compounds were isolated by automated flash chromatography on silica gel (200-400 mesh). High-resolution mass spectra (HRMS) were recorded on Bruker maXis. 
Table 5. In Vitro Antibacterial Activities of 8-Quinolinamines ${ }^{a}$

\begin{tabular}{|c|c|c|c|c|c|c|c|c|c|}
\hline \multirow[b]{2}{*}{ no. } & \multicolumn{3}{|c|}{ SA } & \multicolumn{3}{|c|}{ MRSA } & \multicolumn{3}{|c|}{ M. intracellulare } \\
\hline & $\mathrm{IC}_{50}$ & MIC & $\mathrm{MBC}$ & $\mathrm{IC}_{50}$ & MIC & $\mathrm{MBC}$ & $\mathrm{IC}_{50}$ & MIC & MBC \\
\hline 45 & NA & NA & NA & NA & NA & NA & NA & NA & NA \\
\hline 46 & 9.04 & $>20$ & $>20$ & 8.68 & $>20$ & $>20$ & NA & NA & NA \\
\hline 47 & 2.77 & 5.00 & 5.00 & 2.77 & 5.00 & 10.00 & 6.30 & 10.00 & 10.00 \\
\hline 48 & 2.77 & 5.00 & 20.00 & 2.36 & 5.00 & 10.00 & 3.72 & 5.00 & 5.00 \\
\hline 49 & 3.40 & 5.00 & 10.00 & 2.85 & 5.00 & 20.00 & 7.43 & 10.00 & 20.00 \\
\hline 50 & 3.49 & 5.00 & 10.00 & 2.96 & 5.00 & 5.00 & 5.97 & 10.00 & 20.00 \\
\hline 51 & 18.90 & $>20$ & $>20$ & 10.48 & 20.00 & $>20$ & 10.77 & 20.00 & 20.00 \\
\hline 52 & 2.83 & 5.00 & 5.00 & 2.75 & 5.00 & 10.00 & 3.43 & 5.00 & 5.00 \\
\hline 53 & 1.33 & 2.50 & 5.00 & 1.38 & 2.50 & 5.00 & 3.12 & 5.00 & 5.00 \\
\hline 54 & NA & NA & NA & NA & NA & NA & 18.59 & $>20$ & $>20$ \\
\hline 55 & 5.96 & 10.00 & 10.00 & 5.64 & 10.00 & 10.00 & 9.51 & 20.00 & 20.00 \\
\hline 90 & NA & NA & NA & NA & NA & NA & NA & NA & NA \\
\hline 91 & NA & NA & NA & NA & NA & NA & NA & NA & NA \\
\hline 92 & NA & NA & NA & NA & NA & NA & NA & NA & NA \\
\hline 93 & NA & NA & NA & NA & NA & NA & 8.99 & $>20$ & $>20$ \\
\hline 94 & 5.85 & 10.00 & 20.00 & 7.27 & 10.00 & 20.00 & 11.23 & 20.00 & 20.00 \\
\hline 95 & 2.56 & 5.00 & 5.00 & 3.57 & 10.00 & 20.00 & 12.56 & 20.00 & 20.00 \\
\hline 96 & 5.35 & 10.00 & 20.00 & 5.46 & 10.00 & 10.00 & 12.20 & 20.00 & 20.00 \\
\hline 97 & 5.81 & 10.00 & $>20$ & 8.23 & 20.00 & 20.00 & 14.95 & $>20$ & $>20$ \\
\hline 98 & 1.95 & 5.00 & 10.00 & 1.95 & 5.00 & 10.00 & 8.47 & 10.00 & 20.00 \\
\hline 99 & NA & NA & NA & NA & NA & NA & NA & NA & NA \\
\hline 100 & NA & NA & NA & NA & NA & NA & 9.34 & $>20$ & $>20$ \\
\hline 101 & 8.87 & $>20$ & $>20$ & 8.95 & $>20$ & $>20$ & 18.44 & 20.00 & $>20.00$ \\
\hline 102 & 5.03 & 10.00 & 20.00 & 4.77 & 20.00 & 20.00 & 11.17 & 20.00 & 20.00 \\
\hline 103 & 2.89 & 5.00 & 10.00 & 2.64 & 5.00 & 20.00 & 5.94 & 10.00 & 10.00 \\
\hline 104 & 13.18 & $>20$ & $>20$ & 10.02 & $>20$ & $>20$ & NA & NA & NA \\
\hline 105 & 2.79 & 5.00 & 10.00 & 4.42 & 10.00 & 20.00 & 5.94 & 10.00 & 10.00 \\
\hline 106 & 10.72 & 20.00 & $>20$ & 9.71 & 20.00 & 20.00 & 18.05 & $>20$ & $>20$ \\
\hline 107 & NA & NA & NA & NA & NA & NA & NA & NA & NA \\
\hline 108 & 4.98 & 10.00 & $>20$ & 5.43 & 10.00 & $>20$ & 12.73 & 20.00 & 20.00 \\
\hline 109 & NA & NA & NA & NA & NA & NA & NA & NA & NA \\
\hline 110 & NA & NA & NA & NA & NA & NA & NA & NA & NA \\
\hline 111 & NA & NA & NA & NA & NA & NA & NA & NA & NA \\
\hline 112 & 4.06 & 10.00 & 10.00 & 4.33 & 10.00 & 20.00 & NA & NA & NA \\
\hline 113 & 3.52 & 10.00 & 10.00 & 3.16 & 5.00 & 20.00 & 16.67 & 20.00 & 20.00 \\
\hline 114 & 2.19 & 5.00 & 5.00 & 2.34 & 5.00 & 5.00 & 5.63 & 10.00 & 20.00 \\
\hline 115 & 4.56 & 10.00 & 10.00 & 2.68 & 5.00 & 10.00 & 8.74 & 10.00 & 20.00 \\
\hline 116 & 4.07 & 10.00 & 10.00 & 3.02 & 5.00 & 10.00 & NA & NA & NA \\
\hline 117 & NA & NA & NA & NA & NA & NA & NA & NA & NA \\
\hline 118 & NA & NA & NA & NA & NA & NA & 7.71 & $>20$ & $>20$ \\
\hline 119 & 5.03 & $>20$ & $>20$ & 15.34 & $>20$ & $>20$ & NA & NA & NA \\
\hline 120 & 11.65 & 20.00 & $>20$ & 10.74 & 20.00 & 20.00 & 20.00 & $>20$ & $>20$ \\
\hline 121 & 7.79 & $>20$ & $>20$ & NA & NA & NA & NA & NA & NA \\
\hline 122 & 11.99 & 20.00 & $>20$ & 8.31 & 20.00 & $>20$ & NA & NA & NA \\
\hline 123 & 10.45 & 20.00 & 20.00 & 5.49 & 10.00 & 20.00 & NA & NA & NA \\
\hline ciprofloxacin & 0.13 & 0.50 & 1.0 & 0.14 & 0.25 & 0.50 & 0.28 & 0.50 & 1.0 \\
\hline
\end{tabular}

${ }^{a} \mathrm{IC}_{50}=$ the concentration $(\mu \mathrm{g} / \mathrm{mL})$ that affords $50 \%$ growth inhibition. $\mathrm{MBC}$, minimum bactericidal concentration (the lowest concentration in $\mu \mathrm{g} /$ $\mathrm{mL}$ that kills the organism). NA, no activity at the highest test concentration of $20 \mu \mathrm{g} / \mathrm{mL}$.

General Procedure for the Synthesis of 5-Substituted2-tert-butyl-6-methoxy-8-nitroquinolines 12-22. 5-Substituted-6-methoxy-8-nitroquinolines (1-11, $1.0 \mathrm{mmol})$ in $\mathrm{CH}_{3} \mathrm{CN}(5 \mathrm{~mL})$ were dissolved, and the reaction mixture was heated to $80{ }^{\circ} \mathrm{C}$. Silver nitrate $(0.6 \mathrm{mmol})$, trimethylacetic acid ( $3.0 \mathrm{mmol})$, and $10 \% \mathrm{H}_{2} \mathrm{SO}_{4}(10 \mathrm{~mL})$ were then added to the reaction mixture. A freshly prepared solution of ammonium persulfate $(3.0 \mathrm{mmol})$ in water $(10 \mathrm{~mL})$ was added drop wise to the preheated mixture $\left(80^{\circ} \mathrm{C}\right)$ during $10 \mathrm{~min}$. The heating source was then removed, and reaction proceeded with the evolution of carbon dioxide. After $15 \mathrm{~min}$, the reaction mixture was poured onto ice and made alkaline by adding $30 \%$ aqueous $\mathrm{NH}_{4} \mathrm{OH}$ solution. The reaction mixture was extracted with ethylacetate $(4 \times 50 \mathrm{~mL})$, and combined extracts were washed with brine solution $(2 \times 10 \mathrm{~mL})$ and dried over $\mathrm{Na}_{2} \mathrm{SO}_{4}$, and the solvent was removed under vacuum to afford oil, which upon column chromatography over silica gel (230-400 mesh) afforded products. For products 12-16, elution was done in EtOAc/hexane (1:99), while products 17-21 were eluted in 
EtOAc/hexane (3:97), and compound 22 was isolated in EtOAc/hexane (2:98).

General Procedure for the Synthesis of 5-Substituted2-tert-butyl-6-methoxy-8-quinolinamines 23-33. A solution of 5-substituted-2-tert-butyl-6-methoxy-8-nitroquinolines $(12-22,5.0 \mathrm{mmol})$ in $95 \%$ absolute alcohol $(15 \mathrm{~mL})$ was hydrogenated over Raney nickel (T1 grade) at 45 psi in a Parr hydrogenator for $45 \mathrm{~min}$. The catalyst was removed by filtration, and the filtrate was evaporated under vacuum to afford 5-alkoxy-2-tert-butyl-6-methoxy-8-quinolinamines.

General Procedure for the Synthesis of 2-[4-(5Substituted-2-tert-butyl-6-methoxy-8-quinolylamino)pentyl]-1,3-isoindolinediones 34-44. To a stirred solution of 5-substituted-2-tert-butyl-6-methoxy-8-quinolamine (23-33, $1.0 \mathrm{mmol}$ ) and 2-(4-bromopentyl)-1,3-isoindolinedione (3.0 $\mathrm{mmol})$, TEA ( $3.0 \mathrm{mmol})$ was added. The reaction mixture was allowed to stir at $120^{\circ} \mathrm{C}$ for $16 \mathrm{~h}$. The residue was purified on silica (230-400 mesh) using EtOAc/hexanes (60:40) to afford product as viscous oil.

General Procedure for the Synthesis of $N^{8}$-(4-Amino1-methylbutyl)-5-substituted-2-tert-butyl-6-methoxy-8quinolinamines $45-55$. To a solution of 2-[4-(5-substituted2-tert-butyl-6-methoxy-8-quinolylamino)pentyl]-1,3-isoindolinedione $(34-44,1.0 \mathrm{mmol})$ in $95 \%$ ethyl alcohol $(25 \mathrm{~mL})$ was added hydrazine hydrate $(25 \mathrm{mmol})$, and the mixture was heated under reflux for $8 \mathrm{~h}$. The solvent was removed under reduced pressure, and the residue was diluted with water $(25$ $\mathrm{mL})$. The reaction mixture was extracted with $\mathrm{CH}_{2} \mathrm{Cl}_{2}(3 \times 20$ $\mathrm{mL}$ ), and evaporation of the solvent under reduced under pressure gave the desired product.

General Procedure for the Synthesis of Amino Acid Conjugates of $N^{8}$-(4-Amino-1-methylbutyl)-5-alkoxy-2tert-butyl-6-methoxy-8-quinolinamines 90-123. To an ice-cooled stirred solution of $N^{8}$-(4-amino-1-methylbutyl)-5alkoxy-2-tert-butyl-6-methoxy-8-quinolinamines (45-49, 1.0 $\mathrm{mmol})$ and $\mathrm{D} / \mathrm{L}-\mathrm{Z} / \mathrm{Boc}$-amino acid $(1.1 \mathrm{mmol})$ in $\mathrm{CH}_{2} \mathrm{Cl}_{2}$ $(15 \mathrm{~mL})$, DCC $(1.1 \mathrm{mmol})$ was added. The reaction mixture was allowed to attain room temperature, and stirring was continued for another $4 \mathrm{~h}$. The reaction mixture was kept in a refrigerator overnight, and the separated 1,3-dicyclohexylurea was filtered. The filtrate was washed with saturated sodium bicarbonate solution $(3-5 \mathrm{~mL})$ followed by water $(2-5 \mathrm{~mL})$ and dried over $\mathrm{Na}_{2} \mathrm{SO}_{4}$. The solvent was removed under reduced pressure to afford the crude product, which was purified by flash column chromatography on silica gel (230400 mesh) using $\mathrm{CH}_{3} \mathrm{OH} / \mathrm{CHCl}_{3}(2: 98)$ to afford $\mathrm{N}^{8}$-(4amino-1-methylbutyl)-5-alkoxy-2-tert-butyl-6-methoxy-8-quinolinamine-amino acid conjugates $(56-89)$ as viscous oil.

For the Arg-conjugated derivative, first carbobenzyloxy (Cbz) on the side chain was removed. To a mixture of side chain Cbz-protected amino acid-linked derivatives (1 mmol), glacial acetic acid $(1 \mathrm{~mL})$ was added $10 \% \mathrm{Pd}-\mathrm{C}(200 \mathrm{mg})$ in methanol $(30 \mathrm{~mL})$. A slow stream of hydrogen gas was bubbled through the reaction mixture for $1 \mathrm{~h}$. The catalyst was removed by filtration, and the filtrate was concentrated in vacuum to afford the product.

To a mixture of the Boc-amino acid-linked derivative (1 mmol) was added a solution of $4 \mathrm{~N} \mathrm{HCl}$ in $\mathrm{MeOH}$, and the reaction mixture was stirred for $1 \mathrm{~h}$ at ambient temperature. The removal of the solvent afforded the product.

Characterization Data of Synthesized Compounds. 5Butoxy-2-tert-butyl-6-methoxy-8-nitroquinoline (12). Yield = 22\%; ${ }^{1} \mathrm{H} \mathrm{NMR}\left(400 \mathrm{MHz}, \mathrm{CDCl}_{3}\right.$ ): $\delta 8.43$ (d, $J=9.03 \mathrm{~Hz}$,
1H), $7.90(\mathrm{~s}, 1 \mathrm{H}), 7.59$ (d, $J=9.03 \mathrm{~Hz}, 1 \mathrm{H}), 4.26(\mathrm{t}, J=6.65$ $\mathrm{Hz}, 2 \mathrm{H}), 4.01(\mathrm{~s}, 3 \mathrm{H}), 1.79-1.88(\mathrm{~m}, 2 \mathrm{H}), 1.53-1.60(\mathrm{~m}, 2 \mathrm{H})$, 1.44 (s, 9H), 1.26-1.28 (m, 2H), 1.01 (s, 3H); HRMS (ESITOF) $m / z:\left[\left(\mathrm{M}+\mathrm{H}^{+}\right)\right]$calcd for 333.1736; found, 333.1744.

2-tert-Butyl-6-methoxy-5-pentyloxy-8-nitroquinoline (13). Yield $=28 \%$; ${ }^{1} \mathrm{H}$ NMR $\left(400 \mathrm{MHz}, \mathrm{CDCl}_{3}\right): \delta 8.42(\mathrm{~d}, J=9.03$ $\mathrm{Hz}, 1 \mathrm{H}), 7.89(\mathrm{~s}, 1 \mathrm{H}), 7.58(\mathrm{~d}, J=9.03 \mathrm{~Hz}, 1 \mathrm{H}), 4.23(\mathrm{t}, J=$ $6.40 \mathrm{~Hz}, 2 \mathrm{H}), 4.00(\mathrm{~s}, 3 \mathrm{H}), 1.85(\mathrm{t}, J=6.78 \mathrm{~Hz}, 2 \mathrm{H}), 1.35-$ $1.55(\mathrm{~m}, 14 \mathrm{H}), 1.26($ br s, $5 \mathrm{H}), 0.95(\mathrm{t}, J=6.90 \mathrm{~Hz}, 3 \mathrm{H}), 0.81-$ $0.91(\mathrm{~m}, 2 \mathrm{H})$; HRMS (ESI-TOF) $m / z:\left[\left(\mathrm{M}+\mathrm{H}^{+}\right)\right]$calcd 347.1893; found, 347.1960.

2-tert-Butyl-5-hexyloxy-6-methoxy-8-nitroquinoline (14). Yield $=23 \% ;{ }^{1} \mathrm{H}$ NMR $\left(400 \mathrm{MHz}, \mathrm{CDCl}_{3}\right): \delta 8.42(\mathrm{~d}, J=$ $9.03 \mathrm{~Hz}, 1 \mathrm{H}), 7.90(\mathrm{~s}, 1 \mathrm{H}), 7.75(\mathrm{~d}, J=2.76 \mathrm{~Hz}, 1 \mathrm{H}), 7.59$ (d, $J$ $=9.03 \mathrm{~Hz}, 1 \mathrm{H}), 6.90(\mathrm{~d}, J=9.03 \mathrm{~Hz}, 1 \mathrm{H}), 4.25(\mathrm{t}, J=6.65 \mathrm{~Hz}$, $2 \mathrm{H}), 4.11(\mathrm{t}, J=6.78 \mathrm{~Hz}, 1 \mathrm{H}), 4.01(\mathrm{~s}, 3 \mathrm{H}), 3.95(\mathrm{~s}, 2 \mathrm{H})$, 1.79-1.94 (m, 3H), $1.62(\mathrm{~s}, 1 \mathrm{H}), 1.51(\mathrm{~d}, J=7.28 \mathrm{~Hz}, 3 \mathrm{H})$, $1.44(\mathrm{~s}, 9 \mathrm{H}), 1.32-1.41(\mathrm{~m}, 7 \mathrm{H}), 1.26(\mathrm{~s}, 1 \mathrm{H}), 0.88-0.96(\mathrm{~m}$, $5 \mathrm{H})$; HRMS (ESI-TOF) $m / z:\left[\left(\mathrm{M}+\mathrm{H}^{+}\right)\right]$calcd for 361.2049; found, 361.2124.

2-tert-Butyl-5-heptyloxy-6-methoxy-8-nitroquinoline (15). Yield $=24 \%$; ${ }^{1} \mathrm{H}$ NMR $\left(400 \mathrm{MHz}, \mathrm{CDCl}_{3}\right): \delta 8.43(\mathrm{~d}, J=9.03$ $\mathrm{Hz}, 1 \mathrm{H}), 7.90(\mathrm{~s}, 1 \mathrm{H}), 7.59$ (d, $J=9.03 \mathrm{~Hz}, 1 \mathrm{H}), 4.24(\mathrm{t}, J=$ $6.65 \mathrm{~Hz}, 2 \mathrm{H}), 4.13(\mathrm{~d}, J=7.28 \mathrm{~Hz}, 1 \mathrm{H}), 4.01(\mathrm{~s}, 3 \mathrm{H}), 2.05$ (s, $1 \mathrm{H}), 1.41-1.46(\mathrm{~m}, 10 \mathrm{H}), 1.33(\mathrm{dd}, J=2.64,3.89 \mathrm{~Hz}, 5 \mathrm{H})$, 1.24-1.30 (m, 2H), 0.88-0.95 (m, 3H); HRMS (ESI-TOF) $m / z:\left[\left(\mathrm{M}+\mathrm{H}^{+}\right)\right]$calcd for 375.2006; found, 375.2218 .

2-tert-Butyl-5-octyloxy-6-methoxy-8-nitroquinoline (16). Yield $=21 \%$; ${ }^{1} \mathrm{H}$ NMR $\left(400 \mathrm{MHz}, \mathrm{CDCl}_{3}\right): \delta 8.43(\mathrm{~d}, J=$ $9.03 \mathrm{~Hz}, 1 \mathrm{H}), 7.90(\mathrm{~s}, 1 \mathrm{H}), 7.59(\mathrm{~d}, J=9.03 \mathrm{~Hz}, 1 \mathrm{H}), 4.24(\mathrm{t}, J$ $=6.65 \mathrm{~Hz}, 2 \mathrm{H}), 4.13(\mathrm{~d}, J=7.28 \mathrm{~Hz}, 1 \mathrm{H}), 4.01(\mathrm{~s}, 3 \mathrm{H}), 2.05(\mathrm{~s}$, $1 \mathrm{H}), 1.41-1.46(\mathrm{~m}, 10 \mathrm{H}), 1.33(\mathrm{dd}, J=2.64,3.89 \mathrm{~Hz}, 5 \mathrm{H})$, 1.24-1.30 (m, 2H), 0.88-0.95 (m, 3H); HRMS (ESI-TOF) $m / z:\left[\left(\mathrm{M}+\mathrm{H}^{+}\right)\right]$calcd for 389.2362; found, 389.2300.

5-Butoxy-2-tert-butyl-6-methoxy-4-methyl-8-nitroquinoline (17). Yield $=30 \% ;{ }^{1} \mathrm{H} \mathrm{NMR}\left(400 \mathrm{MHz}, \mathrm{CDCl}_{3}\right): \delta 7.75(\mathrm{~s}$, $1 \mathrm{H}), 7.29$ (d, $J=0.75 \mathrm{~Hz}, 1 \mathrm{H}), 4.10(\mathrm{t}, J=6.78 \mathrm{~Hz}, 2 \mathrm{H}), 3.99$ (s, 3H), 2.89 (d, $J=0.75 \mathrm{~Hz}, 3 \mathrm{H}), 1.80-1.93(\mathrm{~m}, 2 \mathrm{H}), 1.50-$ $1.61(\mathrm{~m}, 3 \mathrm{H}), 1.40(\mathrm{~s}, 9 \mathrm{H}), 1.27(\mathrm{~s}, 3 \mathrm{H}), 1.02(\mathrm{t}, J=7.28 \mathrm{~Hz}$, $3 \mathrm{H}$ ); HRMS (ESI-TOF) $m / z:\left[\left(\mathrm{M}+\mathrm{H}^{+}\right)\right]$calcd for 347.1893; found, 347.1893 .

2-tert-Butyl-6-methoxy-4-methyl-5-pentyloxy-8-nitroquinoline (18). Yield $=28 \%$; ${ }^{1} \mathrm{H} \mathrm{NMR}\left(400 \mathrm{MHz}, \mathrm{CDCl}_{3}\right): \delta 7.75$ $(\mathrm{s}, 1 \mathrm{H}), 7.29(\mathrm{~d}, J=1.00 \mathrm{~Hz}, 1 \mathrm{H}), 4.09(\mathrm{t}, J=6.90 \mathrm{~Hz}, 2 \mathrm{H})$, 3.99 (s, 3H), 2.89 (d, $J=1.00 \mathrm{~Hz}, 3 \mathrm{H}), 1.88$ (d, $J=7.78 \mathrm{~Hz}$, $2 \mathrm{H}), 1.57(\mathrm{~s}, 2 \mathrm{H}), 1.44(\mathrm{dd}, J=1.25,6.78 \mathrm{~Hz}, 4 \mathrm{H}), 1.40(\mathrm{~s}$, 9H), 1.27 (s, 1H), 0.94-0.99 (m, 3H); HRMS (ESI-TOF) $\mathrm{m} /$ $z:\left[\left(\mathrm{M}+\mathrm{H}^{+}\right)\right]$calcd for 361.2049; found, 361.2100.

2-tert-Butyl-5-hexyloxy-6-methoxy-4-methyl-8-nitroquinoline (19). Yield $=27 \%$; ${ }^{1} \mathrm{H}$ NMR $\left(400 \mathrm{MHz}, \mathrm{CDCl}_{3}\right): \delta 7.67$ $(\mathrm{s}, 1 \mathrm{H}), 7.17-7.23(\mathrm{~m}, 2 \mathrm{H}), 4.01(\mathrm{t}, J=6.90 \mathrm{~Hz}, 2 \mathrm{H}), 3.91(\mathrm{~s}$, $3 \mathrm{H}), 2.81(\mathrm{~d}, J=1.00 \mathrm{~Hz}, 3 \mathrm{H}), 1.73-1.84(\mathrm{~m}, 3 \mathrm{H}), 1.50(\mathrm{~s}$, $2 \mathrm{H}), 1.42$ (br s, 3H), 1.26-1.32 (m, 13H), 1.18 (s, 3H), 0.80$0.89(\mathrm{~m}, 4 \mathrm{H})$; HRMS (ESI-TOF) $m / z:\left[\left(\mathrm{M}+\mathrm{H}^{+}\right)\right]$calcd for 375.2206; found, 375.2200.

2-tert-Butyl-5-heptyloxy-6-methoxy-4-methyl-8-nitroquinoline (20). Yield $=32 \% ;{ }^{1} \mathrm{H} \mathrm{NMR}\left(400 \mathrm{MHz}, \mathrm{CDCl}_{3}\right): \delta 7.74$ (s, 1H), 7.19-7.33 (m, 1H), $4.08(\mathrm{t}, J=6.90 \mathrm{~Hz}, 2 \mathrm{H}), 3.98(\mathrm{~s}$, $3 \mathrm{H}), 2.88(\mathrm{~d}, J=0.75 \mathrm{~Hz}, 3 \mathrm{H}), 1.79-1.90(\mathrm{~m}, 2 \mathrm{H}), 1.57(\mathrm{~s}$, $1 \mathrm{H}), 1.48$ (br s, $2 \mathrm{H}), 1.35-1.39(\mathrm{~m}, 9 \mathrm{H}), 1.27-1.35(\mathrm{~m}, 4 \mathrm{H})$, $0.83-0.93(\mathrm{~m}, 3 \mathrm{H})$; HRMS (ESI-TOF) $m / z:\left[\left(\mathrm{M}+\mathrm{H}^{+}\right)\right]$calcd for 389.2362; found, 389.2333. 
2-tert-Butyl-6-methoxy-4-methyl-5-octyloxy-8-nitroquinoline (21). Yield $=24 \%$; ${ }^{1} \mathrm{H} \mathrm{NMR}\left(400 \mathrm{MHz}, \mathrm{CDCl}_{3}\right): \delta 7.75$ (s, $1 \mathrm{H}), 7.24-7.49(\mathrm{~m}, 1 \mathrm{H}), 4.09(\mathrm{t}, J=6.90 \mathrm{~Hz}, 2 \mathrm{H}), 3.99(\mathrm{~s}$, $3 \mathrm{H}), 2.89$ (d, $J=1.00 \mathrm{~Hz}, 3 \mathrm{H}), 1.87(\mathrm{~d}, J=7.78 \mathrm{~Hz}, 2 \mathrm{H}), 1.58$ (s, 3H), 1.26-1.42 (m, 18H), 0.79-1.05 (m, 4H); HRMS (ESI-TOF) $m / z:\left[\left(\mathrm{M}+\mathrm{H}^{+}\right)\right]$calcd for 403.2519; found, 403.2533.

2-tert-Butyl-5-(3,4-dichlorophenyl)-6-methoxy-8-nitroquinoline (22). Yield $=34 \% ;{ }^{1} \mathrm{H} \mathrm{NMR}\left(400 \mathrm{MHz}, \mathrm{CDCl}_{3}\right): \delta 8.16$ $(\mathrm{d}, J=8.03 \mathrm{~Hz}, 1 \mathrm{H}), 7.90($ br s, $1 \mathrm{H}), 7.59(\mathrm{~d}, J=8.03 \mathrm{~Hz}, 1 \mathrm{H})$, $7.34(\mathrm{~d}, J=9.03 \mathrm{~Hz}, 1 \mathrm{H}), 6.94$ (br s, $1 \mathrm{H}), 6.71$ (br s, $1 \mathrm{H}), 3.93$ (br s, 3H), 1.43 (br s, 9H); HRMS (ESI-TOF) $\mathrm{m} / z$ : [( $\left.\mathrm{H}^{+}\right)$] calcd for 421.0644; found, 421.0590 .

5-Butoxy-2-tert-butyl-6-methoxyquinolin-8-amine (23). Yield $=97 \%$; ${ }^{1} \mathrm{H}$ NMR $\left(400 \mathrm{MHz}, \mathrm{CDCl}_{3}\right): \delta 8.25(\mathrm{~d}, J=$ $8.78 \mathrm{~Hz}, 1 \mathrm{H}), 7.47(\mathrm{~d}, J=8.78 \mathrm{~Hz}, 1 \mathrm{H}), 6.71(\mathrm{~s}, 1 \mathrm{H}), 3.97(\mathrm{t}, J$ $=6.65 \mathrm{~Hz}, 2 \mathrm{H}), 3.92(\mathrm{~s}, 3 \mathrm{H}), 1.78-1.86(\mathrm{~m}, 2 \mathrm{H}), 1.42-1.45$ (m, 9H), $0.94(\mathrm{t}, J=7.15 \mathrm{~Hz}, 3 \mathrm{H})$; HRMS (ESI-TOF) $m / z$ : $\left[\left(\mathrm{M}+\mathrm{H}^{+}\right)\right]$calcd for 303.1994; found, 303.1094.

2-tert-Butyl-6-methoxy-5-(pentyloxy)quinolin-8-amine (24). Yield $=95 \% ;{ }^{1} \mathrm{H}$ NMR $\left(400 \mathrm{MHz}, \mathrm{CDCl}_{3}\right): \delta 8.27$ (d, $J=$ $8.78 \mathrm{~Hz}, 1 \mathrm{H}), 7.48$ (d, J = 9.03 Hz, 1H), $6.72(\mathrm{~s}, 1 \mathrm{H}), 3.99(\mathrm{t}, J$ $=6.78 \mathrm{~Hz}, 2 \mathrm{H}), 3.94(\mathrm{~s}, 3 \mathrm{H}), 1.83(\mathrm{~d}, J=8.03 \mathrm{~Hz}, 2 \mathrm{H}), 1.48-$ $1.59(\mathrm{~m}, 6 \mathrm{H}), 1.35-1.48(\mathrm{~m}, 12 \mathrm{H}), 0.96(\mathrm{t}, J=7.28 \mathrm{~Hz}, 4 \mathrm{H})$; HRMS (ESI-TOF) $m / z:\left[\left(\mathrm{M}+\mathrm{H}^{+}\right)\right]$calcd for 317.2151; found, 317.2144.

2-tert-Butyl-5-(hexyloxy)-6-methoxyquinolin-8-amine (25). Yield $=90 \% ;{ }^{1} \mathrm{H}$ NMR $\left(400 \mathrm{MHz}, \mathrm{CDCl}_{3}\right): \delta 8.27$ (d, $J=$ $9.03 \mathrm{~Hz}, 1 \mathrm{H}), 7.48(\mathrm{~d}, J=9.03 \mathrm{~Hz}, 1 \mathrm{H}), 6.72(\mathrm{~s}, 1 \mathrm{H}), 5.31(\mathrm{~s}$, $1 \mathrm{H}), 3.90-4.04(\mathrm{~m}, 6 \mathrm{H}), 3.82(\mathrm{~s}, 1 \mathrm{H}), 1.75-1.88(\mathrm{~m}, 2 \mathrm{H})$, 1.53 (br s, $2 \mathrm{H}), 1.45(\mathrm{~s}, 8 \mathrm{H}), 1.31-1.42(\mathrm{~m}, 5 \mathrm{H}), 1.27(\mathrm{~s}, 1 \mathrm{H})$, 0.86-0.97 (m, 4H); HRMS (ESI-TOF) $m / z:\left[\left(\mathrm{M}+\mathrm{H}^{+}\right)\right]$calcd for 331.2037; found, 331.2050.

2-tert-Butyl-5-(heptyloxy)-6-methoxyquinolin-8-amine (26). Yield $=94 \% ;{ }^{1} \mathrm{H}$ NMR $\left(400 \mathrm{MHz}, \mathrm{CDCl}_{3}\right): \delta 8.27(\mathrm{~d}, J=$ $8.78 \mathrm{~Hz}, 1 \mathrm{H}), 7.48$ (d, J = 8.28 Hz, 1H), 7.28 (br s, $1 \mathrm{H}), 6.72$ (br s, $1 \mathrm{H}), 4.88$ (br s, $2 \mathrm{H}), 4.00(\mathrm{~d}, J=6.53 \mathrm{~Hz}, 3 \mathrm{H}), 3.94$ (br s, $3 \mathrm{H}), 1.83$ (br s, 3H), 1.53 (br s, $5 \mathrm{H}), 1.46$ (br s, 10H), 1.34 (br s, 7H), 1.22 (br s, 1H), 0.92 (br s, 4H); HRMS (ESI-TOF) $m / z:\left[\left(\mathrm{M}+\mathrm{H}^{+}\right)\right]$calcd for 345.2464; found, 345.2400.

2-tert-Butyl-6-methoxy-5-(octyloxy)quinolin-8-amine (27). Yield $=69 \%$; ${ }^{1} \mathrm{H}$ NMR $\left(400 \mathrm{MHz} \mathrm{CDCl}_{3}\right): \delta 8.27(\mathrm{~d}, J=8.78$ $\mathrm{Hz}, 1 \mathrm{H}), 7.49$ (d, $J=8.78 \mathrm{~Hz}, 1 \mathrm{H}), 6.72($ br s, $1 \mathrm{H}), 3.99(\mathrm{t}, J=$ $6.65 \mathrm{~Hz}, 2 \mathrm{H}), 3.93(\mathrm{~s}, 3 \mathrm{H}), 1.79-1.87(\mathrm{~m}, 2 \mathrm{H}), 1.49-1.56(\mathrm{~m}$, $2 \mathrm{H}), 1.43-1.48(\mathrm{~m}, 9 \mathrm{H}), 1.26-1.37(\mathrm{~m}, 12 \mathrm{H}), 0.88-0.93(\mathrm{~m}$, $3 \mathrm{H})$; HRMS (ESI-TOF) $m / z$ : $\left[\left(\mathrm{M}+\mathrm{H}^{+}\right)\right]$calcd for 359.2620; found, 359.2600.

5-Butoxy-2-tert-butyl-6-methoxy-4-methylquinolin-8amine (28). Yield $=88 \% ;{ }^{1} \mathrm{H} \mathrm{NMR}\left(400 \mathrm{MHz}, \mathrm{CDCl}_{3}\right): \delta 7.18$ (br s, $1 \mathrm{H}), 6.73$ (br s, 1H), 4.93 (br s, $1 \mathrm{H}), 3.79-4.00(\mathrm{~m}, 5 \mathrm{H})$, $2.80-2.89(\mathrm{~m}, 3 \mathrm{H}), 1.81(\mathrm{~d}, J=6.02 \mathrm{~Hz}, 2 \mathrm{H}), 1.41(\mathrm{~d}, J=5.27$ $\mathrm{Hz}, 9 \mathrm{H}), 1.34$ (br s, 1H), 1.26 (br s, $2 \mathrm{H}), 0.99$ (d, $J=6.78 \mathrm{~Hz}$, $3 \mathrm{H})$; HRMS (ESI-TOF) $m / z$ : $\left[\left(\mathrm{M}+\mathrm{H}^{+}\right)\right]$calcd for 317.2151; found, 317.2100.

2-tert-Butyl-6-methoxy-4-methyl-5-(pentyloxy)quinolin-8amine (29). Yield $=77 \% ;{ }^{1} \mathrm{H} \mathrm{NMR}\left(400 \mathrm{MHz}, \mathrm{CDCl}_{3}\right): \delta 7.26$ $(\mathrm{s}, 1 \mathrm{H}), 6.73(\mathrm{~s}, 1 \mathrm{H}), 3.82-3.95(\mathrm{~m}, 6 \mathrm{H}), 2.85(\mathrm{~d}, J=1.00 \mathrm{~Hz}$, $4 \mathrm{H}), 1.77-1.90(\mathrm{~m}, 3 \mathrm{H}), 1.32-1.51(\mathrm{~m}, 18 \mathrm{H}), 1.25(\mathrm{~s}, 4 \mathrm{H})$, 0.84-0.99 (m, 5H); HRMS (ESI-TOF) $m / z:\left[\left(\mathrm{M}+\mathrm{H}^{+}\right)\right]$calcd for 331.2307; found, 331.2410.

2-tert-Butyl-5-(hexyloxy)-6-methoxy-4-methylquinolin-8amine (30). Yield $=83 \%$; $\left.{ }^{1} \mathrm{H} \mathrm{NMR} \mathrm{(400} \mathrm{MHz}, \mathrm{CDCl}_{3}\right): \delta 7.19$ (s, 1H), 7.11 (br s, 1H), 6.65 (br s, $1 \mathrm{H}), 3.65-3.95(\mathrm{~m}, 6 \mathrm{H})$, $2.78(\mathrm{br} \mathrm{s}, 3 \mathrm{H}), 2.00-2.20(\mathrm{~m}, 2 \mathrm{H}), 1.62-1.82(\mathrm{~m}, 4 \mathrm{H}), 1.22-$ 1.32 (m, 7H), 1.18 (br s, 4H), 1.12 (br s, $2 \mathrm{H}), 0.65-0.88$ (m, $6 \mathrm{H})$; HRMS (ESI-TOF) $m / z$ : $\left[\left(\mathrm{M}+\mathrm{H}^{+}\right)\right]$calcd for 345.2464; found, 344.2519.

2-tert-Butyl-5-(heptyloxy)-6-methoxy-4-methylquinolin-8amine (31). Yield $=86 \% ;{ }^{1} \mathrm{H}$ NMR $\left(400 \mathrm{MHz} \mathrm{CDCl}_{3}\right): \delta 7.18$ (d, $J=0.75 \mathrm{~Hz}, 1 \mathrm{H}), 6.73(\mathrm{~s}, 1 \mathrm{H}), 3.80-3.97(\mathrm{~m}, 5 \mathrm{H}), 2.78-$ $2.90(\mathrm{~m}, 3 \mathrm{H}), 1.74-1.91(\mathrm{~m}, 2 \mathrm{H}), 1.21-1.51(\mathrm{~m}, 19 \mathrm{H}), 0.83-$ $0.94(\mathrm{~m}, 3 \mathrm{H})$; HRMS (ESI-TOF) $m / z:\left[\left(\mathrm{M}+\mathrm{H}^{+}\right)\right]$calcd for 359.2620; found, 359.2410 .

2-tert-Butyl-6-methoxy-4-methyl-5-(octyloxy)quinolin-8amine (32). Yield $=77 \% ;{ }^{1} \mathrm{H}$ NMR $\left(400 \mathrm{MHz}, \mathrm{CDCl}_{3}\right): \delta 7.18$ $(\mathrm{s}, 1 \mathrm{H}), 6.73(\mathrm{~s}, 1 \mathrm{H}), 4.93(\mathrm{br} \mathrm{s}, 2 \mathrm{H}), 3.87(\mathrm{t}, J=6.90 \mathrm{~Hz}, 3 \mathrm{H})$, $2.85(\mathrm{~s}, 4 \mathrm{H}), 1.71-1.90(\mathrm{~m}, 3 \mathrm{H}), 1.25(\mathrm{~s}, 4 \mathrm{H}), 1.29(\mathrm{~s}, 6 \mathrm{H})$, 1.20 (br s, $1 \mathrm{H}), 0.81-0.96(\mathrm{~m}, 6 \mathrm{H})$; HRMS (ESI-TOF) $\mathrm{m} / z$ : $\left[\left(\mathrm{M}+\mathrm{H}^{+}\right)\right]$calcd for 373.2777; found, 373.2589.

2-tert-Butyl-5-(3,4-dichlorophenyl)-6-methoxyquinolin-8amine (33). Yield $=88 \% ;{ }^{1} \mathrm{H}$ NMR $\left(400 \mathrm{MHz}, \mathrm{CDCl}_{3}\right): \delta 7.94$ $(\mathrm{d}, J=8.78 \mathrm{~Hz}, 1 \mathrm{H}), 7.45(\mathrm{~d}, J=8.78 \mathrm{~Hz}, 1 \mathrm{H}), 7.29(\mathrm{~d}, J=$ $8.78 \mathrm{~Hz}, 1 \mathrm{H}), 6.93(\mathrm{~d}, J=3.01 \mathrm{~Hz}, 1 \mathrm{H}), 6.73-6.80(\mathrm{~m}, 2 \mathrm{H})$, $3.87(\mathrm{~s}, 3 \mathrm{H}), 1.32-1.52(\mathrm{~m}, 11 \mathrm{H})$; HRMS (ESI-TOF) $\mathrm{m} / z$ : $\left[\left(\mathrm{M}+\mathrm{H}^{+}\right)\right]$calcd for 391.0902; found, 391.0944.

2-(4-(5-Butoxy-2-tert-butyl-6-methoxyquinolin-8ylamino)pentyl)isoindoline-1,3-dione (34). Yield $=88 \% ;{ }^{1} \mathrm{H}$ $\operatorname{NMR}\left(400 \mathrm{MHz}, \mathrm{CDCl}_{3}\right): \delta 8.21(\mathrm{~d}, J=8.78 \mathrm{~Hz}, 1 \mathrm{H}), 7.45(\mathrm{~d}$, $J=8.78 \mathrm{~Hz}, 1 \mathrm{H}), 6.40(\mathrm{~s}, 1 \mathrm{H}), 4.93(\mathrm{~d}, J=1.00 \mathrm{~Hz}, 2 \mathrm{H}), 3.89-$ $3.99(\mathrm{~m}, 5 \mathrm{H}), 3.69-3.72(\mathrm{~m}, 5 \mathrm{H}), 1.43(\mathrm{~s}, 9 \mathrm{H}), 1.21(\mathrm{~s}, 5 \mathrm{H})$ $1.00(\mathrm{t}, J=7.40 \mathrm{~Hz}, 4 \mathrm{H})$; HRMS (ESI-TOF) $\mathrm{m} / z:\left[\left(\mathrm{M}+\mathrm{H}^{+}\right)\right]$ calcd for 518.2941; found, 518.2801.

2-(4-(2-tert-Butyl-6-methoxy-5-(pentyloxy)quinolin-8ylamino)pentyl)isoindoline-1,3-dione (35). Yield $=78 \% ;{ }^{1} \mathrm{H}$ NMR (400 MHz, $\mathrm{CDCl}_{3}$ ): $\delta 8.21$ (d, $\left.J=8.78 \mathrm{~Hz}, 1 \mathrm{H}\right), 7.79-$ $7.86(\mathrm{~m}, 3 \mathrm{H}), 7.67-7.73(\mathrm{~m}, 3 \mathrm{H}), 7.45(\mathrm{~d}, J=8.78 \mathrm{~Hz}, 1 \mathrm{H})$, $6.39(\mathrm{~s}, 1 \mathrm{H}), 4.17(\mathrm{~s}, 1 \mathrm{H}), 3.89-3.99(\mathrm{~m}, 5 \mathrm{H}), 3.72-3.77(\mathrm{~m}$, $3 \mathrm{H}), 2.18(\mathrm{~s}, 3 \mathrm{H}), 1.71(\mathrm{~d}, J=6.53 \mathrm{~Hz}, 3 \mathrm{H}), 1.61(\mathrm{~s}, 2 \mathrm{H})$, $1.41-1.43(\mathrm{~m}, 9 \mathrm{H}), 1.31(\mathrm{~d}, J=6.27 \mathrm{~Hz}, 3 \mathrm{H}), 0.95(\mathrm{t}, J=7.28$ $\mathrm{Hz}, 3 \mathrm{H})$; HRMS (ESI-TOF) $m / z$ : $\left[\left(\mathrm{M}+\mathrm{H}^{+}\right)\right]$calcd for 532.3097; found, 532.3000.

2-(4-(2-tert-Butyl-5-(hexyloxy)-6-methoxyquinolin-8ylamino)pentyl)isoindoline-1,3-dione (36). Yield $=88 \% ;{ }^{1} \mathrm{H}$ NMR (400 MHz, $\mathrm{CDCl}_{3}$ ): $\delta 8.21$ (d, $\left.J=8.78 \mathrm{~Hz}, 1 \mathrm{H}\right), 7.78-$ $7.90(\mathrm{~m}, 3 \mathrm{H}), 7.67-7.75(\mathrm{~m}, 3 \mathrm{H}), 7.45(\mathrm{~d}, J=9.03 \mathrm{~Hz}, 1 \mathrm{H})$, $6.39(\mathrm{~s}, 1 \mathrm{H}), 3.90-3.98(\mathrm{~m}, 5 \mathrm{H}), 3.60-3.78(\mathrm{~m}, 5 \mathrm{H}), 2.18(\mathrm{~s}$, $6 \mathrm{H}), 2.06(\mathrm{~s}, 1 \mathrm{H}), 1.77-1.88(\mathrm{~m}, 5 \mathrm{H}), 1.72(\mathrm{~d}, J=6.78 \mathrm{~Hz}$, $2 \mathrm{H}), 1.59$ (s, $5 \mathrm{H}), 1.42(\mathrm{~s}, 9 \mathrm{H}), 1.32-1.38(\mathrm{~m}, 5 \mathrm{H}), 1.23-1.32$ $(\mathrm{m}, 3 \mathrm{H}), 1.19(\mathrm{~s}, 1 \mathrm{H})$; HRMS (ESI-TOF) $\mathrm{m} / z$ : $\left[\left(\mathrm{M}+\mathrm{H}^{+}\right)\right]$ calcd for 546.3254; found, 546.3280 .

2-(4-(2-tert-Butyl-5-(heptyloxy)-6-methoxyquinolin-8ylamino)pentyl)isoindoline-1,3-dione (37). Yield $=79 \% ;{ }^{1} \mathrm{H}$ NMR $\left(400 \mathrm{MHz}, \mathrm{CDCl}_{3}\right): \delta 8.23(\mathrm{~d}, J=8.78 \mathrm{~Hz}, 1 \mathrm{H}), 7.80-$ $7.91(\mathrm{~m}, 2 \mathrm{H}), 7.66-7.75(\mathrm{~m}, 2 \mathrm{H}), 7.47(\mathrm{~d}, J=8.78 \mathrm{~Hz}, 1 \mathrm{H})$, $6.41(\mathrm{~s}, 1 \mathrm{H}), 3.94-4.01(\mathrm{~m}, 5 \mathrm{H}), 3.77(\mathrm{t}, J=7.03 \mathrm{~Hz}, 2 \mathrm{H})$, $3.68(\mathrm{~d}, J=6.02 \mathrm{~Hz}, 1 \mathrm{H}), 1.78-1.89(\mathrm{~m}, 4 \mathrm{H}), 1.63(\mathrm{br} \mathrm{s}, 1 \mathrm{H})$ $1.50-1.57(\mathrm{~m}, 3 \mathrm{H}), 1.43-1.48(\mathrm{~m}, 10 \mathrm{H}), 1.29-1.38(\mathrm{~m}, 9 \mathrm{H})$, $0.93(\mathrm{t}, J=6.27 \mathrm{~Hz}, 4 \mathrm{H})$; HRMS (ESI-TOF) $m / z:\left[\left(\mathrm{M}+\mathrm{H}^{+}\right)\right]$ calcd for 560.3410; found, 560.3389 .

2-(4-(2-tert-Butyl-6-methoxy-5-(octyloxy)quinolin-8ylamino)pentyl)isoindoline-1,3-dione (38). Yield $=72 \% ;{ }^{1} \mathrm{H}$ $\operatorname{NMR}\left(\mathrm{CDCl}_{3}\right): \delta 7.94(\mathrm{~d}, 1 \mathrm{H}, J=8.4 \mathrm{~Hz}), 7.82(\mathrm{~m}, 4 \mathrm{H}), 7.44$ $(\mathrm{d}, 1 \mathrm{H}, J=8.4 \mathrm{~Hz}), 6.76(\mathrm{~s}, 1 \mathrm{H}), 6.04(\mathrm{br} \mathrm{s}, 1 \mathrm{H}), 3.95(\mathrm{~s}, 3 \mathrm{H})$, $3.87(\mathrm{t}, 2 \mathrm{H}), 3.70(\mathrm{~m}, 3 \mathrm{H}), 1.76(\mathrm{~m}, 6 \mathrm{H}), 1.44(\mathrm{~s}, 9 \mathrm{H}), 1.32(\mathrm{t}$, $3 \mathrm{H}, J=6.9 \mathrm{~Hz}), 1.02(\mathrm{t}, 3 \mathrm{H}, J=6.9 \mathrm{~Hz})$; HRMS (ESI-TOF) $m / z:\left[\left(\mathrm{M}+\mathrm{H}^{+}\right)\right]$calcd for 574.3567; found, 574.3476. 
5-Butoxy-2-tert-butyl-N-(5-(isoindolin-2-yl)pentan-2-yl)-6methoxy-4-methylqui-nolin-8-amine (39). Yield $=82 \% ;{ }^{1} \mathrm{H}$ NMR (400 MHz, $\left.\mathrm{CDCl}_{3}\right): \delta 7.78-7.86(\mathrm{~m}, 2 \mathrm{H}), 7.65-7.77$ $(\mathrm{m}, 2 \mathrm{H}), 7.15(\mathrm{~s}, 1 \mathrm{H}), 6.41(\mathrm{~s}, 1 \mathrm{H}), 6.18(\mathrm{~d}, J=7.53 \mathrm{~Hz}, 1 \mathrm{H})$, $3.93(\mathrm{~s}, 3 \mathrm{H}), 3.85(\mathrm{t}, J=6.78 \mathrm{~Hz}, 2 \mathrm{H}), 3.73(\mathrm{t}, J=6.90 \mathrm{~Hz}$, $2 \mathrm{H}), 3.65(\mathrm{~d}, J=6.27 \mathrm{~Hz}, 1 \mathrm{H}), 2.82(\mathrm{~s}, 3 \mathrm{H}), 1.72-1.96(\mathrm{~m}$, $5 \mathrm{H}), 1.63-1.70(\mathrm{~m}, 1 \mathrm{H}), 1.59(\mathrm{~s}, 2 \mathrm{H}), 1.46-1.54(\mathrm{~m}, 2 \mathrm{H})$, $1.31-1.43(\mathrm{~m}, 10 \mathrm{H}), 1.24-1.31(\mathrm{~m}, 4 \mathrm{H}), 0.99(\mathrm{t}, J=7.28 \mathrm{~Hz}$, $3 \mathrm{H}), 0.88$ (br s, $1 \mathrm{H})$; HRMS (ESI-TOF) $m / z:\left[\left(\mathrm{M}+\mathrm{H}^{+}\right)\right]$ calcd for 532.3097; found, 532.2981.

5-Pentyloxy-2-tert-butyl-N-(5-(isoindolin-2-yl)pentan-2yl)-6-methoxy-4-methylquinolin-8-amine (40). Yield = 75\%; ${ }^{1} \mathrm{H} \mathrm{NMR}\left(400 \mathrm{MHz}, \mathrm{CDCl}_{3}\right): \delta 7.80-7.90(\mathrm{~m}, 1 \mathrm{H}), 7.65-7.79$ (m, $1 \mathrm{H}), 7.10-7.18(\mathrm{~m}, 1 \mathrm{H}), 4.94(\mathrm{~d}, J=6.53 \mathrm{~Hz}, 1 \mathrm{H}), 4.02-$ $4.25(\mathrm{~m}, 2 \mathrm{H}), 3.81-4.01(\mathrm{~m}, 4 \mathrm{H}), 3.66-3.79(\mathrm{~m}, 2 \mathrm{H}), 3.39-$ $3.54(\mathrm{~m}, 2 \mathrm{H}), 2.85(\mathrm{~d}, J=0.75 \mathrm{~Hz}, 2 \mathrm{H}), 2.30(\mathrm{~d}, J=7.53 \mathrm{~Hz}$, $1 \mathrm{H}), 1.76-2.06(\mathrm{~m}, 9 \mathrm{H}), 1.65-1.76(\mathrm{~m}, 5 \mathrm{H}), 1.21-1.51(\mathrm{~m}$, $13 \mathrm{H}), 0.84-1.10(\mathrm{~m}, 5 \mathrm{H})$; HRMS (ESI-TOF) $m / z:[(\mathrm{M}+$ $\left.\mathrm{H}^{+}\right)$] calcd for 546.3254; found, 546.3321.

5-Hexyloxy-2-tert-butyl-N-(5-(isoindolin-2-yl)pentan-2-yl)6-methoxy-4-methylquinolin-8-amine (41). Yield $=77 \% ;{ }^{1} \mathrm{H}$ NMR (400 MHz, $\left.\mathrm{CDCl}_{3}\right): \delta 7.85-8.00(\mathrm{~m}, 1 \mathrm{H}), 6.73(\mathrm{~m}, 1 \mathrm{H})$, $7.60-7.75(\mathrm{~m}, 1 \mathrm{H}), 7.14-7.17(\mathrm{~m}, 1 \mathrm{H}), 4.74(\mathrm{~d}, J=6.33 \mathrm{~Hz}$, $1 \mathrm{H}), 4.12-4.23(\mathrm{~m}, 2 \mathrm{H}), 3.79-4.11(\mathrm{~m}, 4 \mathrm{H}), 3.68-3.80(\mathrm{~m}$, $2 \mathrm{H}), 3.40-3.55(\mathrm{~m}, 3 \mathrm{H}), 2.88(\mathrm{~d}, J=0.77 \mathrm{~Hz}, 2 \mathrm{H}), 2.32(\mathrm{~d}, J=$ $7.54 \mathrm{~Hz}, 1 \mathrm{H}), 1.77-2.04(\mathrm{~m}, 9 \mathrm{H}), 1.63-1.73$ (m, 5H), 1.20$1.53(\mathrm{~m}, 13 \mathrm{H}), 0.82-1.00(\mathrm{~m}, 5 \mathrm{H})$; HRMS (ESI-TOF) $\mathrm{m} / z$ : $\left[\left(\mathrm{M}+\mathrm{H}^{+}\right)\right]$calcd for 560.3254; found, 560.3175 .

5-Heptyloxy-2-tert-butyl-N-(5-(isoindolin-2-yl)pentan-2yl)-6-methoxy-4-methylquinolin-8-amine (42). Yield = 79\%; ${ }^{1} \mathrm{H}$ NMR (400 MHz, $\mathrm{CDCl}_{3}$ ): $\delta 7.79$ (br s, 3H), 7.68 (br s, $2 \mathrm{H}), 7.25(\mathrm{~d}, J=3.01 \mathrm{~Hz}, 2 \mathrm{H}), 7.14(\mathrm{br} \mathrm{s}, 1 \mathrm{H}), 6.40(\mathrm{br} \mathrm{s}, 1 \mathrm{H})$, 6.17 (br s, $1 \mathrm{H}), 3.88-4.18(\mathrm{~m}, 4 \mathrm{H}), 3.84$ (br s, $2 \mathrm{H}), 3.73$ (br s, $2 \mathrm{H}$ ), 3.63 (br s, $1 \mathrm{H}), 2.82$ (br s, $4 \mathrm{H}), 1.81$ (br s, $6 \mathrm{H}), 1.67$ (br s, $3 \mathrm{H}), 1.46-1.60(\mathrm{~m}, 8 \mathrm{H}), 1.34-1.46(\mathrm{~m}, 15 \mathrm{H}), 1.29-1.31$ (m, 10H), 0.89-0.92 (m, 5H); HRMS (ESI-TOF) $m / z:[(\mathrm{M}+$ $\left.\mathrm{H}^{+}\right)$] calcd for 574.3567; found, 574.3200.

5-Octyloxy-2-tert-butyl-N-(5-(isoindolin-2-yl)pentan-2-yl)6-methoxy-4-methylquinolin-8-amine (43). Yield $=82 \% ;{ }^{1} \mathrm{H}$ NMR $\left(400 \mathrm{MHz}, \mathrm{CDCl}_{3}\right): \delta 7.85(\mathrm{dd}, J=2.51,5.02 \mathrm{~Hz}, 3 \mathrm{H})$, 7.69-7.75 (m, 3H), $7.18(\mathrm{~s}, 1 \mathrm{H}), 6.73(\mathrm{~s}, 1 \mathrm{H}), 4.94($ br s, $2 \mathrm{H})$, 4.11-4.22 (m, 1H), $3.91(\mathrm{~s}, 3 \mathrm{H}), 3.87(\mathrm{t}, J=6.90 \mathrm{~Hz}, 2 \mathrm{H})$, $3.68-3.76(\mathrm{~m}, 3 \mathrm{H}), 2.85(\mathrm{~s}, 3 \mathrm{H}), 1.90-2.00(\mathrm{~m}, 1 \mathrm{H}), 1.78-$ $1.87(\mathrm{~m}, 6 \mathrm{H}), 1.70(\mathrm{~d}, J=6.78 \mathrm{~Hz}, 4 \mathrm{H}), 1.59$ (br s, $2 \mathrm{H}), 1.41$ (s, 9H), $1.27-1.36(\mathrm{~m}, 8 \mathrm{H}), 0.86-0.92(\mathrm{~m}, 3 \mathrm{H})$; HRMS (ESITOF) $m / z:\left[\left(\mathrm{M}+\mathrm{H}^{+}\right)\right]$calcd for 588.3723; found, 588.3856 .

2-(4-(2-tert-Butyl-5-(3,4-dichlorophenoxy)-6-methoxyquinolin-8-ylamino)pentyl)tetrahydro- $1 \mathrm{H}$-isoindole-4,7(2H,7H)dione (44). Yield $=71 \%$; ${ }^{1} \mathrm{H}$ NMR $\left(400 \mathrm{MHz}, \mathrm{CDCl}_{3}\right): \delta 7.86$ $(\mathrm{d}, J=8.78 \mathrm{~Hz}, 1 \mathrm{H}), 7.81($ br s, $2 \mathrm{H}), 7.71(\mathrm{~d}, J=2.51 \mathrm{~Hz}, 2 \mathrm{H})$, 7.40 (d, $J=8.78 \mathrm{~Hz}, 1 \mathrm{H}), 7.27$ (br s, $1 \mathrm{H}), 6.94$ (br s, $1 \mathrm{H}), 6.74$ $(\mathrm{d}, J=9.29 \mathrm{~Hz}, 1 \mathrm{H}), 6.40(\mathrm{~s}, 1 \mathrm{H}), 6.20(\mathrm{~d}, J=7.03 \mathrm{~Hz}, 1 \mathrm{H})$, $3.83-3.92(\mathrm{~m}, 3 \mathrm{H}), 3.67-3.82(\mathrm{~m}, 3 \mathrm{H}), 1.82-1.99(\mathrm{~m}, 3 \mathrm{H})$, $1.80(\mathrm{br} \mathrm{s}, 1 \mathrm{H}), 1.74(\mathrm{~d}, J=6.27 \mathrm{~Hz}, 1 \mathrm{H}), 1.41(\mathrm{~s}, 10 \mathrm{H}), 1.35$ $(\mathrm{d}, J=6.27 \mathrm{~Hz}, 3 \mathrm{H})$; HRMS (ESI-TOF) $m / z:\left[\left(\mathrm{M}+\mathrm{H}^{+}\right)\right]$ calcd for 606.1848; found, 606.1892.

$N^{4}$-(5-Butoxy-2-tert-butyl-6-methoxyquinolin-8-yl)pentane-1,4-diamine (45). Yield $=92 \%$; ${ }^{1} \mathrm{H}$ NMR $(400 \mathrm{MHz}$, $\left.\mathrm{CDCl}_{3}\right): \delta 8.23(\mathrm{~d}, J=9.03 \mathrm{~Hz}, 1 \mathrm{H}), 7.46(\mathrm{~d}, J=8.78 \mathrm{~Hz}, 1 \mathrm{H})$, $6.39(\mathrm{~s}, 1 \mathrm{H}), 4.86-4.91(\mathrm{~m}, 4 \mathrm{H}), 3.90-3.99(\mathrm{~m}, 6 \mathrm{H}), 2.66-$ $2.75(\mathrm{~m}, 11 \mathrm{H}), 1.38-1.43(\mathrm{~m}, 11 \mathrm{H}), 0.99(\mathrm{t}, J=7.40 \mathrm{~Hz}, 4 \mathrm{H})$; HRMS (ESI-TOF) $m / z:\left[\left(\mathrm{M}+\mathrm{H}^{+}\right)\right]$calcd for 388.2886; found, 388.2889.
$N^{4}$-(2-tert-Butyl-6-methoxy-5-(pentyloxy)quinolin-8-yl)pentane-1,4-diamine (46). Yield $=88 \%$; ${ }^{1} \mathrm{H}$ NMR $(400 \mathrm{MHz}$, $\left.\mathrm{CD}_{3} \mathrm{OD}\right): \delta 8.53(\mathrm{~d}, J=9.03 \mathrm{~Hz}, 1 \mathrm{H}), 7.89(\mathrm{~s}, 1 \mathrm{H}), 7.81(\mathrm{~d}, J=$ $9.03 \mathrm{~Hz}, 1 \mathrm{H}), 4.24(\mathrm{t}, J=6.53 \mathrm{~Hz}, 2 \mathrm{H}), 4.07(\mathrm{~s}, 5 \mathrm{H}), 3.50(\mathrm{~d}, J$ $=7.03 \mathrm{~Hz}, 1 \mathrm{H}), 3.36(\mathrm{~s}, 1 \mathrm{H}), 2.98(\mathrm{t}, J=7.40 \mathrm{~Hz}, 2 \mathrm{H}), 1.85(\mathrm{~d}$ $J=8.03 \mathrm{~Hz}, 3 \mathrm{H}), 1.89(\mathrm{~d}, J=6.78 \mathrm{~Hz}, 3 \mathrm{H}), 1.38-1.59(\mathrm{~m}$, $19 \mathrm{H}), 1.18(\mathrm{t}, J=6.90 \mathrm{~Hz}, 1 \mathrm{H}), 0.97(\mathrm{t}, J=7.28 \mathrm{~Hz}, 4 \mathrm{H})$; HRMS (ESI-TOF) $m / z$ : $\left[\left(\mathrm{M}+\mathrm{H}^{+}\right)\right]$calcd for 402.3042; found, 402.3000 .

$N^{4}$-(2-tert-Butyl-5-(hexyloxy)-6-methoxyquinolin-8-yl)pentane-1,4-diamine (47). Yield $=94 \% ;{ }^{1} \mathrm{H}$ NMR $(400 \mathrm{MHz}$, $\left.\mathrm{CD}_{3} \mathrm{OD}\right): \delta 8.24(\mathrm{~d}, J=8.78 \mathrm{~Hz}, 1 \mathrm{H}), 7.47(\mathrm{~d}, J=8.78 \mathrm{~Hz}$, $1 \mathrm{H}), 6.41(\mathrm{~s}, 1 \mathrm{H}), 6.04(\mathrm{br} \mathrm{s}, 1 \mathrm{H}), 3.97(\mathrm{~s}, 6 \mathrm{H}), 3.62$ (br s, $1 \mathrm{H}), 2.76$ (br s, $2 \mathrm{H}), 1.70-1.88(\mathrm{~m}, 2 \mathrm{H}), 1.57-1.70(\mathrm{~m}, 2 \mathrm{H})$, $1.52(\mathrm{br} \mathrm{s}, 1 \mathrm{H}), 1.39-1.48(\mathrm{~m}, 11 \mathrm{H}), 1.30-1.37(\mathrm{~m}, 12 \mathrm{H})$, $0.88-0.91(\mathrm{~m}, 3 \mathrm{H})$; HRMS (ESI-TOF) $m / z:\left[\left(\mathrm{M}+\mathrm{H}^{+}\right)\right]$calcd for 416.3199; found, 416.3178 .

$N^{4}$-(2-tert-Butyl-5-(heptyloxy)-6-methoxyquinolin-8-yl)pentane-1,4-diamine (48). Yield $=86 \% ;{ }^{1} \mathrm{H}$ NMR $(400 \mathrm{MHz}$, $\left.\mathrm{CD}_{3} \mathrm{OD}\right): \delta 8.49(\mathrm{~d}, J=9.03 \mathrm{~Hz}, 1 \mathrm{H}), 7.78(\mathrm{~d}, J=9.03 \mathrm{~Hz}$, $1 \mathrm{H}), 4.21(\mathrm{t}, J=6.53 \mathrm{~Hz}, 2 \mathrm{H}), 4.02-4.07(\mathrm{~m}, 3 \mathrm{H}), 3.36(\mathrm{~s}$, $1 \mathrm{H}), 2.97(\mathrm{t}, J=7.40 \mathrm{~Hz}, 2 \mathrm{H}), 1.79-1.94(\mathrm{~m}, 4 \mathrm{H}), 1.47-1.59$ (m, 12H), $1.28-1.47(\mathrm{~m}, 11 \mathrm{H}), 0.86-0.98(\mathrm{~m}, 3 \mathrm{H})$; HRMS (ESI-TOF) $m / z:\left[\left(\mathrm{M}+\mathrm{H}^{+}\right)\right]$calcd for 430.3355; found, 430.3480 .

$N^{4}$-(2-tert-Butyl-6-methoxy-5-(octyloxy)quinolin-8-yl)pentane-1,4-diamine (49). Yield $=89 \%$; ${ }^{1} \mathrm{H}$ NMR $(400 \mathrm{MHz}$, $\left.\mathrm{CDCl}_{3}\right): \delta 8.23(\mathrm{~d}, J=8.78 \mathrm{~Hz}, 1 \mathrm{H}), 7.45(\mathrm{~d}, J=8.78 \mathrm{~Hz}, 1 \mathrm{H})$, 6.39 (s, $1 \mathrm{H}), 3.95$ (br s, $5 \mathrm{H}), 3.62$ (br s, $1 \mathrm{H}), 2.70-2.79(\mathrm{~m}$, $2 \mathrm{H}), 1.71-1.87(\mathrm{~m}, 4 \mathrm{H}), 1.63$ (br s, $4 \mathrm{H}), 1.51$ (br s, $3 \mathrm{H}), 1.43$ $(\mathrm{s}, 9 \mathrm{H}), 1.32(\mathrm{~d}, J=6.27 \mathrm{~Hz}, 9 \mathrm{H}), 1.26(\mathrm{br} \mathrm{s}, 3 \mathrm{H}), 0.80-0.95$ $(\mathrm{m}, 5 \mathrm{H})$; HRMS (ESI-TOF) $m / z:\left[\left(\mathrm{M}+\mathrm{H}^{+}\right)\right]$calcd for 444.3512; found, 444.3553.

$N^{4}$-(5-Butoxy-2-tert-butyl-6-methoxy-4-methylquinolin-8yl)pentane-1,4-diamine (50). Yield $=88 \% ;{ }^{1} \mathrm{H}$ NMR $(400$ $\left.\mathrm{MHz}, \mathrm{CDCl}_{3}\right): \delta 7.18-7.28(\mathrm{~m}, 1 \mathrm{H}), 7.02-7.18(\mathrm{~m}, 1 \mathrm{H})$, 6.34-6.47 (m, 1H), 3.74-4.00 (m, 5H), 3.60 (br s, $1 \mathrm{H}), 2.77-$ $2.90(\mathrm{~m}, 3 \mathrm{H}), 2.74($ br s, $2 \mathrm{H}), 1.92-2.05(\mathrm{~m}, 1 \mathrm{H}), 1.82(\mathrm{~d}, J=$ $13.80 \mathrm{~Hz}, 4 \mathrm{H}), 1.62$ (br s, $6 \mathrm{H}), 1.51(\mathrm{~d}, J=7.78 \mathrm{~Hz}, 3 \mathrm{H})$, $1.32-1.40(\mathrm{~m}, 7 \mathrm{H}), 1.26$ (br s, $5 \mathrm{H}), 0.91-1.05(\mathrm{~m}, 3 \mathrm{H}), 0.87$ $(\mathrm{d}, J=7.78 \mathrm{~Hz}, 1 \mathrm{H})$; HRMS (ESI-TOF) $\mathrm{m} / z$ : $\left[\left(\mathrm{M}+\mathrm{H}^{+}\right)\right]$ calcd for 402.3042; found, 402.3122 .

$N^{4}$-(5-Pentyloxy-2-tert-butyl-6-methoxy-4-methylquinolin8-yl)pentane-1,4-diamine (51). Yield $=94 \% ;{ }^{1} \mathrm{H}$ NMR $(400$ $\mathrm{MHz}_{\mathrm{CDCl}}$ ): $\delta 7.26(\mathrm{~s}, 1 \mathrm{H}), 7.14(\mathrm{~d}, J=0.75 \mathrm{~Hz}, 3 \mathrm{H}), 6.64$ $(\mathrm{s}, 2 \mathrm{H}), 5.30(\mathrm{~s}, 1 \mathrm{H}), 3.72-4.02(\mathrm{~m}, 14 \mathrm{H}), 2.67-2.95(\mathrm{~m}, 8 \mathrm{H})$, $1.75-2.04(\mathrm{~m}, 14 \mathrm{H}), 1.34-1.58(\mathrm{~m}, 36 \mathrm{H}), 1.12-1.33(\mathrm{~m}$, $16 \mathrm{H}), 0.80-1.01(\mathrm{~m}, 16 \mathrm{H})$; HRMS (ESI-TOF) $m / z:[(\mathrm{M}+$ $\left.\mathrm{H}^{+}\right)$] calcd for 416.3199; found, 416.3213 .

$N^{4}$-(5-Hexyloxy-2-tert-butyl-6-methoxy-4-methylquinolin8-yl)pentane-1,4-diamine (52). Yield $=84 \% ;{ }^{1} \mathrm{H}$ NMR $(400$ $\mathrm{MHz}, \mathrm{CDCl}_{3}$ ): $\delta 8.23(\mathrm{~d}, J=8.78 \mathrm{~Hz}, 1 \mathrm{H}), 7.46(\mathrm{~d}, J=8.78$ $\mathrm{Hz}, 1 \mathrm{H}), 6.39(\mathrm{~s}, 1 \mathrm{H}), 3.89-4.00(\mathrm{~m}, 5 \mathrm{H}), 2.75$ (br s, $2 \mathrm{H})$, $1.72-1.87(\mathrm{~m}, 3 \mathrm{H}), 1.64(\mathrm{~d}, J=5.02 \mathrm{~Hz}, 3 \mathrm{H}), 1.40-1.55(\mathrm{~m}$, $14 \mathrm{H}), 1.26-1.40(\mathrm{~m}, 8 \mathrm{H}), 1.11-1.26(\mathrm{~m}, 2 \mathrm{H}), 0.85-0.96(\mathrm{~m}$, $3 \mathrm{H})$; HRMS (ESI-TOF) $m / z$ : $\left[\left(\mathrm{M}+\mathrm{H}^{+}\right)\right]$calcd for 430.3355 ; found, 430.3289 .

$N^{4}$-(5-Heptyloxy-2-tert-butyl-6-methoxy-4-methylquinolin-8-yl)pentane-1,4-diamine (53). Yield $=91 \% ;{ }^{1} \mathrm{H} \mathrm{NMR}$ $\left(400 \mathrm{MHz}, \mathrm{CDCl}_{3}\right): \delta 7.17(\mathrm{~s}, 1 \mathrm{H}), 6.42(\mathrm{~s}, 1 \mathrm{H}), 3.94(\mathrm{~s}, 3 \mathrm{H})$, $3.85(\mathrm{t}, J=6.65 \mathrm{~Hz}, 2 \mathrm{H}), 3.60(\mathrm{~d}, J=5.02 \mathrm{~Hz}, 1 \mathrm{H}), 2.84(\mathrm{~s}$, $3 \mathrm{H}), 2.74(\mathrm{br} \mathrm{s}, 2 \mathrm{H}), 2.02(\mathrm{~s}, 1 \mathrm{H}), 1.72-1.92(\mathrm{~m}, 4 \mathrm{H}), 1.70(\mathrm{~d}$, $J=7.03 \mathrm{~Hz}, 1 \mathrm{H}), 1.52-1.66(\mathrm{~m}, 6 \mathrm{H}), 1.36-1.52(\mathrm{~m}, 14 \mathrm{H})$, 
1.15-1.36 (m, 12H), 0.73-1.00 (m, 5H); HRMS (ESI-TOF) $m / z:\left[\left(\mathrm{M}+\mathrm{H}^{+}\right)\right]$calcd for 444.3512 ; found, 444.3488 .

$N^{4}$-(5-Octyloxy-2-tert-butyl-6-methoxy-4-methylquinolin8-yl)pentane-1,4-diamine (54). Yield $=92 \% ;{ }^{1} \mathrm{H}$ NMR $(400$ $\left.\mathrm{MHz}, \mathrm{CDCl}_{3}\right): \delta 7.25$ (br s, $\left.1 \mathrm{H}\right), 7.18(\mathrm{~s}, 1 \mathrm{H}), 6.73(\mathrm{~s}, 1 \mathrm{H})$, $3.88-3.92(\mathrm{~m}, 3 \mathrm{H}), 3.85-3.88(\mathrm{~m}, 1 \mathrm{H}), 2.82-2.86(\mathrm{~m}, 3 \mathrm{H})$, $1.78-1.87(\mathrm{~m}, 2 \mathrm{H}), 1.43-1.50(\mathrm{~m}, 3 \mathrm{H}), 1.38-1.43(\mathrm{~m}, 10 \mathrm{H})$, 1.24-1.37 (m, 10H), 0.85-0.92 (m, 3H); (ESI-TOF) $\mathrm{m} / z$ : $\left[\left(\mathrm{M}+\mathrm{H}^{+}\right)\right]$calcd for 458.6746; found, 458.3733 .

$N^{4}$-(2-tert-Butyl-5-(3,4-dichlorophenoxy)-6-methoxyquinolin-8-yl)pentane-1,4-diamine (55). Yield $=86 \%$; ${ }^{1} \mathrm{H}$ NMR $\left(400 \mathrm{MHz}, \mathrm{CDCl}_{3}\right): \delta 7.89(\mathrm{~d}, J=9.03 \mathrm{~Hz}, 1 \mathrm{H}), 7.42(\mathrm{~d}, J=$ $8.53 \mathrm{~Hz}, 1 \mathrm{H}), 6.93($ br s, $1 \mathrm{H}), 6.76(\mathrm{~d}, J=7.78 \mathrm{~Hz}, 1 \mathrm{H}), 6.41$ (s, 1H), 6.26 (br s, $1 \mathrm{H}), 3.89$ (br s, $3 \mathrm{H}), 3.66$ (br s, $1 \mathrm{H}), 2.78$ (br s, 2H), 1.83 (d, $J=9.03 \mathrm{~Hz}, 3 \mathrm{H}), 1.62-1.72(\mathrm{~m}, 3 \mathrm{H}), 1.42$ (br s, 9H); (ESI-TOF) $m / z:\left[\left(\mathrm{M}+\mathrm{H}^{+}\right)\right]$calcd for 476.1860; found, 476.1864 .

2,6-Diamino-N-(4-(5-butoxy-2-tert-butyl-6-methoxyquinolin-8-ylamino)pentyl)-hexanamide (90). Yield $=87 \% ;{ }^{1} \mathrm{H}$ NMR (400 MHz, CD 3 OD): $\delta 8.23(\mathrm{~d}, J=8.78 \mathrm{~Hz}, 1 \mathrm{H}), 7.57$ $(\mathrm{d}, J=8.78 \mathrm{~Hz}, 1 \mathrm{H}), 6.56(\mathrm{~s}, 1 \mathrm{H}), 4.03(\mathrm{~s}, 3 \mathrm{H}), 4.05(\mathrm{~s}, 3 \mathrm{H})$, 3.97-3.98 (m, 4H), 3.90 (br s, $5 \mathrm{H}), 2.99$ (br s, 11H), 1.44 (s, $10 \mathrm{H})$; (ESI-TOF) $\mathrm{m} / z$ : $\left[\left(\mathrm{M}+\mathrm{H}^{+}\right)\right]$calcd for 516.3835; found, 516.3867 .

2,5-Diamino-N-(4-(5-butoxy-2-tert-butyl-6-methoxyquinolin-8-ylamino)pentyl)-pentanamide (91). Yield $=83 \% ;{ }^{1} \mathrm{H}$ NMR (400 MHz, CD $\mathrm{OD}): \delta 8.05(\mathrm{~d}, J=9.03 \mathrm{~Hz}, 1 \mathrm{H}), 7.89$ $(\mathrm{s}, 1 \mathrm{H}), 7.81(\mathrm{~d}, J=9.03 \mathrm{~Hz}, 1 \mathrm{H}), 4.24(\mathrm{t}, J=6.53 \mathrm{~Hz}, 3 \mathrm{H})$, $4.07(\mathrm{~s}, 4 \mathrm{H}), 3.97(\mathrm{~s}, 1 \mathrm{H}), 3.84(\mathrm{td}, J=6.53,13.05 \mathrm{~Hz}, 7 \mathrm{H})$, $3.36(\mathrm{~s}, 1 \mathrm{H}), 3.02(\mathrm{br} \mathrm{s}, 3 \mathrm{H}), 1.73-1.85(\mathrm{~m}, 7 \mathrm{H}), 1.50(\mathrm{~s}, 8 \mathrm{H})$, $1.37-1.43(\mathrm{~m}, 7 \mathrm{H}), 0.97(\mathrm{t}, J=7.28 \mathrm{~Hz}, 4 \mathrm{H})$; (ESI-TOF) $m / z$ : $\left[\left(\mathrm{M}+\mathrm{H}^{+}\right)\right]$calcd for 502.3679; found, 502.3689.

2,6-Diamino-N-(4-(2-tert-butyl-6-methoxy-5-(pentyloxy)quinolin-8-ylamino)-pentyl)hexanamide (92). Yield $=82 \%$; ${ }^{1} \mathrm{H}$ NMR (400 MHz, CD $\left.3 \mathrm{OD}\right): \delta 8.50(\mathrm{~d}, J=9.03 \mathrm{~Hz}, 1 \mathrm{H})$, 7.79-7.83 (m, 1H), $4.23(\mathrm{q}, J=6.36 \mathrm{~Hz}, 2 \mathrm{H}), 4.05(\mathrm{~s}, 3 \mathrm{H})$, $3.91(\mathrm{~s}, 1 \mathrm{H}), 3.49(\mathrm{~d}, J=7.03 \mathrm{~Hz}, 1 \mathrm{H}), 2.86-3.00(\mathrm{~m}, 3 \mathrm{H})$, $1.79-1.91(\mathrm{~m}, 4 \mathrm{H}), 1.60-1.79(\mathrm{~m}, 4 \mathrm{H}), 1.47-1.56(\mathrm{~m}, 11 \mathrm{H})$, $1.35-1.42(\mathrm{~m}, 6 \mathrm{H}), 1.30(\mathrm{~d}, J=6.53 \mathrm{~Hz}, 3 \mathrm{H}), 1.18(\mathrm{t}, J=7.03$ $\mathrm{Hz}, 1 \mathrm{H}), 0.96(\mathrm{t}, J=7.28 \mathrm{~Hz}, 3 \mathrm{H})$; (ESI-TOF) $m / z$ : $[(\mathrm{M}+$ $\left.\mathrm{H}^{+}\right)$] calcd for 530.3992; found, 530.3876 .

2,5-Diamino-N-(4-(2-tert-butyl-6-methoxy-5-(pentyloxy)quinolin-8-ylamino)-pentyl)pentanamide (93). Yield = 86\%; ${ }^{1} \mathrm{H}$ NMR (400 MHz, CD $\left.\mathrm{OD}\right): \delta 8.53(\mathrm{~d}, J=9.03 \mathrm{~Hz}, 1 \mathrm{H})$, $7.92(\mathrm{~s}, 1 \mathrm{H}), 7.81(\mathrm{~d}, J=9.03 \mathrm{~Hz}, 1 \mathrm{H}), 4.24(\mathrm{t}, J=6.53 \mathrm{~Hz}$, $3 \mathrm{H}), 4.07(\mathrm{~s}, 4 \mathrm{H}), 3.97(\mathrm{~s}, 1 \mathrm{H}), 3.81(\mathrm{td}, J=6.53,13.05 \mathrm{~Hz}$, $7 \mathrm{H}), 3.36(\mathrm{~s}, 1 \mathrm{H}), 3.02(\mathrm{br} \mathrm{s}, 3 \mathrm{H}), 1.76-1.91(\mathrm{~m}, 9 \mathrm{H}), 1.50(\mathrm{~s}$, $8 \mathrm{H}), 1.37-1.43(\mathrm{~m}, 7 \mathrm{H}), 0.97(\mathrm{t}, J=7.28 \mathrm{~Hz}, 4 \mathrm{H})$; (ESI-TOF) $m / z:\left[\left(\mathrm{M}+\mathrm{H}^{+}\right)\right]$calcd for 516.3835; found, 516.3809.

2-Amino-N-(4-(2-tert-butyl-6-methoxy-5-(pentyloxy)quinolin-8-ylamino)pentyl)-5-guanidinopentanamide (94). Yield $=78 \% ;{ }^{1} \mathrm{H}$ NMR $\left(400 \mathrm{MHz}, \mathrm{CDCl}_{3}\right): \delta 8.42$ (br s, $1 \mathrm{H}), 8.38$ (br s, $1 \mathrm{H}), 8.17-8.30(\mathrm{~m}, 1 \mathrm{H}), 7.42-7.47(\mathrm{~m}, 1 \mathrm{H})$, 6.57 (br s, 1H), 6.36-6.45 (m, 1H), 6.26 (br s, 1H), 5.20-5.27 (m, 3H), 5.07-5.13 (m, 4H), 4.25-4.36 (m, 1H), 3.94-3.97 (m, 5H), 3.38-3.60 (m, 4H), $2.26(\mathrm{~s}, 1 \mathrm{H}), 2.05(\mathrm{~s}, 5 \mathrm{H}), 1.80-$ $1.85(\mathrm{~m}, 2 \mathrm{H}), 1.43(\mathrm{~s}, 5 \mathrm{H}), 1.34-1.38(\mathrm{~m}, 5 \mathrm{H}), 1.20-1.24(\mathrm{~m}$, $5 \mathrm{H}), 1.16(\mathrm{~d}, J=1.76 \mathrm{~Hz}, 1 \mathrm{H}), 0.92(\mathrm{~s}, 3 \mathrm{H})$; (ESI-TOF) $\mathrm{m} / z$ : $\left[\left(\mathrm{M}+\mathrm{H}^{+}\right)\right]$calcd for 557.4053; found, 557.4456.

2-Amino-N-(4-(2-tert-butyl-6-methoxy-5-(pentyloxy)quinolin-8-ylamino)pentyl)-4-methylpentanamide (95). Yield $=85 \%$; ${ }^{1} \mathrm{H}$ NMR $\left(400 \mathrm{MHz}, \mathrm{CD}_{3} \mathrm{OD}\right): \delta 8.52(\mathrm{~d}, J=$ $9.03 \mathrm{~Hz}, 1 \mathrm{H}), 7.71-7.92(\mathrm{~m}, 2 \mathrm{H}), 4.23(\mathrm{t}, J=6.53 \mathrm{~Hz}, 2 \mathrm{H})$, $4.11(\mathrm{~s}, 1 \mathrm{H}), 3.94-4.08(\mathrm{~m}, 3 \mathrm{H}), 3.84$ (br s, $1 \mathrm{H}), 1.79-1.90$ $(\mathrm{m}, 3 \mathrm{H}), 1.60-1.72(\mathrm{~m}, 4 \mathrm{H}), 1.53-1.58(\mathrm{~m}, 2 \mathrm{H}), 1.47-1.53$ $(\mathrm{m}, 8 \mathrm{H}), 1.44-1.47(\mathrm{~m}, 2 \mathrm{H}), 1.35-1.43(\mathrm{~m}, 6 \mathrm{H}), 1.25-1.34$ $(\mathrm{m}, 4 \mathrm{H}), 0.87-1.03(\mathrm{~m}, 10 \mathrm{H})$; (ESI-TOF) $m / z:\left[\left(\mathrm{M}+\mathrm{H}^{+}\right)\right]$ calcd for 515.3883; found, 515.3560.

2-Amino-N-(4-(2-tert-butyl-6-methoxy-5-(pentyloxy)quinolin-8-ylamino)pentyl)-3-methylpentanamide (96). Yield $=88 \% ;{ }^{1} \mathrm{H}$ NMR $\left(400 \mathrm{MHz}, \mathrm{CD}_{3} \mathrm{OD}\right): \delta 8.53(\mathrm{~d}, J=$ $9.03 \mathrm{~Hz}, 1 \mathrm{H}), 7.90(\mathrm{~d}, J=6.53 \mathrm{~Hz}, 1 \mathrm{H}), 7.81(\mathrm{~d}, J=9.03 \mathrm{~Hz}$, $1 \mathrm{H}), 4.23-4.25(\mathrm{~m}, 3 \mathrm{H}), 4.15(\mathrm{br} \mathrm{s}, 1 \mathrm{H}), 4.07$ (s, 3H), $3.95(\mathrm{~d}$, $J=3.51 \mathrm{~Hz}, 3 \mathrm{H}), 3.70(\mathrm{~d}, J=5.52 \mathrm{~Hz}, 1 \mathrm{H}), 2.16(\mathrm{~s}, 1 \mathrm{H}), 2.00$ (br s, $1 \mathrm{H}), 1.85-1.90(\mathrm{~m}, 4 \mathrm{H}), 1.54-1.63(\mathrm{~m}, 4 \mathrm{H}), 1.36-1.41$ $(\mathrm{m}, 21 \mathrm{H}), 0.95-0.96(\mathrm{~m}, 5 \mathrm{H})$; (ESI-TOF) $m / z:\left[\left(\mathrm{M}+\mathrm{H}^{+}\right)\right]$ calcd for 515.3883; found, 515.3949.

2-Amino-N-(4-(2-tert-butyl-6-methoxy-5-(pentyloxy)quinolin-8-ylamino)pentyl)-3-phenylpropanamide (97). Yield $=84 \% ;{ }^{1} \mathrm{H}$ NMR $\left(400 \mathrm{MHz}, \mathrm{CDCl}_{3}\right): \delta 8.71$ (br s, $1 \mathrm{H}), 8.55$ (d, $J=17.57 \mathrm{~Hz}, 1 \mathrm{H}), 8.38$ (br s, 3H), 7.72 (br s, $2 \mathrm{H}), 7.14-7.23(\mathrm{~m}, 5 \mathrm{H}), 4.49$ (br s, $1 \mathrm{H}), 4.14-4.23(\mathrm{~m}, 2 \mathrm{H})$, $3.98-4.06(\mathrm{~m}, 4 \mathrm{H}), 3.32(\mathrm{~d}, J=7.78 \mathrm{~Hz}, 2 \mathrm{H}), 3.20-3.27(\mathrm{~m}$, $1 \mathrm{H}), 3.06$ (br s, $1 \mathrm{H}), 2.22$ (br s, $1 \mathrm{H}), 2.02$ (br s, $1 \mathrm{H}), 1.81$ (br $\mathrm{s}, 3 \mathrm{H}), 1.58(\mathrm{~d}, J=9.29 \mathrm{~Hz}, 11 \mathrm{H}), 1.26-1.45(\mathrm{~m}, 9 \mathrm{H}), 0.78-$ $1.03(\mathrm{~m}, 5 \mathrm{H})$; (ESI-TOF) $m / z:\left[\left(\mathrm{M}+\mathrm{H}^{+}\right)\right]$calcd for 549.3828; found, 549.3828 .

2-Amino-N-(4-(2-tert-butyl-6-methoxy-5-(pentyloxy)quinolin-8-ylamino)pentyl)-3-(1H-indol-2-yl)propanamide (98). Yield $=86 \% ;{ }^{1} \mathrm{H}$ NMR $\left(400 \mathrm{MHz}, \mathrm{CDCl}_{3}\right): \delta 10.0$ (br s, $1 \mathrm{H}), 8.60$ (br s, $1 \mathrm{H}), 8.30$ (d, $J=15.81 \mathrm{~Hz}, 1 \mathrm{H}), 8.11$ (br s, $2 \mathrm{H}), 7.47-7.75(\mathrm{~m}, 1 \mathrm{H}), 7.32($ br s, $2 \mathrm{H}), 6.88(\mathrm{~d}, J=18.82 \mathrm{~Hz}$, $1 \mathrm{H}), 4.11$ (br s, $1 \mathrm{H}), 3.88$ (br s, $2 \mathrm{H}), 3.37$ (m, $5 \mathrm{H}), 3.03$ (dd, $J$ $=7.91,14.68 \mathrm{~Hz}, 8 \mathrm{H}), 1.76($ br s, $1 \mathrm{H}), 1.63(\mathrm{br} \mathrm{s}, 1 \mathrm{H}), 1.52(\mathrm{br}$ s, $5 \mathrm{H}), 1.32-1.48(\mathrm{~m}, 4 \mathrm{H}), 1.26(\mathrm{br} \mathrm{s}, 1 \mathrm{H}), 1.06-1.23(\mathrm{~m}$, $10 \mathrm{H}), 0.93$ (br s, $2 \mathrm{H})$; (ESI-TOF) $m / z:\left[\left(\mathrm{M}+\mathrm{H}^{+}\right)\right]$calcd for 588.3835; found, 588.3921 .

2,6-Diamino-N-(4-(2-tert-butyl-5-(hexyloxy)-6-methoxyquinolin-8-ylamino)-pentyl)hexanamide (99). Yield $=83 \%$; ${ }^{1} \mathrm{H}$ NMR (400 MHz, CD $\left.3 \mathrm{OD}\right): \delta 8.53(\mathrm{~d}, J=9.03 \mathrm{~Hz}, 1 \mathrm{H})$, $7.91(\mathrm{~d}, J=3.76 \mathrm{~Hz}, 1 \mathrm{H}), 7.81(\mathrm{~d}, J=9.03 \mathrm{~Hz}, 1 \mathrm{H}), 4.24(\mathrm{t}, J=$ $6.53 \mathrm{~Hz}, 2 \mathrm{H}), 4.07(\mathrm{~s}, 3 \mathrm{H}), 3.93(\mathrm{~s}, 1 \mathrm{H}), 2.97(\mathrm{~d}, J=5.77 \mathrm{~Hz}$, $2 \mathrm{H}), 1.80-1.96(\mathrm{~m}, 6 \mathrm{H}), 1.68-1.80(\mathrm{~m}, 3 \mathrm{H}), 1.47-1.52(\mathrm{~m}$, $10 \mathrm{H}), 1.38-1.41(\mathrm{~m}, 5 \mathrm{H}), 0.88-0.99(\mathrm{~m}, 3 \mathrm{H})$; (ESI-TOF) $\mathrm{m} /$ $z:\left[\left(\mathrm{M}+\mathrm{H}^{+}\right)\right]$calcd for 544.4148; found, 544.4179.

2,5-Diamino-N-(4-(2-tert-butyl-5-(hexyloxy)-6-methoxyquinolin-8-ylamino)-pentyl)pentanamide (100). Yield = 85\%; ${ }^{1} \mathrm{H}$ NMR (400 MHz, CD $\left.3 \mathrm{OD}\right): \delta 8.52(\mathrm{~d}, J=9.03 \mathrm{~Hz}, 1 \mathrm{H})$, $7.91(\mathrm{~s}, 1 \mathrm{H}), 7.80(\mathrm{~d}, J=9.03 \mathrm{~Hz}, 1 \mathrm{H}), 4.17-4.24(\mathrm{~m}, 2 \mathrm{H})$, $4.06(\mathrm{~s}, 4 \mathrm{H}), 3.76-3.82(\mathrm{~m}, 6 \mathrm{H}), 1.49(\mathrm{~s}, 11 \mathrm{H}), 1.37-1.40(\mathrm{~m}$, $9 \mathrm{H}), 1.42-1.47(\mathrm{~m}, 8 \mathrm{H}), 1.29(\mathrm{~s}, 3 \mathrm{H}), 0.90-0.95(\mathrm{~m}, 4 \mathrm{H})$; (ESI-TOF) $m / z:\left[\left(\mathrm{M}+\mathrm{H}^{+}\right)\right]$calcd for 530.3992; found, 530.3865.

2-Amino-N-(4-(2-tert-butyl-5-(hexyloxy)-6-methoxyquinolin-8-ylamino)pentyl)-5-guanidinopentanamide (101). Yield $=88 \% ;{ }^{1} \mathrm{H}$ NMR $\left(400 \mathrm{MHz}, \mathrm{CDCl}_{3}\right): \delta 8.06-8.31(\mathrm{~m}, 1 \mathrm{H})$, $7.38-7.52(\mathrm{~m}, 2 \mathrm{H}), 6.57$ (br s, $2 \mathrm{H}), 6.24$ (br s, 1H), 5.20-5.24 $(\mathrm{m}, 4 \mathrm{H}), 5.05-5.14(\mathrm{~m}, 6 \mathrm{H}), 4.29(\mathrm{~d}, J=7.03 \mathrm{~Hz}, 2 \mathrm{H}), 3.92-$ $3.96(\mathrm{~m}, 6 \mathrm{H}), 3.41-3.58(\mathrm{~m}, 7 \mathrm{H}), 2.32(\mathrm{~s}, 2 \mathrm{H}), 1.42-1.46(\mathrm{~m}$, $8 \mathrm{H}), 1.49(\mathrm{~s}, 6 \mathrm{H}), 0.90-0.95(\mathrm{~m}, 4 \mathrm{H})$; (ESI-TOF) $\mathrm{m} / z$ : $[(\mathrm{M}+$ $\left.\mathrm{H}^{+}\right)$] calcd for 572.4210; found, 572.4479.

2-Amino-N-(4-(2-tert-butyl-5-(hexyloxy)-6-methoxyquinolin-8-ylamino)pentyl)-4-(methylthio)butanamide (102). Yield $=87 \%$; ${ }^{1} \mathrm{H}$ NMR (400 MHz, CD 3 OD): $\delta 8.42(\mathrm{~d}, J=9.03 \mathrm{~Hz}$, $1 \mathrm{H}), 7.83(\mathrm{~d}, J=5.52 \mathrm{~Hz}, 1 \mathrm{H}), 7.70(\mathrm{~d}, J=8.78 \mathrm{~Hz}, 1 \mathrm{H})$, $4.12-4.16(\mathrm{~m}, 2 \mathrm{H}), 4.03(\mathrm{dd}, J=5.02,6.78 \mathrm{~Hz}, 1 \mathrm{H}), 3.96(\mathrm{~s}$, 
$3 \mathrm{H}), 3.90(\mathrm{~s}, 1 \mathrm{H}), 2.47(\mathrm{q}, J=7.11 \mathrm{~Hz}, 3 \mathrm{H}), 2.00-2.02(\mathrm{~m}$, $4 \mathrm{H}), 1.96-1.99(\mathrm{~m}, 3 \mathrm{H}), 1.72-1.78(\mathrm{~m}, 2 \mathrm{H}), 1.39(\mathrm{~s}, 9 \mathrm{H})$, $1.26-1.32(\mathrm{~m}, 12 \mathrm{H}), 1.15-1.19(\mathrm{~m}, 3 \mathrm{H}), 0.98-1.09(\mathrm{~m}, 2 \mathrm{H})$, $0.77-0.86(\mathrm{~m}, 3 \mathrm{H})$; (ESI-TOF) $m / z$ : $\left[\left(\mathrm{M}+\mathrm{H}^{+}\right)\right]$calcd for 547.3604; found, 547.3668.

N-(4-(2-tert-Butyl-5-(hexyloxy)-6-methoxyquinolin-8lamino)pentyl)pyrrolidine-2-carboxamide (103). Yield = $83 \%$; ${ }^{1} \mathrm{H}$ NMR (400 MHz, CD 3 OD): $\delta 8.53(\mathrm{~d}, J=9.03 \mathrm{~Hz}$, $4 \mathrm{H}), 7.88(\mathrm{~s}, 3 \mathrm{H}), 7.81(\mathrm{~d}, J=9.03 \mathrm{~Hz}, 3 \mathrm{H}), 4.35-4.49(\mathrm{~m}$, $7 \mathrm{H}), 4.20-4.31(\mathrm{~m}, 10 \mathrm{H}), 4.07(\mathrm{~s}, 11 \mathrm{H}), 3.86(\mathrm{~s}, 10 \mathrm{H}), 2.37-$ $2.49(\mathrm{~m}, 10 \mathrm{H}), 2.02-2.13(\mathrm{~m}, 22 \mathrm{H}), 1.82-1.90(\mathrm{~m}, 12 \mathrm{H})$, $1.48-1.52(\mathrm{~m}, 30 \mathrm{H}), 1.35-1.44(\mathrm{~m}, 26 \mathrm{H}), 1.28-1.33(\mathrm{~m}, 6 \mathrm{H})$, 1.13-1.22 (m, 3H), 0.86-0.99 (m, 11H); (ESI-TOF) $\mathrm{m} / z$ : $\left[\left(\mathrm{M}+\mathrm{H}^{+}\right)\right]$calcd for 513.3726; found, 513.3804.

2-Amino-N-(4-(2-tert-butyl-5-(hexyloxy)-6-methoxyquinolin-8-ylamino)pentyl)-3-methylpentanamide (104). Yield = $88 \%$; ${ }^{1} \mathrm{H}$ NMR (400 MHz, $\left.\mathrm{CD}_{3} \mathrm{OD}\right): \delta 8.53$ (d, $J=9.03 \mathrm{~Hz}$, $1 \mathrm{H}), 7.90(\mathrm{~d}, J=6.53 \mathrm{~Hz}, 1 \mathrm{H}), 7.81(\mathrm{~d}, J=9.03 \mathrm{~Hz}, 1 \mathrm{H})$, $4.21-4.28(\mathrm{~m}, 4 \mathrm{H}), 4.07(\mathrm{~s}, 3 \mathrm{H}), 3.95(\mathrm{~d}, J=3.26 \mathrm{~Hz}, 3 \mathrm{H})$, $3.65-3.75(\mathrm{~m}, 1 \mathrm{H}), 1.83-1.91(\mathrm{~m}, 6 \mathrm{H}), 1.37-1.39(\mathrm{~m}, 16 \mathrm{H})$, 0.97-1.01 (m, 10H), 0.93-0.95 (m, 7H); (ESI-TOF) $m / z$ : $\left[\left(\mathrm{M}+\mathrm{H}^{+}\right)\right]$calcd for 529.4039; found, 529.4116.

2-Amino-N-(4-(2-tert-butyl-5-(hexyloxy)-6-methoxyquinolin-8-ylamino)pentyl)-3-(1H-imidazole-5-yl)propanamide (105). Yield $=81 \%$; ${ }^{1} \mathrm{H}$ NMR (400 MHz, $\left.\mathrm{CD}_{3} \mathrm{OD}\right): \delta 8.94(\mathrm{~s}$, $1 \mathrm{H}), 8.51(\mathrm{~d}, J=9.03 \mathrm{~Hz}, 1 \mathrm{H}), 7.91($ br s, $1 \mathrm{H}), 7.81(\mathrm{~d}, J=$ $9.03 \mathrm{~Hz}, 1 \mathrm{H}), 7.54(\mathrm{~d}, J=1.76 \mathrm{~Hz}, 1 \mathrm{H}), 4.21-4.24(\mathrm{~m}, 1 \mathrm{H})$, $4.14(\mathrm{~d}, J=6.27 \mathrm{~Hz}, 1 \mathrm{H}), 4.07(\mathrm{~s}, 2 \mathrm{H}), 3.13-3.28(\mathrm{~m}, 2 \mathrm{H})$, $1.81-1.89(\mathrm{~m}, 2 \mathrm{H}), 1.48-1.67(\mathrm{~m}, 8 \mathrm{H}), 1.37-1.42(\mathrm{~m}, 4 \mathrm{H})$, $1.25-1.30(\mathrm{~m}, 4 \mathrm{H}), 0.94(\mathrm{t}, J=6.78 \mathrm{~Hz}, 2 \mathrm{H})$; (ESI-TOF) $m / z$ : $\left[\left(\mathrm{M}+\mathrm{H}^{+}\right)\right]$calcd for 553.3788; found, 553.3832.

2-Amino-N-(4-(2-tert-butyl-5-(hexyloxy)-6-methoxyquinolin-8-ylamino)pentyl)-3-phenylpropanamide (106). Yield = $85 \% ;{ }^{1} \mathrm{H}$ NMR (400 MHz, CD $\left.3 \mathrm{OD}\right): \delta 8.52(\mathrm{dd}, J=2.01,9.03$ $\mathrm{Hz}, 1 \mathrm{H}), 7.87(\mathrm{~d}, J=5.02 \mathrm{~Hz}, 1 \mathrm{H}), 7.82(\mathrm{~d}, J=9.03 \mathrm{~Hz}, 1 \mathrm{H})$, $7.25-7.37(\mathrm{~m}, 6 \mathrm{H}), 4.18-4.26(\mathrm{~m}, 2 \mathrm{H}), 4.07(\mathrm{~d}, J=2.51 \mathrm{~Hz}$, $3 \mathrm{H}), 3.25(\mathrm{~d}, J=6.78 \mathrm{~Hz}, 1 \mathrm{H}), 3.09-3.18(\mathrm{~m}, 2 \mathrm{H}), 2.95-3.08$ $(\mathrm{m}, 1 \mathrm{H}), 1.78-1.92(\mathrm{~m}, 3 \mathrm{H}), 1.53-1.71(\mathrm{~m}, 6 \mathrm{H}), 1.52(\mathrm{~s}, 5 \mathrm{H})$, $1.36-1.45(\mathrm{~m}, 7 \mathrm{H}), 1.13(\mathrm{td}, J=4.30,6.96 \mathrm{~Hz}, 2 \mathrm{H}), 0.95(\mathrm{t}, J=$ $6.90 \mathrm{~Hz}, 3 \mathrm{H})$; (ESI-TOF) $\mathrm{m} / z:\left[\left(\mathrm{M}+\mathrm{H}^{+}\right)\right]$calcd for 563.3883; found, 563.3867.

2-Amino-N-(4-(2-tert-butyl-5-(hexyloxy)-6-methoxyquinolin-8-ylamino)pentyl)-propanamide (107). Yield $=86 \% ;{ }^{1} \mathrm{H}$ NMR (400 MHz, CD $\left.\mathrm{CD}_{3} \mathrm{OD}\right): \delta 8.53(\mathrm{~d}, J=9.03 \mathrm{~Hz}, 1 \mathrm{H}), 7.67-$ $7.92(\mathrm{~m}, 3 \mathrm{H}), 4.18-4.34(\mathrm{~m}, 3 \mathrm{H}), 4.07(\mathrm{~s}, 5 \mathrm{H}), 4.02(\mathrm{~d}, J=$ $6.78 \mathrm{~Hz}, 1 \mathrm{H}), 3.84-3.97(\mathrm{~m}, 1 \mathrm{H}), 3.29(\mathrm{~d}, J=8.03 \mathrm{~Hz}, 2 \mathrm{H})$, $1.77-1.95(\mathrm{~m}, 4 \mathrm{H}), 1.25-1.49(\mathrm{~m}, 22 \mathrm{H}), 0.89-0.99(\mathrm{~m}, 4 \mathrm{H})$; (ESI-TOF) $\mathrm{m} / z:\left[\left(\mathrm{M}+\mathrm{H}^{+}\right)\right]$calcd for 487.3570; found, 487.3659.

2-Amino-N-(4-(2-tert-butyl-5-(hexyloxy)-6-methoxyquinolin-8-ylamino)pentyl)-3-(1H-indol-2-yl)propanamide (108). Yield $=81 \%$; ${ }^{1} \mathrm{H}$ NMR (400 MHz, $\left.\mathrm{CD}_{3} \mathrm{OD}\right): \delta 8.53(\mathrm{~d}, J=$ $9.03 \mathrm{~Hz}, 1 \mathrm{H}), 7.90(\mathrm{~d}, J=8.03 \mathrm{~Hz}, 1 \mathrm{H}), 7.74-7.86(\mathrm{~m}, 2 \mathrm{H})$, 7.43-7.52 (m, 1H), 7.28-7.38 (m, 1H), 7.14-7.22 (m, 1H), $7.07(\mathrm{~d}, J=7.53 \mathrm{~Hz}, 1 \mathrm{H}), 4.45-4.56(\mathrm{~m}, 1 \mathrm{H}), 4.23(\mathrm{t}, J=6.53$ $\mathrm{Hz}, 2 \mathrm{H}), 4.12-4.19(\mathrm{~m}, 1 \mathrm{H}), 4.03-4.07(\mathrm{~m}, 4 \mathrm{H}), 3.09(\mathrm{dd}, J=$ 12.05, $15.56 \mathrm{~Hz}, 1 \mathrm{H}), 2.08$ (br s, $1 \mathrm{H}), 1.98$ (s, 1H); (ESI-TOF) $m / z:\left[\left(\mathrm{M}+\mathrm{H}^{+}\right)\right]$calcd for 602.3992; found, 602.3788 .

2,6-Diamino-N-(4-(2-tert-butyl-5-(heptyloxy)-6-methoxyquinolin-8-ylamino)-pentyl)hexanamide (109). Yield $=89 \%$; ${ }^{1} \mathrm{H}$ NMR (400 MHz, CD $\left.3 \mathrm{OD}\right): \delta 8.34(\mathrm{~d}, J=9.03 \mathrm{~Hz}, 1 \mathrm{H})$, $7.83-7.86(\mathrm{~m}, 1 \mathrm{H}), 4.29(\mathrm{q}, J=6.36 \mathrm{~Hz}, 2 \mathrm{H}), 4.02(\mathrm{~s}, 3 \mathrm{H})$, $3.83(\mathrm{~s}, 1 \mathrm{H}), 3.42(\mathrm{~d}, J=7.03 \mathrm{~Hz}, 1 \mathrm{H}), 2.87-3.05(\mathrm{~m}, 3 \mathrm{H})$, $1.71-1.95(\mathrm{~m}, 4 \mathrm{H}), 1.64-1.82(\mathrm{~m}, 4 \mathrm{H}), 1.38-1.49(\mathrm{~m}, 11 \mathrm{H})$, $1.32-1.47(\mathrm{~m}, 10 \mathrm{H}), 1.32(\mathrm{~d}, J=6.53 \mathrm{~Hz}, 3 \mathrm{H}), 1.21(\mathrm{t}, J=7.03$ $\mathrm{Hz}, 1 \mathrm{H}), 0.96(\mathrm{t}, J=7.28 \mathrm{~Hz}, 3 \mathrm{H})$; (ESI-TOF) $m / z$ : $[(\mathrm{M}+$ $\left.\mathrm{H}^{+}\right)$] calcd for 558.4305; found, 558.4201.

2,5-Diamino-N-(4-(2-tert-butyl-5-(heptyloxy)-6-methoxyquinolin-8-ylamino)-pentyl)pentanamide (110). Yield $=84 \%$; ${ }^{1} \mathrm{H}$ NMR (400 MHz, $\left.\mathrm{CD}_{3} \mathrm{OD}\right): \delta 8.52(\mathrm{~d}, J=9.03 \mathrm{~Hz}, 1 \mathrm{H})$, $7.92(\mathrm{~s}, 1 \mathrm{H}), 7.80(\mathrm{~d}, J=9.03 \mathrm{~Hz}, 1 \mathrm{H}), 4.17-4.35(\mathrm{~m}, 4 \mathrm{H})$, 4.03-4.13 (m, 5H), 2.95-3.04 (m, 5H), 1.73-1.99 (m, 12H), $1.61-1.73(\mathrm{~m}, 3 \mathrm{H}), 1.40(\mathrm{~d}, J=2.51 \mathrm{~Hz}, 5 \mathrm{H}), 1.27(\mathrm{~d}, J=2.01$ $\mathrm{Hz}, 2 \mathrm{H}), 0.97$ (d, $J=6.53 \mathrm{~Hz}, 1 \mathrm{H}), 0.90-0.93$ (m, 3H); (ESITOF) $\mathrm{m} / z:\left[\left(\mathrm{M}+\mathrm{H}^{+}\right)\right]$calcd for 544.4148 ; found, 544.4456 .

2-Amino-N-(4-(2-tert-butyl-5-(heptyloxy)-6-methoxyquinolin-8-ylamino)pentyl)-5-guanidinopentanamide (111). Yield $=86 \%$; ${ }^{1} \mathrm{H}$ NMR $\left(400 \mathrm{MHz}, \mathrm{CDCl}_{3}\right): \delta 9.42$ (br s, $1 \mathrm{H}), 9.29$ (br s, $1 \mathrm{H}), 8.17-8.30(\mathrm{~m}, 1 \mathrm{H}), 7.39-7.47(\mathrm{~m}, 1 \mathrm{H})$, 6.57 (br s, 1H), 6.33-6.42 (m, 1H), 6.24 (br s, 1H), 5.18-5.26 $(\mathrm{m}, 3 \mathrm{H}), 5.07-5.13(\mathrm{~m}, 4 \mathrm{H}), 4.25-4.36(\mathrm{~m}, 1 \mathrm{H}), 3.94-3.97$ $(\mathrm{m}, 5 \mathrm{H}), 3.38-3.60(\mathrm{~m}, 4 \mathrm{H}), 2.26(\mathrm{~s}, 1 \mathrm{H}), 2.05(\mathrm{~s}, 5 \mathrm{H}), 1.80-$ $1.85(\mathrm{~m}, 2 \mathrm{H}), 1.43(\mathrm{~s}, 5 \mathrm{H}), 1.34-1.38(\mathrm{~m}, 7 \mathrm{H}), 1.20-1.24(\mathrm{~m}$, $7 \mathrm{H}), 1.16(\mathrm{~d}, J=1.76 \mathrm{~Hz}, 1 \mathrm{H}), 0.92(\mathrm{~s}, 3 \mathrm{H})$; (ESI-TOF) $m / z$ : $\left[\left(\mathrm{M}+\mathrm{H}^{+}\right)\right]$calcd for 586.4366; found, 586.4258 .

2-Amino-N-(4-(2-tert-butyl-5-(heptyloxy)-6-methoxyquinolin-8-ylamino)pentyl)-3-phenylpropanamide (112). Yield $=85 \% ;{ }^{1} \mathrm{H}$ NMR (400 MHz, $\left.\mathrm{CD}_{3} \mathrm{OD}\right): \delta 8.45-8.55(\mathrm{~m}, 2 \mathrm{H})$, 7.85-7.90 (m, 1H), 7.70-7.72 (m, 1H), 7.10-7.43 (m, 5H), 4.18-4.22 (m, 2H), 4.05-4.09 (m, 4H), 3.35 (s, 5H), 2.97$3.17(\mathrm{~m}, 4 \mathrm{H}), 1.74-1.88(\mathrm{~m}, 3 \mathrm{H}), 1.47-1.57(\mathrm{~m}, 12 \mathrm{H}), 1.36-$ $1.42(\mathrm{~m}, 5 \mathrm{H}), 1.33(\mathrm{dd}, J=3.64,6.40 \mathrm{~Hz}, 5 \mathrm{H}), 1.31(\mathrm{~s}, 2 \mathrm{H})$, $1.22-1.30(\mathrm{~m}, 3 \mathrm{H}), 1.10(\mathrm{dd}, J=4.39,6.90 \mathrm{~Hz}, 2 \mathrm{H}), 0.86-$ $0.95(\mathrm{~m}, 4 \mathrm{H})$; (ESI-TOF) $m / z:\left[\left(\mathrm{M}+\mathrm{H}^{+}\right)\right]$calcd for 577.4039; found, 577.4116.

N-(4-(2-tert-Butyl-5-(heptyloxy)-6-methoxyquinolin-8lamino)pentyl)pyrrolidine-2-carboxamide (113). Yield = 87\%; ${ }^{1} \mathrm{H}$ NMR (400 MHz, CD $\left.3 \mathrm{OD}\right): \delta 8.52$ (d, $J=9.03 \mathrm{~Hz}$, $1 \mathrm{H}), 7.73-7.91(\mathrm{~m}, 2 \mathrm{H}), 4.16-4.28(\mathrm{~m}, 3 \mathrm{H}), 4.05(\mathrm{~s}, 3 \mathrm{H})$, 1.96-2.07 (m, 3H), 1.72-1.94 (m, 5H), 1.52-1.61 (m, 3H), $1.47-1.52(\mathrm{~m}, 9 \mathrm{H}), 1.41(\mathrm{~d}, J=6.78 \mathrm{~Hz}, 5 \mathrm{H}), 1.31-1.39(\mathrm{~m}$, $7 \mathrm{H}), 1.27-1.31(\mathrm{~m}, 5 \mathrm{H}), 1.18-1.26(\mathrm{~m}, 1 \mathrm{H}), 1.13(\mathrm{~d}, J=6.53$ $\mathrm{Hz}, 1 \mathrm{H}), 0.89-0.93(\mathrm{~m}, 3 \mathrm{H})$; (ESI-TOF) $m / z:\left[\left(\mathrm{M}+\mathrm{H}^{+}\right)\right]$ calcd for 527.3883; found, 527.3961.

2-Amino-N-(4-(2-tert-butyl-5-(heptyloxy)-6-methoxyquinolin-8-ylamino)pentyl)-3-methylpentanamide (114). Yield $=80 \% ;{ }^{1} \mathrm{H} \mathrm{NMR}\left(400 \mathrm{MHz}, \mathrm{CD}_{3} \mathrm{OD}\right): \delta 8.52(\mathrm{~d}, J=9.03 \mathrm{~Hz}$, $1 \mathrm{H}), 7.86(\mathrm{~d}, J=6.27 \mathrm{~Hz}, 1 \mathrm{H}), 7.80(\mathrm{~d}, J=9.03 \mathrm{~Hz}, 1 \mathrm{H})$, $4.20-4.30(\mathrm{~m}, 3 \mathrm{H}), 4.01-4.08(\mathrm{~m}, 3 \mathrm{H}), 3.93(\mathrm{~d}, J=3.26 \mathrm{~Hz}$, $1 \mathrm{H}), 3.63-3.70(\mathrm{~m}, 1 \mathrm{H}), 3.37-3.45(\mathrm{~m}, 1 \mathrm{H}), 3.13-3.26(\mathrm{~m}$, $1 \mathrm{H}), 1.79-1.90(\mathrm{~m}, 5 \mathrm{H}), 1.51-1.60(\mathrm{~m}, 4 \mathrm{H}), 1.41(\mathrm{dd}, J=$ $3.01,6.53 \mathrm{~Hz}, 5 \mathrm{H}), 1.37(\mathrm{dd}, J=3.14,6.90 \mathrm{~Hz}, 8 \mathrm{H}), 1.27-1.32$ $(\mathrm{m}, 8 \mathrm{H}), 0.95-1.00(\mathrm{~m}, 4 \mathrm{H}), 0.89-0.95(\mathrm{~m}, 10 \mathrm{H})$; (ESI-TOF) $m / z:\left[\left(\mathrm{M}+\mathrm{H}^{+}\right)\right]$calcd for 543.4196; found, 543.4272.

2-Amino-N-(4-(2-tert-butyl-5-(heptyloxy)-6-methoxyquinolin-8-ylamino)pentyl)-3-(1H-indol-2-yl)propanamide (115). Yield $=78 \% ;{ }^{1} \mathrm{H}$ NMR $\left(400 \mathrm{MHz}, \mathrm{CD}_{3} \mathrm{OD}\right): \delta 8.48(\mathrm{~s}$, $1 \mathrm{H}), 7.68-7.87(\mathrm{~m}, 2 \mathrm{H}), 7.57(\mathrm{~s}, 1 \mathrm{H}), 7.34(\mathrm{~s}, 1 \mathrm{H}), 7.06(\mathrm{~s}$, $1 \mathrm{H}), 6.99(\mathrm{~d}, J=7.78 \mathrm{~Hz}, 2 \mathrm{H}), 4.24(\mathrm{~s}, 1 \mathrm{H}), 4.13-4.19(\mathrm{~m}$, $2 \mathrm{H}), 4.03(\mathrm{~d}, J=2.26 \mathrm{~Hz}, 4 \mathrm{H}), 1.73-1.84(\mathrm{~m}, 3 \mathrm{H}), 1.49(\mathrm{~d}, J=$ $5.02 \mathrm{~Hz}, 10 \mathrm{H}), 1.32-1.39(\mathrm{~m}, 10 \mathrm{H}), 1.29(\mathrm{~s}, 9 \mathrm{H}), 1.20$ (d, J = $6.53 \mathrm{~Hz}, 1 \mathrm{H}), 0.98(\mathrm{~d}, J=6.78 \mathrm{~Hz}, 2 \mathrm{H}), 0.92(\mathrm{~d}, J=5.52 \mathrm{~Hz}$, $4 \mathrm{H}), 0.92(\mathrm{~d}, J=18.32 \mathrm{~Hz}, 2 \mathrm{H})$; (ESI-TOF) $m / z:\left[\left(\mathrm{M}+\mathrm{H}^{+}\right)\right]$ calcd for 616.4148; found, 616.4192.

2-Amino-N-(4-(2-tert-butyl-5-(heptyloxy)-6-methoxyquinolin-8-ylamino)pentyl)-4-(methylthio)butanamide (116). 
Yield $=82 \% ;{ }^{1} \mathrm{H}$ NMR $\left(400 \mathrm{MHz}, \mathrm{CD}_{3} \mathrm{OD}\right): \delta 8.52(\mathrm{~d}, J=$ $8.78 \mathrm{~Hz}, 1 \mathrm{H}), 7.81(\mathrm{~s}, 1 \mathrm{H}), 7.80(\mathrm{~d}, J=3.26 \mathrm{~Hz}, 1 \mathrm{H}), 4.24$ (s, $3 \mathrm{H}), 4.05(\mathrm{~s}, 3 \mathrm{H}), 3.85(\mathrm{~s}, 1 \mathrm{H}), 2.57(\mathrm{~d}, J=7.53 \mathrm{~Hz}, 3 \mathrm{H})$, 2.09-2.12 (m, 5H), $2.08(\mathrm{~s}, 2 \mathrm{H}), 1.38-1.42(\mathrm{~m}, 6 \mathrm{H}), 1.37(\mathrm{~d}, J$ $=3.26 \mathrm{~Hz}, 3 \mathrm{H}), 1.32-1.36(\mathrm{~m}, 5 \mathrm{H}), 1.30(\mathrm{~d}, J=6.53 \mathrm{~Hz}, 6 \mathrm{H})$, $1.26(\mathrm{~d}, J=3.76 \mathrm{~Hz}, 1 \mathrm{H}), 1.24(\mathrm{~s}, 1 \mathrm{H}), 1.20(\mathrm{~d}, J=6.78 \mathrm{~Hz}$, $2 \mathrm{H}), 0.89-0.93(\mathrm{~m}, 4 \mathrm{H})$; (ESI-TOF) $\mathrm{m} / z$ : $\left[\left(\mathrm{M}+\mathrm{H}^{+}\right)\right]$calcd for 561.3760; found, 561.3824.

2,6-Diamino-N-(4-(2-tert-butyl-6-methoxy-5-(octyloxy)quinolin-8-lamino)pentyl)-hexanamide (117). Yield $=79 \%$; ${ }^{1} \mathrm{H}$ NMR (400 MHz, CD $\left.\mathrm{CD}_{3}\right): \delta 8.52(\mathrm{~d}, J=9.03 \mathrm{~Hz}, 1 \mathrm{H})$, $7.91(\mathrm{~d}, J=4.02 \mathrm{~Hz}, 1 \mathrm{H}), 7.80(\mathrm{~d}, J=9.03 \mathrm{~Hz}, 1 \mathrm{H}), 4.24(\mathrm{t}, J=$ $6.53 \mathrm{~Hz}, 2 \mathrm{H}), 4.07(\mathrm{~s}, 3 \mathrm{H}), 3.93(\mathrm{~s}, 1 \mathrm{H}), 2.97(\mathrm{~d}, J=6.78 \mathrm{~Hz}$ $3 \mathrm{H}), 1.82-1.94(\mathrm{~m}, 5 \mathrm{H}), 1.67-1.80(\mathrm{~m}, 5 \mathrm{H}), 1.47-1.53(\mathrm{~m}$, $11 \mathrm{H}), 1.36-1.43(\mathrm{~m}, 9 \mathrm{H}), 1.31(\mathrm{~d}, J=6.53 \mathrm{~Hz}, 5 \mathrm{H}), 0.86-$ $0.97(\mathrm{~m}, 3 \mathrm{H})$; (ESI-TOF) $\mathrm{m} / z:\left[\left(\mathrm{M}+\mathrm{H}^{+}\right)\right]$calcd for 572.4461; found, 572.4167 .

2,5-Diamino-N-(4-(2-tert-butyl-6-methoxy-5-(octyloxy)quinolin-8-lamino)pentyl)-pentanamide (118). Yield = 77\%; ${ }^{1} \mathrm{H}$ NMR (400 MHz, $\mathrm{CDCl}_{3}$ ): $\delta 8.32$ (br s, $2 \mathrm{H}$ ), 7.88 (br s, $1 \mathrm{H}), 6.51$ (br s, $4 \mathrm{H}), 3.91$ (br s, $3 \mathrm{H}), 3.48$ (s, $1 \mathrm{H}), 3.28$ (br s, $2 \mathrm{H}), 2.24$ (br s, 4H), 2.06 (br s, 3H), 1.79 (br s, 4H), 1.49 (br $\mathrm{s}, 6 \mathrm{H}), 1.40-1.46(\mathrm{~m}, 9 \mathrm{H}), 1.28(\mathrm{~d}, J=5.52 \mathrm{~Hz}, 16 \mathrm{H}), 0.87(\mathrm{br}$ $\mathrm{s}, 2 \mathrm{H}),(\mathrm{ESI}-\mathrm{TOF}) \mathrm{m} / z$ : $\left[\left(\mathrm{M}+\mathrm{H}^{+}\right)\right]$calcd for 558.4305; found, 558.4228 .

2-Amino-N-(4-(2-tert-butyl-6-methoxy-5-(octyloxy)quinolin-8-ylamino)pentyl)-3-methylpentanamide (119). Yield $=90 \% ;{ }^{1} \mathrm{H}$ NMR $\left(400 \mathrm{MHz}, \mathrm{CDCl}_{3}\right): \delta 8.96$ (br s, $1 \mathrm{H}), 8.64$ (br s, $1 \mathrm{H}), 8.59$ (br s, $1 \mathrm{H}), 8.26$ (br s, $1 \mathrm{H}), 7.59$ (br s, $1 \mathrm{H}$ ), 4.18 (br s, $4 \mathrm{H}), 3.99$ (d, $J=7.53 \mathrm{~Hz}, 3 \mathrm{H}), 3.63$ (br s, $1 \mathrm{H}), 3.21$ (br s, $1 \mathrm{H}), 2.45$ (br s, $1 \mathrm{H}), 2.19$ (br s, $1 \mathrm{H}), 2.11$ (br s, $1 \mathrm{H}), 1.97$ (br s, $1 \mathrm{H}), 1.84$ (br s, $4 \mathrm{H}), 1.48$ (br s, $8 \mathrm{H}), 1.43$ (br s, $2 \mathrm{H}), 1.11-1.39(\mathrm{~m}, 14 \mathrm{H}), 1.02(\mathrm{t}, J=5.52 \mathrm{~Hz}, 5 \mathrm{H})$, 0.75-0.96 (m, 5H); (ESI-TOF) $m / z$ : $\left[\left(\mathrm{M}+\mathrm{H}^{+}\right)\right]$calcd for 557.4352; found, 557.4411.

2-Amino-N-(4-(2-tert-butyl-6-methoxy-5-(octyloxy)quinolin-8-ylamino)pentyl)-4-(methylthio)butanamide (120). Yield $=85 \% ;{ }^{1} \mathrm{H}$ NMR (400 MHz, $\left.\mathrm{CD}_{3} \mathrm{OD}\right): \delta 8.54(\mathrm{~s}$, $1 \mathrm{H}), 7.94(\mathrm{~d}, J=5.52 \mathrm{~Hz}, 1 \mathrm{H}), 7.80(\mathrm{~d}, J=9.03 \mathrm{~Hz}, 1 \mathrm{H}), 4.24$ $(\mathrm{t}, J=6.53 \mathrm{~Hz}, 3 \mathrm{H}), 4.14(\mathrm{dd}, J=5.02,6.53 \mathrm{~Hz}, 2 \mathrm{H}), 4.07(\mathrm{~s}$, $3 \mathrm{H}), 4.01(\mathrm{~s}, 1 \mathrm{H}), 2.58(\mathrm{~d}, J=7.03 \mathrm{~Hz}, 3 \mathrm{H}), 2.08-2.12(\mathrm{~m}$, $5 \mathrm{H}), 1.76-1.96(\mathrm{~m}, 5 \mathrm{H}), 1.50(\mathrm{~s}, 10 \mathrm{H}), 1.39(\mathrm{dd}, J=4.77,7.78$ $\mathrm{Hz}, 11 \mathrm{H}), 1.26-1.29(\mathrm{~m}, 3 \mathrm{H}), 1.05-1.22(\mathrm{~m}, 2 \mathrm{H}), 0.92-0.95$ $(\mathrm{m}, 3 \mathrm{H})$; (ESI-TOF) $\mathrm{m} / z$ : $\left[\left(\mathrm{M}+\mathrm{H}^{+}\right)\right]$calcd for 575.3917; found, 575.3981 .

2-Amino-N-(4-(2-tert-butyl-6-methoxy-5-(octyloxy)quinolin-8-ylamino)pentyl)-3-phenylpropanamide (121). Yield $=82 \% ;{ }^{1} \mathrm{H}$ NMR $\left(400 \mathrm{MHz}, \mathrm{CDCl}_{3}\right): \delta 8.49$ (br s, $3 \mathrm{H}), 7.24-7.28(\mathrm{~m}, 7 \mathrm{H}), 4.09-4.23(\mathrm{~m}, 4 \mathrm{H}), 3.97(\mathrm{~d}, J=7.78$ $\mathrm{Hz}, 3 \mathrm{H}), 3.45$ (s, $1 \mathrm{H}), 3.34$ (br s, $1 \mathrm{H}), 1.81$ (br s, $4 \mathrm{H}), 1.41-$ $1.57(\mathrm{~m}, 11 \mathrm{H}), 1.23-1.37(\mathrm{~m}, 20 \mathrm{H}), 0.85-0.94(\mathrm{~m}, 4 \mathrm{H})$; (ESITOF) $m / z:\left[\left(\mathrm{M}+\mathrm{H}^{+}\right)\right]$calcd for 591.4196; found, 591.4261.

2-Amino-N-(4-(2-tert-butyl-6-methoxy-5-(octyloxy)quinolin-8-ylamino)pentyl)-3-(1H-indol-2-yl)propanamide (122). Yield $=81 \% ;{ }^{1} \mathrm{H}$ NMR $\left(400 \mathrm{MHz}, \mathrm{CDCl}_{3}\right): \delta 8.31$ (br s, $2 \mathrm{H}), 7.61(\mathrm{~d}, J=7.78 \mathrm{~Hz}, 1 \mathrm{H}), 7.36(\mathrm{~d}, J=7.78 \mathrm{~Hz}, 1 \mathrm{H})$, $7.16-7.24(\mathrm{~m}, 1 \mathrm{H}), 6.93-7.16(\mathrm{~m}, 3 \mathrm{H}), 5.54(\mathrm{br} \mathrm{s}, 1 \mathrm{H}), 4.01-$ $4.26(\mathrm{~m}, 3 \mathrm{H}), 3.85$ (br s, $1 \mathrm{H}), 3.38$ (d, $J=13.55 \mathrm{~Hz}, 2 \mathrm{H}), 3.03$ (dd, $J=8.16,14.68 \mathrm{~Hz}, 2 \mathrm{H}), 1.80($ br s, $1 \mathrm{H}), 1.36-1.60(\mathrm{~m}$, $5 \mathrm{H}), 1.06-1.36(\mathrm{~m}, 16 \mathrm{H}), 0.89$ (br s, $2 \mathrm{H})$; (ESI-TOF) $\mathrm{m} / \mathrm{z}$ : $\left[\left(\mathrm{M}+\mathrm{H}^{+}\right)\right]$calcd for 630.4039; found, 630.4379.

N-(4-(2-tert-Butyl-6-methoxy-5-(octyloxy)quinolin-8ylamino)pentyl)pyrrolidine-2-carboxamide (123). Yield =
$75 \% ;{ }^{1} \mathrm{H}$ NMR $\left(400 \mathrm{MHz}, \mathrm{CDCl}_{3}\right): \delta 8.24(\mathrm{~d}, J=8.76 \mathrm{~Hz}$, $1 \mathrm{H}), 7.47(\mathrm{~d}, J=8.8 \mathrm{~Hz}, 1 \mathrm{H}), 6.30(\mathrm{~s}, 1 \mathrm{H}), 4.58(\mathrm{~m}, 2 \mathrm{H}), 4.49$ $(\mathrm{m}, 1 \mathrm{H}, J=2.2 \mathrm{~Hz}), 4.20(\mathrm{~s}, 1 \mathrm{H}), 3.86-4.04(\mathrm{~m}, 5 \mathrm{H}), 3.50-$ $3.60(\mathrm{~m}, 1 \mathrm{H}), 3.43(\mathrm{~m}, 1 \mathrm{H}), 1.78-1.91(\mathrm{~m}, 4 \mathrm{H}), 1.69(\mathrm{~d}, J=$ $7.28 \mathrm{~Hz}, 3 \mathrm{H}), 1.63(\mathrm{~s}, 5 \mathrm{H}), 1.38-1.48(\mathrm{~m}, 19 \mathrm{H}), 1.22-1.13$ $(\mathrm{m}, 4 \mathrm{H}), 0.85-0.94(\mathrm{~m}, 3 \mathrm{H})$; (ESI-TOF) $m / z:\left[\left(\mathrm{M}+\mathrm{H}^{+}\right)\right]$ calcd for 541.4039; found, 541.4135.

Assay for in Vitro Antimalarial Activity. A suspension of red blood cells infected with D6 or W2 strains of P. falciparum (200 $\mu \mathrm{L}$, with $2 \%$ parasitemia and $2 \%$ hematocrit in RPMI 1640 medium supplemented with $10 \%$ human serum and 60 $\mu \mathrm{g} / \mathrm{mL}$ amikacin) is added to the wells of a 96-well plate containing $10 \mu \mathrm{L}$ of test samples diluted in medium at various concentrations. The plate is placed in a modular incubation chamber (Billups-Rothenberg, CA) and flushed with a gas mixture of $90 \% \mathrm{~N}_{2}, 5 \% \mathrm{O}_{2}$, and $5 \% \mathrm{CO}_{2}$ and incubated at $37{ }^{\circ} \mathrm{C}$ for $72 \mathrm{~h}$. Parasitic LDH activity, as a measure of growth, is determined by using Malstat reagent (Flow Inc., Portland, OR) according to the procedure of Makler and Hinrichs. ${ }^{21}$ Briefly, $20 \mu \mathrm{L}$ of the incubation mixture is mixed with $100 \mu \mathrm{L}$ of the Malstat reagent and incubated at room temperature for $30 \mathrm{~min}$. A 1:1 mixture $(20 \mu \mathrm{L})$ of NBT/PES (Sigma, St. Louis, MO) is then added, and the plate is further incubated in the dark for 1 h. The reaction is then stopped by the addition of $100 \mu \mathrm{L}$ of a $5 \%$ acetic acid solution. The plate is read at $650 \mathrm{~nm}$ using the EL-340 Biokinetics Reader (BioTek Instruments, Vermont). $\mathrm{IC}_{50}$ values are computed from the dose response curves. ART and $\mathrm{CQ}$ are included in each assay as the drug controls. Dimethyl sulfoxide (DMSO) (0.25\%) is used as vehicle control.

Cytotoxicity Assay. The in vitro cytotoxicity studies were performed against four human cancer cell lines (SK-OV-3, SKMEL, KB, and BT-549) and two noncancerous mammalian kidney cell lines (LLC-PK1 and VERO). ${ }^{22,23}$ All cell lines were obtained from American Type Culture Collection (ATCC).

The assay was performed in 96-well tissue culture-treated microplates, and targeted peptides were tested up to a highest concentration of $10 \mu \mathrm{g} / \mathrm{mL}$. The cells (25000 cells/well) were seeded to the wells of the plate and incubated for $24 \mathrm{~h}$ for confluence. The 8-quinolinamine samples were added and plates again incubated for $48 \mathrm{~h}$. The number of viable cells was calculated through a modified version of neutral red uptake assay. The marketed drug doxorubicin was used in study as a positive control, while DMSO was used as the negative control.

Assay for Blood-Schizontocidal Activity Evaluation Against $P$. berghei and $P$. yoelli nigeriensis Infection in Mice. The method used for screening of the synthesized compounds for their blood-schizontocidal activity is based on a comparison of responses by groups of treated and control mice, six in each group, after infection with $P$. berghei or $P$. yoelli nigeriensis. ${ }^{10}$ Test animals (Swiss mice of either sex, approximately 15-20 g and same age) were housed in metaltopped cages and given a standard laboratory diet and water ad libitum. To check factors such as changes in the infectivity of the strain or in the susceptibility of the host or to detect technical errors, a group of infected animals treated with CQ diphosphate at dose levels $(10 \mathrm{mg} / \mathrm{kg} /$ day $\times 4)$, producing definite increases in the survival time, is included as a positive control in every experiment. In each experiment, the test compounds were administered in graded doses of 100, 50, 25, and $10 \mathrm{mg} / \mathrm{kg}$. The compounds showing curative activity at 10 $\mathrm{mg} / \mathrm{kg}$ were further selected for screening at lower doses. On day " 0 ", groups of six mice each were inoculated intraperitoneally with $1 \times 10^{7}$ infected erythrocytes from a donor 
mouse. Four hours later, mice were administered test compounds/CQ/vehicle orally. A total of four doses were given orally on days $\mathrm{D}$ " 0 ", $\mathrm{D}+1, \mathrm{D}+2$, and $\mathrm{D}+3$. The tail blood smears were made on days $\mathrm{D}+4$ and $\mathrm{D}+7$, stained with Giemsa, and examined microscopically. The minimum dose that completely suppressed parasitaemia on days $\mathrm{D}+4$ and $\mathrm{D}+$ 7 was termed as the minimum effective dose, and the minimum dose that cleared the parasitaemia for up to 60 days was termed as the curative dose. The terms "curative", "active", and "inactive" are used to describe the biological activities exhibited by the tested compounds. The term "curative" indicates complete elimination of malaria parasites from the body, so that relapse cannot occur up to day $\mathrm{D}+60$, and all mice survived. The term "active" indicates that the treated animals show negative parasitaemia up to $\mathrm{D}+7$. However, by $\mathrm{D}+28$, $50 \%$ or more mice show a negative and the remaining mice may show a positive test result for parasitaemia. The term "inactive" indicates that the treated animals show a positive test result for parasitaemia either on $\mathrm{D}+4$ or $\mathrm{D}+7$ or on both $\mathrm{D}+4$ and $\mathrm{D}$ +7 and animal usually dies by $\mathrm{D}+14$.

Assay for in Vitro Antileishmanial Activity. Antileishmanial activity of the compounds was tested in vitro against a culture of $L$. donovani promastigotes. They were grown in RPMI 1640 medium supplemented with $10 \%$ fetal calf serum (Gibco Chem. Co.) at $26^{\circ} \mathrm{C}$. A 3 day-old culture was diluted to $5 \times 10^{5}$ promastigotes $/ \mathrm{mL}$. Drug dilutions $(50-3.1 \mu \mathrm{g} / \mathrm{mL})$ were prepared directly in cell suspension in 96-well plates. Plates were incubated at $26{ }^{\circ} \mathrm{C}$ for $48 \mathrm{~h}$, and growth of leishmania promastigotes was determined by alamarBlue assay as described earlier. ${ }^{24,25}$ Standard fluorescence was measured on a FLUOstar Galaxy plate reader (BMG Lab Technologies) at an excitation wavelength of $544 \mathrm{~nm}$ and an emission wavelength of $590 \mathrm{~nm}$. Pentamidine and amphotericin B were used as the standard antileishmanial agents. $\mathrm{IC}_{50}$ and $\mathrm{IC}_{90}$ values were computed from dose curves generated by plotting percent growth versus drug concentration.

Assay for in Vitro Antimicrobial Activity. The antifungal activities of the compounds against C. albicans ATCC90028, C. glabrata ATCC90030, C. krusei ATCC6258, C. neoformans ATCC90113, and A. fumigatus ATCC 90906 were determined according to modified NCCLS methods. ${ }^{26-28}$ The antibacterial activities of synthesized compounds were evaluated against SA (ATCC29213), MRSA (ATCC33591), and M. intracellulare (ATCC23068). SA and MRSA susceptibility to test compounds was determined using NCCLS methods, ${ }^{27,28}$ and M. intracellulare susceptibility to the synthetic compounds was tested by using the modified alamarBlue procedure of Franzblau et al. $^{29}$

The test compounds were serially diluted in 20\% DMSO/ saline and transferred in duplicate to 96-well flat-bottomed microplates, and inocula were prepared by correcting the OD630 of microbe suspensions in an incubation broth [Sabouraud Dextrose (Difco) for fungi, cation-adjusted Mueller-Hinton (Difco) at $\mathrm{pH} 7.3$ for non-mycobacterial bacteria, and 5\% alamarBlue (BioSource International, Camarillo, CA) in Middlebrook $7 \mathrm{H} 9$ broth with OADC enrichment, $\mathrm{pH} 7.3$ for $M$. intracellulare] to afford the following: fungi $1.5 \times 10^{3}$, non-mycobaterial bacteria $5 \times 10^{5}$, and $M$. intracellulare $2.0 \times 10^{6} \mathrm{CFU} / \mathrm{mL}$. The drug controls [Ciprofloxacin (ICN Biomedicals, Ohio) for bacteria and amphotericin B (ICN Biomedicals, Ohio) for fungi] were used in each assay of tested peptides. All organisms were read at either $530 \mathrm{~nm}$ using the BioTek PowerWave XS plate reader
(BioTek Instruments, Vermont) or $544_{\mathrm{ex}} / 590_{\mathrm{em}}$ (M. intracellulare) using the POLARstar Galaxy plate reader (BMG Lab Technologies, Germany) prior to and after incubation: SA/ MRSA at $35{ }^{\circ} \mathrm{C}$ for $16-20 \mathrm{~h}$, fungi at $35^{\circ} \mathrm{C}$ for $70-74 \mathrm{~h}$, and M. intracellulare at $37^{\circ} \mathrm{C}$ and $10 \% \mathrm{CO}_{2}$ for $70-74 \mathrm{~h}$. The MIC value was defined as the lowest test concentration that allows no detectable growth (for $M$. intracellulare, no color changes from blue to pink). For all 8-quinolinamines, minimum fungicidal or bactericidal concentrations were determined by removing $5 \mathrm{DL}$ from each clear (or blue) well, transferring to agar and incubating, as mentioned previously. The MFC and MBC for tested compounds were defined as the lowest test concentration that kills the organism (exhibited no growth on agar plates).

\section{ASSOCIATED CONTENT}

\section{Supporting Information}

The Supporting Information is available free of charge on the ACS Publications website at DOI: 10.1021/acsomega.7b02047.

${ }^{1} \mathrm{H}$ NMR files of representative analogues (PDF)

\section{AUTHOR INFORMATION}

\section{Corresponding Author}

*E-mail: rahuljain@niper.ac.in. Phone: 91+172-2292024 (R.J.). ORCID

Rahul Jain: 0000-0002-9180-2812

Notes

The authors declare no competing financial interest.

\section{ACKNOWLEDGMENTS}

This research project was supported by the Department of Science and Technology (DST), New Delhi, India, grant no. SR/FTP/CS-12/2006, SERB fast track scheme for young scientists. The authors thank Marsha Wright for conducting the antifungal and antibacterial testing and John Trott for conducting antimalarial testing. The biological testing was supported by the NIH, NIAID, Division of AIDS, grant no. AI 27094, and the USDA Agricultural Research Service Specific Cooperative Agreement no. 58-6408-2-0009.

\section{REFERENCES}

(1) Shetty, P. The numbers game. Nature 2012, 484, S14-S15.

(2) World Health Organization (WHO). World Malaria Report, 2017. http://www.who.int/malaria/publications/world-malaria-report$2017 / \mathrm{en} /$.

(3) World Health Organization (WHO). World Leishmania Report, 2014. http://www.who.int/leishmaniasis/en/.

(4) Kieffer, C.; Cohen, A.; Verhaeghe, P.; Paloque, L.; Hutter, S.; Castera-Ducros, C.; Laget, M.; Rault, S.; Valentin, A.; Rathelot, P.; Azas, N.; Vanelle, P. Antileishmanial pharmacomodulation in 8nitroquinolin-2(1H)-one series. Bioorg. Med. Chem. 2015, 23, 23772386.

(5) (a) Sharma, K. K.; Maurya, I. K.; Khan, S. I.; Jacob, M. R.; Kumar, V.; Tikoo, K.; Jain, R. Discovery of a membrane-active, ring-modified histidine containing ultrashort amphiphilic peptide that exhibits potent inhibition of Cryptococcus neoformans. J. Med. Chem. 2017, 60, 6607-6621. (b) Roemer, T.; Krysan, D. J. Antifungal drug development: challenges, unmet clinical needs, and new approaches. Cold Spring Harbor Perspect. Med. 2014, 4, a019703. (c) Mahindra, A.; Sharma, K. K.; Rathore, D.; Khan, S. I.; Jacob, M. R.; Jain, R. Synthesis and antimicrobial activities of His(2-aryl)-Arg and Trp-His(2-aryl) classes of dipeptidomimetics. Med. Chem. Commun. 2014, 5, 671-676. (d) Liu, J.; Balasubramanian, M. 1,3-beta-Glucan Synthase: A useful 
target for antifungal drugs. Curr. Drug Targets: Infect. Disord. 2001, 1, 159-169.

(6) Vangapandu, S.; Sachdeva, S.; Jain, M.; Singh, S.; Singh, P. P.; Kaul, C. L.; Jain, R. 8-Quinolinamines and their pro prodrug conjugates as potent blood-schizontocidal antimalarial agents. Bioorg. Med. Chem. 2003, 11, 4557-4568.

(7) Jain, R.; Jain, S.; Gupta, R. C.; Anand, N.; Dutta, G. P.; Puri, S. K. Synthesis of amino acid derivatives of 8-(4-amino-1-methylbutyl)amino-6-methoxy-4-substitute/4,5-disubstituted quinolines as potential tissue-schizontocidal anti-malarial agents. Indian J. Chem., Sect. B: Org. Chem. Incl. Med. Chem. 1994, 33, 251-254.

(8) LaMontagne, M. P.; Markovac, A.; Khan, M. S. Antimalarials. 13. 5-Alkoxy analogs of 4-methylprimaquine. J. Med. Chem. 1982, 25, 964-968.

(9) Carroll, F. I.; Berrang, B.; Linn, C. P. 4-Substituted 5-[m(trifluoromethyl)phenoxy]primaquine analogs as potential antimalarial agents. J. Med. Chem. 1985, 28, 1564-1567.

(10) Vangapandu, S.; Sachdeva, S.; Jain, M.; Singh, S.; Singh, P. P.; Kaul, C. L.; Jain, R. 8-quinolinamines and their pro prodrug conjugates as potent blood-schizontocidal antimalarial agents. Bioorg. Med. Chem. 2003, 11, 4557-4568.

(11) Jain, M.; Vangapandu, S.; Sachdeva, S.; Singh, S.; Singh, P. P.; Jena, G. B.; Tikoo, K.; Ramarao, P.; Kaul, C. L.; Jain, R. Discovery of a Bulky 2-tert-Butyl Group Containing Primaquine Analogue That Exhibits Potent Blood-Schizontocidal Antimalarial Activities and Complete Elimination of Methemoglobin Toxicity. J. Med. Chem. 2004, 47, 285-287.

(12) Jain, M.; Khan, S. I.; Tekwani, B. L.; Jacob, M. R.; Singh, S.; Singh, P. P.; Jain, R. Synthesis, antimalarial, antileishmanial, and antimicrobial activities of some 8-quinolinamine analogues. Bioorg. Med. Chem. 2005, 13, 4458-4466.

(13) Kaur, K.; Patel, S. R.; Patil, P.; Jain, M.; Khan, S. I.; Jacob, M. R.; Ganesan, S.; Tekwani, B. L.; Jain, R. Synthesis, antimalarial, antileishmanial, antimicrobial, cytotoxicity, and methemoglobin (MetHB) formation activities of new 8-quinolinamines. Bioorg. Med. Chem. 2007, 15, 915-930.

(14) Vangapandu, S.; Sachdeva, S.; Jain, M.; Singh, S.; Singh, P. P.; Kaul, C. L.; Jain, R. 8-Quinolinamines conjugated with amino acids are exhibiting potent blood-schizontocidal antimalarial activities. Bioorg. Med. Chem. 2004, 12, 239-247.

(15) Huy, N. T.; Mizunuma, K.; Kaur, K.; Nhien, N. T. T.; Jain, M.; Uyen, D. T.; Harada, S.; Jain, R.; Kamei, K. 2-tert-Butyl-8quinolinamines exhibit potent blood schizontocidal antimalarial activity via inhibition of heme crystallization. Antimicrob. Agents Chemother. 2007, 51, 2842-2847.

(16) Kaur, K.; Jain, M.; Khan, S. I.; Jacob, M. R.; Tekwani, B. L.; Singh, S.; Singh, P. P.; Jain, R. Synthesis, antiprotozoal, antimicrobial, $\beta$-hematin inhibition, cytotoxicity and methemoglobin (MetHb) formation activities of bis(8-aminoquinolines). Bioorg. Med. Chem. 2011, 19, 197-210.

(17) Kaur, K.; Jain, M.; Khan, S. I.; Jacob, M. R.; Tekwani, B. L.; Singh, S.; Singh, P. P.; Jain, R. Extended side chain analogues of 8aminoquinolines: Synthesis and evaluation of antiprotozoal, antimicrobial, $\beta$-hematin inhibition, and cytotoxic activities. MedChemComm 2011, 2, 300-307.

(18) Kaur, K.; Jain, M.; Khan, S. I.; Jacob, M. R.; Tekwani, B. L.; Singh, S.; Singh, P. P.; Jain, R. Amino acid, dipeptide and pseudodipeptide conjugates of ring-substituted 8-aminoquinolines: Synthesis and evaluation of anti-infective, $\beta$-haematin inhibition and cytotoxic activities. Eur. J. Med. Chem. 2012, 52, 230-241.

(19) Trouet, A.; Pirson, P.; Steiger, R.; Masquelier, M.; Baurain, R.; Gillet, J. Development of new derivatives of primaquine by association with lysosomotropic carriers. Bull. W. H. O. 1981, 59, 449-458.

(20) Philip, A.; Kepler, J. A.; Johnson, B. H.; Carroll, F. I. Peptide derivatives of primaquine as potential antimalarial agents. J. Med. Chem. 1988, 31, 870-874.

(21) Makler, M. T.; Hinrichs, D. J. Measurement of the Lactate Dehydrogenase Activity of Plasmodium falciparum as an Assessment of Parasitemia. Am. J. Trop. Med. Hyg. 1993, 48, 205-210.
(22) Borenfreund, E.; Babich, H.; Martin-Alguacil, N. Rapid chemosensitivity assay with human normal and tumor cells in vitro. In Vitro Cell. Dev. Biol. 1990, 26, 1030-1034.

(23) Mustafa, J.; Khan, S. I.; Ma, G.; Walker, L. A.; Khan, I. A. Synthesis and anticancer activities of fatty acid analogs of podophyllotoxin. Lipids 2004, 39, 167-172.

(24) Ma, G.; Khan, S. I.; Jacob, M. R.; Tekwani, B. L.; Li, Z.; Pasco, D. S.; Walker, L. A.; Khan, I. A. Antimicrobial and antileishmanial activities of hypocrellins A and B. Antimicrob. Agents Chemother. 2004, $48,4450-4452$.

(25) Mikus, J.; Steverding, D. A simple colorimetric method to screen drug cytotoxicity against Leishmania using the dye Alamar Blue. Parasitol. Int. 2000, 48, 265-269.

(26) National Committee for Clinical Laboratory Standards. Reference Method for Broth Dilution Antifungal Susceptibility Testing of Yeasts: Approved Standard, 2nd ed., Wayne, PA, 2002; M27-A2.

(27) National Committee for Clinical Laboratory Standards. Methods for Dilution Antimicrobial Susceptibility Tests for Bacteria That Grow Aerobically, 7th ed., Wayne, PA, 2006; M7-A7.

(28) National Committee for Clinical Laboratory Standards. Susceptibility Testing of Mycobacteria, Nocardia, and Other Aerobic Actinomycetes, 2nd ed., Wayne, PA, 2001; M24-T2.

(29) Franzblau, S. G.; Witzig, R. S.; McLaughlin, J. C.; Torres, P.; Madico, G.; Hernandez, A.; Degnan, M. T.; Cook, M. B.; Quenzer, V. K.; Ferguson, R. M.; Gilman, R. H. Rapid, low-technology MIC determination with clinical Mycobacterium tuberculosis isolates by using the microplate Alamar Blue assay. J. Clin. Microbiol. 1998, 36, $362-366$. 